Kaiserkult in den Provinzen des Römischen Reiches 
Bereitgestellt von | De Gruyter / TCS

Angemeldet

Heruntergeladen am | 14.10.16 13:13 


\section{Kaiserkult in den Provinzen des Römischen Reiches}

Organisation, Kommunikation und Repräsentation

Herausgegeben von Anne Kolb und Marco Vitale

\section{DE GRUYTER}


ISBN: 978-3-11-041671-8

e-ISBN (PDF): 978-3-11-042087-6

e-ISBN (EPUB): 978-3-11-042098-2

\section{Library of Congress Cataloging-in-Publication Data}

A CIP catalog record for this book has been applied for at the Library of Congress.

\section{Bibliografische Information der Deutschen Nationalbibliothek}

Die Deutsche Nationalbibliothek verzeichnet diese Publikation in der Deutschen Nationalbibliografie; detaillierte bibliografische Daten sind im Internet über http://dnb.dnb.de abrufbar.

(C2016 Walter de Gruyter GmbH, Berlin/Boston Einbandabbildung: Kaiserkulttempel des Städtebunds von Asia in Pergamon, Claudius (41-54 n. Chr); Photo: 2014 January World \& Ancient Coin Signature Auction, Auktion 05.01.2014 Nr. 23931

Datenkonvertierung und Satz: Satzstudio Borngräber, Dessau-Roßlau Druck und Bindung: Hubert \& Co GmbH \& Co. KG, Göttingen $@$ Gedruckt auf säurefreiem Papier Printed in Germany

www.degruyter.com 


\section{Inhaltsverzeichnis}

Vorwort - IX

Provinzen und ihre Kaiserkulte - Quellen, Probleme und Ergebnisse - 1

\section{Besonderheiten, Genese und Entwicklung}

Jesper Majbom Madsen

Who Introduced the Imperial Cult in Asia and Bithynia?

The Koinon's Role in the Early Worship of Augustus — 21

Werner Eck

Der Senat und der Herrscherkult — 37

Hadrien Bru

Le culte impérial dans l'Orient romain: mythes, rites et structures -57

Domitilla Campanile

Specificità delle origini e dello sviluppo del culto imperiale in Licia -79

Filippo Battistoni

Dediche licie a Roma - 97

Michael A. Speidel

Augustus-Tempel in Indien und im Partherreich?

Zur Tabula Peutingeriana und zum römischen Kaiserkult

ausserhalb des Römischen Reiches — 101

Peter Herz

Die Agonistik und der Kaiserkult -123

Denise Reitzenstein

Agonistik und Kaiserkult in Lykien — 133 


\section{Städte und ihre Kulte}

Gabrielle Frija

Les cultes impériaux dans les cités d'Asie Mineure:

des spécificités provinciales? — 159

Barbara Holler

Poliskult und Provinzkult - Der Einfluss des Provinzkultes und die Homogenisierung durch den Herrscherkult für Octavian/Augustus in der Provinz Asia — 173

Julie Dalaison

Néocorie et koinon: les attestations et représentations

du culte impérial fédéral sur les monnaies provinciales romaines du nord de l'Asie mineure (Pont, Paphlagonie et Arménie mineure) — 189

Holger Wienholz

Eine severische Neokorie im Bacchustempel von Baalbek - 229

\section{Städtebünde und ihre Kulte}

Francesco Camia

Between Tradition and Innovation:

Cults for Roman Emperors in the Province of Achaia 255

Richard Bouchon

Les Thessaliens et le culte des empereurs de Rome:

Tradition, intégration, polycentrisme et jeu d'échelles - 285

Lorenzo Cigaina

Der Kaiserkult bei den Kretern in Bezug auf ihre Teilhabe am Militärwesen des römischen Reiches — 309

Søren Lund Sørensen

The Bithynians again!

The koina and their supposed involvement in cases of repetundae 337

Marco Vitale

Provinciae als beschlussfassende Instanzen in Inschriften von Baetica bis Anatolien - 353 


\section{Lokale Eliten und Kaiserkult: Priesterinnen und Priester}

Tønnes Bekker-Nielsen

Leading men - 367

Babett Edelmann-Singer

Die Kaiserpriesterinnen in den östlichen Provinzen des Reiches Reflexionen über Titel, Funktion und Rolle - 387

\section{Spätantike: Kontinuitäten - Ende des Kaiserkults?}

Alister Filippini

Fossili e contraddizioni dell' „èra costantiniana“:

i dignitari del culto imperiale nella Tarda Antichità e il loro ruolo nelle „riforme religiose“ di Massimino Daia e Giuliano. — 409

Christian R. Raschle

Bis wann bleibt der Kaiser „Kult“? Die Verehrung des Kaiserbildes als Akt der Zivilreligion in der Spätantike — 477

Die Autoren — 497

Quellenregister — 498 
Bereitgestellt von | De Gruyter / TCS

Angemeldet

Heruntergeladen am | 14.10.16 13:13 


\section{Vorwort}

Der vorliegende Band präsentiert die Beiträge der interdisziplinären Tagung, die vom 25.-27. September 2014 am Historischen Seminar sowie am Institut für Archäologie der Universität Zürich zum Thema „Kaiserkult in den Provinzen des Römischen Reiches - Organisation, Kommunikation und Repräsentation“ stattfand. Zusätzlich sind zwei weitere Beiträge berücksichtigt, die das Leitthema mit relevanten Fallbeispielen und zusätzlichen Quellen ergänzen.

Gewidmet ist der Band unserem akademischen Lehrer, renommierten Forscher und hochgeschätzten Kollegen, Professor Dr. Christian Marek, dessen unzählige profunde Arbeiten zum griechisch-sprachigen Osten auch das Thema der Tagung richtungsweisende methodische Überlegungen verdankt.

Für die großzügige Finanzierung der Tagung und Drucklegung des Bandes danken wir der Hochschulstiftung der Universität Zürich, dem Zürcher Universitätsverein sowie dem Schweizerischen Nationalfonds, der die Reise- und Aufenthaltskosten der Referenten übernommen hat.

Zahlreichen Kollegen sind wir zu tiefem Dank verpflichtet. An erster Stelle steht PD Dr. Babett Edelmann-Singer, die als Mitinitiantin inspirierend an der Konzeption des Tagungsthemas und als Mitorganisatorin tatkräftig an der Planung und Umsetzung der Tagung beteiligt war. Ebenso hat uns Monika Pfau mit ihrer umsichtigen, mitgestaltenden Arbeit wesentlich bei der Genese der Tagung und darüber hinaus unterstützt. Zum reibungslosen Tagungsablauf haben einerseits die Assistierenden Nikolas Hächler, Benjamin Hartmann, Jaqueline Koller und Vanessa Metz durch ihre Präsenz und die wertvolle Hilfestellungen beigetragen andererseits unsere Kollegen Dr. Martin Bürge, Dr. Ursula Kunnert, Prof. Dr. Beat Näf und Prof. Dr. Christoph Reusser. Wir danken Ihnen für die souveräne und anregende Diskussionsleitung und Ratschläge. Auch bei der Drucklegung durften wir tatkräftige Unterstützung erfahren. Dafür danken wir Rainer Petretti (Zürich) sowie Kerstin Protz und Dr. Mirko Vonderstein vom Verlag de Gruyter.

Zürich, März 2016

Anne Kolb und Marco Vitale 
Bereitgestellt von | De Gruyter / TCS 


\title{
Fossili e contraddizioni dell' „èra costantiniana“: i dignitari del culto imperiale nella Tarda Antichità e il loro ruolo nelle „riforme religiose“ di Massimino Daia e Giuliano.*
}

Questo lavoro è dedicato con riconoscenza sincera a Mario Mazza, maestro di humanitas, per il suo $80^{\circ}$ compleanno

\begin{abstract}
Il culto imperiale nella Tarda Antichità (IV-VI sec.) può essere interpretato come un significativo fossile giuridico, che esprime le intrinseche contraddizioni della cosiddetta „èra costantiniana“. Un'analisi epigrafica e prosopografica dei sommi sacerdoti del culto imperiale (flamines, sacerdotes e coronati nell'Occidente, $\alpha \rho \chi เ \varepsilon \rho \varepsilon \check{c}$ nell’Oriente) può mettere in evidenza la durevole importanza di tali dignitari tra l'epoca di Diocleziano e Giustiniano, specialmente per quanto riguarda i sommi sacerdotali provinciali, che erano al contempo presidenti delle assemblee federali (concilia, koıvó) e svolsero un ruolo fondamentale nelle „riforme religiose“ progettate da Massimino Daia e Giuliano l’Apostata.
\end{abstract}

The imperial cult in Late Antiquity ( $4^{\text {th }}-6^{\text {th }}$ cent. AD) can be interpreted as a significant juridical fossile, which conveys the inner contradictions of the so called ,era of Constantine“. An epigraphic and prosopographic analysis of the high priests of the

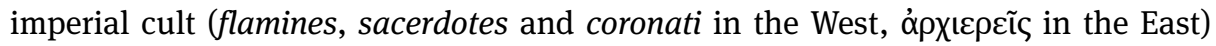
would point out the lasting importance of these dignitaries between the ages of Diocletian and Justinian, especially in the case of provincial high priests, who were in the same time presidents of federal assemblies (concilia, кoıvó) and played a primary role in the „religious reforms“ planned by Maximinus Daia and Julian the Apostate.

\footnotetext{
* Per le preziose osservazioni fornite durante la presentazione del contributo e la sua elaborazione scritta sono sinceramente grato a Tullia Ritti, Gian Luca Gregori, Domitilla Campanile, Laura Mecella, Marco Vitale, Hadrien Bru, Christian Raschle. Di alcuni recenti, importanti contributi ho potuto prendere visione solo nell'ultima fase di correzione delle bozze: pur non avendo potuto tenerne conto in sede di stesura del testo, se non in minima parte, desidero segnalare LeONE 2013; EdELMANNSINGER 2015; FEISSEL-WÖRRLE 2015; GRAF 2015; MILNER 2015.
} 


\section{Premessa: il culto imperiale e le contraddizioni dell' „èra costantiniana“}

Se con „èra costantiniana“ intendiamo quella lunga epoca storica, inaugurata da Costantino, ma già preparata nelle sue linee strutturali dai Tetrarchi, la quale si estende poi per alcuni secoli, almeno per certi aspetti sino a Giustiniano, in quest'epoca di radicali trasformazioni potremo nondimeno trovare vari elementi di continuità rispetto al passato e, al contempo, grandi e irrisolte contraddizioni. Una di queste, apparenti, contraddizioni è proprio la persistenza del culto imperiale: come osservò SANTO MAZZARINo, esso emerge dal panorama dell'Impero cristianizzato come un significativo fossile giuridico-sacrale - un fossile ancora vitale, operativo, efficace nell'assolvimento delle sue molteplici funzioni, socio-religiose e, ancor più, politiche. ${ }^{1}$

Questo contributo da un lato non potrà soddisfare pienamente le attese suscitate dal titolo, dovendo limitare necessariamente la selezione del materiale documentario all'essenziale, dall'altro tenterà di indicare alcuni punti specifici che meriterebbero di essere approfonditi dalla ricerca sul culto imperiale tardoantico. Oggetto dell'analisi non sarà il culto imperiale in sé, nella sua dimensione propriamente religiosa e rituale, quanto gli alti dignitari preposti al culto stesso, a livello civico o federale,

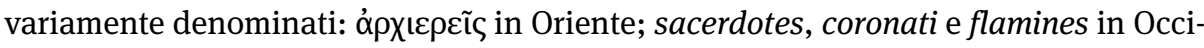
dente (oppure sacerdotales e flamines perpetui per quelli già usciti di carica). Il punto di vista prescelto sarà pertanto prosopografico e sociologico, con una speciale attenzione per l'inquadramento dei dati nella storia locale di singole comunità e nella storia amministrativa provinciale. ${ }^{2}$

1 Sull',„èra costantiniana“ vd. MazzARINo 1970; MAZZARINo 1974, 11 -50 (sul Die Zeit Constantin's des Grossen [1852] di J. Burckhardt); 427-439, partic. 436-437 sulle contraddizioni giuridico-sacrali e sul culto imperiale: ,[...] per gli aspetti che in qualche modo confinano con le tradizioni imperiali di diritto pubblico, o che a queste sono pertinenti, le contraddizioni dell'èra costantiniana' appaiono variamente, secondo varie epoche e luoghi - in certo modo conciliabili. [...] Della tradizione giuridica sacrale, si salva infine solo il culto imperiale. Da Costantino arriva sino ai re vandali [...]“; 438: „Da questo punto di vista l'èra costantiniana' - in quanto caratterizzata, anche, dai tentativi di conciliare il diritto sacro tradizionale (là dove si collega al diritto pubblico) con la religione cristiana - si può estendere sino ai Vandali. Qui si rivela un aspetto particolare della problematica di periodizzazione dell'èra costantiniana'. L'Africa, regione periferica dell'impero tramontato, ha conservato sino all'età vandalica, sia pur entro certi limiti, il senso della città, come questa era concepita nel mondo ellenistico e romano: con la sua festività tradizionale, che Onorio, in una costituzione del 399, aveva definito nei ludi e nei festa convivia; essa ha continuato questa tradizione cittadina [civilitas] mediante i fossili del culto imperiale“; cfr. anche MAzzarino 1966, 2, 251. Sull'„epoca“ di Costantino e la sua percezione tra mondo tardoantico e modernità cfr. GIARDINA 2012.

2 Sul culto imperiale tardoantico e i suoi aspetti rituali tra la metà del III e la fine del IV sec. vd. TROMBLEY 2011 (partic. per la documentazione epigrafica); sulle politiche religiose degli imperatori del IV sec. in merito al culto imperiale vd. CLAuss 1999, 189-216. Sul culto imperiale in epoca alto- 
Le fonti usate nell'indagine saranno quelle letterarie (storiografiche, storicoecclesiastiche, giuridiche) e soprattutto quelle epigrafiche: si ricordi però come lo stile della comunicazione epigrafica cambi sensibilmente a partire dalla seconda metà del III sec., in quella che è stata chiamata la „terza età dell'epigrafia“. Nell’Oriente ellenofono le iscrizioni onorarie „classiche“ di epoca alto-imperiale lasciano spesso il posto a componimenti poetici, come gli epigrammi celebrativi studiati da LouIS ROBERT e REINHOLD MERKELBACH: questo stile, allusivo e complesso, rende più difficile la ricostruzione delle carriere dei notabili e dei magistrati provinciali. L'Occidente di lingua latina invece, pur arricchendo il proprio lessico di una marcata enfasi retorica, si mantiene generalmente più fedele agli schemi tradizionali, come aveva osservato ANDRÉ CHASTAGNOL. ${ }^{3}$ La maggior parte delle iscrizioni qui raccolte provengono, per la pars Occidentis, dalla ricchissima diocesi d'Africa: i testi africani saranno qui citati in funzione esemplificativa e per il loro commento si rimanderà, di volta in volta, agli studi di Chastagnol, NoËL Duval, Claude Lepelley e altri studiosi; a essi si affiancheranno alcuni documenti di area italica. ${ }^{4}$ Per la pars Orientis invece si presentano testi relativi soprattutto alla diocesi d'Asia, che, come è noto, è costellata di molte città antichissime e straordinariamente vivaci in epoca tardoantica: in questo settore si intende presentare alcuni testi di recente pubblicazione e analizzarli in maggiore dettaglio.

In linea generale si possono riscontrare tra II e IV sec. elementi di durevole continuità per la posizione sociale e le prerogative attribuite ai sommi sacerdoti del culto

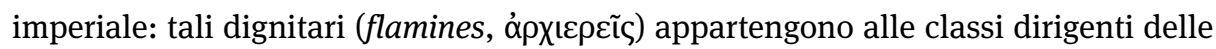
città, costituiscono lo strato superiore dei curiales (i cosiddetti principales) e svolgono un'importante funzione di intermediazione politica tra la dimensione locale e i rappresentanti dell'autorità romana, dai governatori e vicarii sino alla corte imperiale. A un livello più alto i sommi sacerdoti federali (sacerdotes e/o coronati, $\alpha \rho \chi\llcorner\varepsilon \rho \varepsilon \tilde{\varsigma} \tau \tilde{\omega} v$ દ่$\theta v \tilde{\omega} v)$ presiedono le periodiche assemblee degli organismi federali (concilia, кoเvó),

imperiale vd. BASSIGNANo 1974 (province africane); PRICE 1984 (Asia Minore); FISHWICK 1987-2005 (Occidente); LoZANo 2002 (Atene, I sec. d.C.); CHANIOTIS 2003 (Oriente, aspetti rituali); KANTIRÉA 2007 (Grecia, I sec. d.C.); CAMIA/KANTIRÉA 2010 (Peloponneso); LoZANo 2010 (Grecia); CAMIA 2011 (Grecia, II sec. d.C.); VITALE 2014 (Oriente, ruolo dei dignitari federali). Studi prosopografici sui sacerdoti del culto imperiale in epoca alto-imperiale: ALFÖLDY 1973 (flamines in Hispania Citerior); CAMPANILE

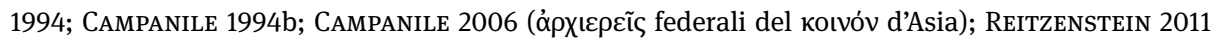

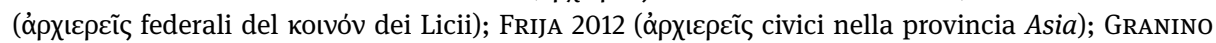
CECERE 2014 (flaminicae in Italia).

3 Terza età dell'epigrafia: DoNATI 1988. Epigrammi celebrativi per funzionari e notabili: ROBERT 1948; cfr. MERKELBACH/STAUBER 1998-2004. Epigrafia greca tardoantica: FEISSEL 1999a. Epigrafia latina tardoantica: Chastagnol 1988a; Christol 1999; BARnes 1999.

4 Sul culto imperiale nell'Africa tardoantica (IV-VI sec.) vd. CHASTAGNOL/Duval 1974; LEPELLEY 1979, 362-369; Chastagnol 1988b; LeONe 2013, 83-119. 
sollecitano e fanno attuare le disposizioni ufficiali decretate da tali organismi (tra cui le onorificenze oppure, al contrario, le accuse di malversazione per i governatori provinciali alla fine del loro mandato), sono incaricati dell'organizzazione di grandi celebrazioni festive e talora di ambascerie di alto rilievo.

Va nondimeno rilevata un'importante differenza tra le assemblee federali di epoca alto-imperiale e quelle tardoantiche: se le prime sono composte da delegati eletti dalle istituzioni civiche di ciascuna città (curia/ßou入ń ed eventualmente populus/ $\delta \tilde{\eta} \mu \circ)$, i membri delle seconde sono invece designati in base al rango sociale e rappresentano le due categorie degli honorati (ex-governatori, ex-funzionari imperiali e sacerdotales federali, che hanno già ricoperto i più alti incarichi e godono pertanto di particolari privilegi e immunità) e dei primates o principales (i più autorevoli tra i curiales municipali, che hanno assolto tutti i munera civilia nella propria città d'origine); entrambe le categorie sono comunque costituite, sotto il profilo economico, da possessores, grandi e medi proprietari terrieri. I sommi sacerdoti, eletti ogni anno dai membri dell'assemblea federale riunita in consesso, sono selezionati tra i principales e rappresentano i gruppi dirigenti urbani e, al contempo, i ricchi proprietari fondiari delle province.

Alcune fonti attestano inoltre l'esistenza di assemblee diocesane, almeno per certe diocesi occidentali (Viennensis, Africa, Hispaniae). ${ }^{5}$

\section{I sommi sacerdoti nell'epigrafia dell'Occidente latino: Africa e Italia}

Il rango dei sommi sacerdoti è esemplificato da due straordinari documenti di epoca giulianea, provenienti da Thamugadi (Timgad, Numidia): nell'album municipale della colonia i sacerdotales sono classificati tra gli honorati, vengono elencati subito dopo i viri clarissimi e perfectissimi, e sono posti al di sopra del curator rei publicae; quindi, nella lista dei decurioni, i flamines perpetui costituiscono il nucleo più prestigioso e precedono gli altri sacerdoti civici, pontifices e augures. ${ }^{6}$ Nell'ordo salutatio-

5 Assemblee federali: GuIRAud 1887; ABBotT/Johnson 1926, 162-176; LARSEN 1955, 106-161; DEININGER 1965; EDELMANN-SINGER 2015. Assemblee federali tardoantiche (IV-VI sec.): ABвоTT/ JOHNSON 1926, 173-176; LARSEN 1934; LARSEN 1955, 145-157; DEININGER 1965, 183-188; DE DoMINICIS 1970; CECCONI 1994, 83-106 (partic. per l'Italia); AMOROso 2004-2005. Ruolo e prerogative dei sommi sacerdoti e presidenti delle assemblee federali: ZuDDAs 2013, 104-111 (Occidente tardoantico); VITALE 2014 (Oriente alto-imperiale). Rapporto tra notabili e istituzioni civiche (specialmente il populus) tra Alto Impero e Tarda Antichità: LEWIN 1995; cfr. FERnoux 2011 (Asia Minore). Assemblee diocesane: Chastagnol 1988b (diocesi d'Africa). Su honorati, possessores e curiales vd. CECCONI 2006.

6 Album di Thamugadi: CIL VIII 17903 = AE 1948, 118 = CHASTAGNOL 1978, 1-74 = AE 1978, 891

= HD021699 (datazione: 363). L’album elenca le varie categorie di membri della curia locale, disponendole in ordine gerarchico discendente: agli honorati appartengono 10 viri clarissimi, 2 viri 
nis del consularis Numidiae Ulpius Mariscianus i coronati provinciali sono ammessi alla presenza del governatore al terzo posto, dopo i senatori, i comites effettivi e onorari (ex comitibus) e i più alti quadri amministrativi, ma prima degli officiales. ${ }^{7}$ Non mancano nel IV sec. singoli casi di notabili illustri che, dopo una densa carriera municipale, costellata di incarichi e culminante nel sommo sacerdozio provinciale, siano stati innalzati al rango di viri perfectissimi ${ }^{8}$ o di ex comitibus. ${ }^{9}$ Nell'epoca di

perfectissimi (tra i quali figura un flamen perpetuus) e 2 sacerdotales (tra i quali un flamen perpetuus); è quindi registrato il curator rei publicae (anch'egli flamen perpetuus); poi i duoviri (tra i quali un flamen perpetuus); la lista dei decuriones si apre con 32 flamines perpetui (per un totale di 36, insieme ai 4 sopra menzionati), cui seguono 4 pontifices, 4 augures, poi gli aediles, i quaestores, i duoviralici e infine i semplici decurioni.

7 Ulpius Mariscianus (PLRE I 561), consularis sexfascalis Numidiae sotto Giuliano. Ordo salutationis: CIL VIII 17896 = AE 1949, 133 = CHASTAGNOL 1978, 75-88 = AE 1978, 892 = HD030051 (datazione: 361-363 [362?]); cfr. ConTI 2004, nr. 172. Ll. 1-12: Ex au[ctori]tate Ulpi Mariscia/ni v(iri) c(larissimi) consularis sexfascalis / promoti primo a domino nostro / Invicto principe Iuliano ordo sa/lutationis factus et ita $a<d=T>$ perpetui/[t]atis memoriam aere incisus. Primo / senatores et comites et ex comitibus / et admin[ist]ratores, secundo prin/ceps cornic[ul]ar[ius pa]latini, ter[t]io co/ronati [provi]nc[iae, quart]o promoti of/ficiales [et magistra]tus cum ordi/ne, [qui]nt[o oflficiales ex ordine [...].

8 Disamina delle fonti epigrafiche e giuridiche in ZUDDAs 2013, 106-107 (province occidentali). In Italia si riscontra il v.p. C. Matrinius Aurellius Antoninus di Hispellum (Spello, Tuscia et Umbria: vd. infra n. 18). Nella diocesi d'Africa i due vv.pp. di Leptis Magna (Lebdah, Tripolitania), entrambi databili alla prima metà del IV sec., T. Flavius Vibianus signo Heraclius (vd. infra, n. 53) e M. Vibius Annianus Geminus signo Amelius (PLRE I 389), che fu flamen perpetuus, pontifex, due volte sacerdotalis provinciae Tripolitaniae, duumviro di Leptis (IRT 578 = TANTILlo/Bigi 2010, nr. 58), e inoltre praefectus omnium sacrorum (cfr. IRT $581+608+627$ = TANTILLO/BIGI 2010, nr. 59 = AE 2010, 1781); e ancora il v.p. Caecilius Cromatius Ecdicius Triumphalis (PLRE I 923) di Cirta/Constantina (Numidia), che fu sacerdotalis provinciae Numidiae negli anni 388-392 (ILAlg II.1, 620 = SAASTAMOINEN 2010, nr. 784; cfr. CIL VIII 7034 = ILAlg II.1, 619 = ILS 5789 = SAASTAMOINEN 2010, nr. 783). Il fatto che non tutti i sacerdotales giungessero al perfettissimato può dedursi dall'esempio di un altro sacerdotalis Numidiae, il vir egregius Valerius, anch'egli attivo a Cirta e databile agli anni 364-367 (CIL VIII $7014=$ ILAlg II.1, 591 = ILS 758). Sulla possibilità di accesso al perfettissimato o all'egregiato per i decuriones vel principales cfr. Cod. Theod. 12,1,5 (Idem A. [Costantino, in realtà anche Licinio] ad Bithynos: [senza luogo], 21 luglio 317 - si noti come la costituzione sia indirizzata al koเvóv di Bitinia). Due

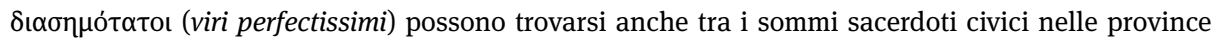
greco-orientali della prima metà del IV sec.: Marcus Aurelius Stephanos a Sparta (Achaia: vd. infra, n. 20) e Flavius Zenon ad Aphrodisias (Caria: vd. infra, n. 55).

9 Un notabile della Colonia Claudia Ara Agrippinensium (Köln, Germania Inferior), Masclinius Maternus, morto nel 352 (CIL XIII 7918 = ILS 7069), presenta una fortunata carriera municipale ascendente (aedilicius, duumviralis, curatoricius), coronata dal sommo sacerdozio provinciale (sacerdotalis) e dal conferimento onorario della comitiva (ex comitibus). Sulla concessione di tale rango ai sacerdotales e principales particolarmente meritevoli cfr. Cod. Theod. 12,1,75 (SC 531, 308-311: Idem AAA. [Valentiniano I, Valente e Graziano] ad Viventium praefectum praetorio: Treviri, 28 giugno 371); Cod. Theod. 12,1,109 (vd. infra, n. 30). 
Valente agli asiarchae è concessa la senatoria dignitas e sotto Onorio i sacerdotales africani paiono ormai equiparati ai senatores. ${ }^{10}$

A proposito delle funzioni di rappresentanza svolte dai sommi sacerdoti federali, specialmente quali portavoce del concilium in occasione di legazioni ufficiali presso la corte imperiale, basti ricordare il caso di L. Aemilius Quintus, sacerdotalis della Tripolitania, che in epoca teodosiana portò personalmente le suppliche dell'intera sua provincia alle „sacre orecchie“ degli Imperatori. ${ }^{11}$ Un caso che riecheggia quello

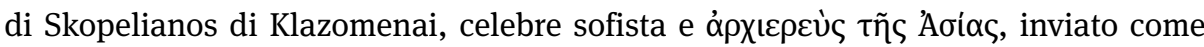
ambasciatore del koเvóv d'Asia presso Domiziano riguardo la questione dei vigneti. ${ }^{12}$

Nell'Africa dei Tetrarchi una politica di generale rilancio delle città, di cui beneficiarono anche i templi pagani, trascurati da parecchi anni, promosse un notevole fervore edilizio: in molti centri, grandi e piccoli, furono restaurati templi di divinità locali (la dea Maura, Hercules, Mercurius, Pluto: si noti che dietro ai nomi latini si celano in realtà antichi dèi 'etnici' pre-romani, ad esempio punici, quali Melkart e

10 Per il rescritto di Valente al proconsul Asiae Festus sull'asiarchia vd. infra nn. 76-78. Un esempio di gerarchia sociale „in negativo“ emerge dalla gravità delle pene pecuniarie comminate agli eretici donatisti d'Africa da Onorio (Cod. Theod. 16,5,52 [SC 497, 306-310, cfr. 488-489]: Idem AA. [Onorio e Teodosio II] Seleuco praefecto praetorio: Ravenna, 30 gennaio 412); in questo caso i sacerdotales sono posti sullo stesso piano economico dei senatores: i viri illustres macchiatisi di donatismo pagheranno al fisco imperiale 50 libbre d'oro, gli spectabiles 40 libbre, i senatores 30 libbre, i clarissimi 20 libbre, i sacerdotales 30 libbre, i principales 20 libbre, i decuriones 5 libbre. Pochi anni dopo si ha una riformulazione al ribasso in libbre d'argento (Cod. Theod. 16,5,54 [SC 497, 312-317, cfr. 489-490]: Idem AA. Iuliano proconsuli Africae: Ravenna, 14 giugno 414): coloro che hanno il rango di ex-proconsoli, di ex-vicari e di comites primi ordinis (si tratta ovviamente di honorati) pagheranno 200 libbre d'argento, i senatores 100 libbre, i sacerdotales 100 libbre, i decemprimi curiales 50 libbre, gli altri decuriones 10 libbre, gli officiales 30 libbre. Sul contesto normativo di tali costituzioni vd. infra n. 37.

$11 \mathrm{~L}$. Aemilius Quintus, flamen perpetuus e sacerdotalis provinciae Tripolitaniae, fu onorato per decreto dell'assemblea provinciale in varie città: CIL VIII 11025 = ILS 787 (Gigthis; datazione: 383-388): Quinto fl(amini) p(er)p(etuo) sac(erdotali) prov(inciae) / salvis ac toto orbe vin(cen)tibus / dddd(ominis) nnnn(ostris) FFFFllll(avis) / Valentiniano Theodosio / Arcadio et Maximo semp(er) August(is) / ob meritum magnific(a)e legati/onis quam pro voto totius / provinciae executus est et [per]/ [eg]it Quintus vir laudabilis / sacerdotalis huic cupiens / conpetentibus meritis / respondere totius pro/ vinciae consilio ad(que) / decreto ord(inis) / n(ostr)i / po/s(ita) p(ecunia) p(ublica). AE 1950, $149=$ IRT 111 (Sabratha): L(uci) Aemili Quinti fl(aminis) p(er)p(etui) / quod laborem continu(u)m / pro provinciae suae / necessitate sustinuit / et quod miserias com/munes sacris aurib(us) / intimabit et remedium / meruit ordo et popul(us) / splendidae col(oniae) Sabrat(hensis) / secundum decreta totius / provinc(iae) dedic(averunt) cur(ante) / Fl(avio) Venantio. AE 1950, $150=$ IRT $588=$ TANTILLO/BIGI 2010, nr. 60 (Leptis Magna): Quintii fl(aminis) p(er)p(etui) sac(erdotalis) // Ob meritum labo/ris et legationis / perfectae / L(ucio) Aemilio Quinto fl(amini) p(er)p(etuo) / sacerdotali / ordo splendidis/ simus civitatis / Lepcimagnensium / dedit. L'ambasceria guidata dal sommo sacerdote provinciale L. Aemilius Quintus può ricollegarsi all'emergenza dovuta alle incursioni dei nomadi Austuriani in Tripolitania: cfr. Felici/MunZi/TANTILLO 2006, 605.

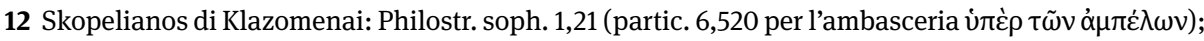
CAMPANILE 1994, 49-50, nr. 27; PIR² S 252. 
Baal, oppure berberi). Al rinnovamento del culto furono associati gli imperatori regnanti, in vario modo, talora con una doppia dedica dell'edificio sacro oppure con formule aggiuntive come pro salute e beatissimo saeculo dominorum nostrorum. Se da un lato non può parlarsi, in tutti i casi, di culto imperiale nel senso pregnante, dall'altro gli Imperatori divengono visibilmente oúvvaoı $\theta \varepsilon o$ delle antiche divinità. ${ }^{13}$

Un caso straordinariamente interessante dal punto di vista religioso e sociologico si riscontra a Thubursicu (Khamissa, Numidia), dove una famiglia di sacerdotes, i Modestii, dedicarono un tempio alla Virtus Augusta di Diocleziano e Massimiano: con una eccezionale ricchezza di dettagli l'iscrizione precisa che per la dedicatio del tempio vennero dalle città vicine e dai villaggi tutti gli dèi locali (numina universa), insieme ai loro fedeli. L'azione devota di questi sacerdoti, il padre Castinianus e i figli Festucius e Purpurius, che sembrano votati al culto imperiale, fa sì che gli dèi stessi compiano un pellegrinaggio per celebrare la Virtus dei sovrani. ${ }^{14}$

Pochi anni dopo un tempio della gens Valeria Aeterna fu eretto a Thibaris (Thibar, Africa Proconsularis): esso fu dedicato dalla città ai primi Tetrarchi come espressione di lealismo politico nella forma di un culto imperiale idealmente dinastico. ${ }^{15}$ A questo

13 Tempio di Hercules a Madauros (M'daourouch, Numidia): ILAlg I 2048 = SAASTAMOINEN 2010, nr. 617 (datazione: 290-294): dedicato a Diocleziano e Massimiano dal proconsul Africae T. Claudius Aurelius Aristobulus (PLRE I 106) per tramite del consularis Numidiae C. Macrinius Sossianus (PLRE I 849, Sossianus 1). Tempio della dea Maura ad Albulae (Ain Temouchent, Mauretania Caesariensis): CIL VIII 21665 = ILS 4501 = SAASTAMOINEN 2010, nr. 633 (datazione: 299): dedicato a Diocleziano, Massimiano, Costanzo Cloro e Galerio dal curator rei publicae C. Iulius Fortunatus, dai duumviri e da altri evergeti locali. Tempio di Mercurius a Castellum Ma[- - -]rensium (Tella, Africa Procos.): CIL VIII 17327 = SAASTAMOINEN 2010, nr. 667 (datazione: 293-305): dedicato pro salute di Diocleziano, Massimiano, Costanzo Cloro e Galerio dai seniores e dal magister locale. Tempio di Pluto a Iubaltianae (Kairouan, Africa Procos.): CIL VIII 11217 = SAASTAMoInEn 2010, nr. 668 (datazione: 293-305): dedicato pro salute di Diocleziano, Massimiano, Costanzo Cloro e Galerio dai magistri locali. Tempio di Mercurius a Thamugadi (Timgad, Numidia): BCTH 1907, p. 274 = SAASTAMOINEN 2010, nr. 662 (datazione: 303-305): restaurato e dedicato pro salute (?) di Diocleziano, Massimiano, Costanzo Cloro e Galerio per ordine del praeses Numidiae Valerius Florus (PLRE I 368), sotto curatela del curator rei publicae Iulius Lambessius.

14 Tempio della Virtus Augusta a Thubursicu: ILAlg I 1241 = SAASTAMoInEn 2010, nr. 628 (datazione: 286-293): V(irtuti) A(ugustae) s(acrum) / pro salute Impp(eratorum) / dd(ominorum) nn(ostrorum) Diocletiani / et [[[Maximiani]]] / Modestii sacerd/otes Castinianus pa/ter et Festucius / et Purpurius fili(i) tem/plum a solo cum san/cto suo quod est / a tergo institue/runt et dedi/[c]averu[nt ad q]uam dedi/c[atione]m de vici/n[i]s c[ivi]tati[b]us et / univ[e]rsis pa[gis] nu/mina universa cum cul/toribus suis convenerunt. La sigla VAS (1. 1) potrebbe altrimenti interpretarsi come una dedica V(ictoriae) A(ugustae) s(acrum): cfr. il tempio della Victoria Augusta di Bedaium (Prutting, Noricum Ripense): CIL III 5565 = 11771 = ILS 664 (datazione: 311-312), interamente ricostruito ex voto e dedicato pro salute di Massimino Daia, Costantino e Licinio dal dux Norici Aurelius Senecio (PLRE I 821) per celebrare una battaglia vinta il 27 giugno 310 .

15 Tempio della gens Valeria Aeterna a Thibaris: AE 2003, 2010 = SAASTAMOINEN 2010, nr. 656 = AE 2010, 1805 (datazione: 296-300): dedicato alla dinastia di Diocleziano, Massimiano, Costanzo Cloro e Galerio dalla città sotto il proconsul Africae L. Aelius Helvius Dionysius (PLRE I 260). Ancora negli 
prezioso documento può affiancarsi una notizia di Aurelio Vittore: dopo la vittoria di Costantino al Ponte Milvio, la provincia (o forse l'intera diocesi) Africa, che Massenzio aveva barbaramente devastato durante la rivolta del vicario Domitius Alexander, avrebbe decretato un sacerdozio consacrato alla gens Flavia e la città di Cirta, capitale di Numidia, sarebbe stata ribattezzata Constantina. ${ }^{16}$

È significativo che Costantino avesse promosso la divinizzazione del presunto antenato Claudio Gotico e del padre Costanzo Cloro, fondando così il culto dinastico della gens Flavia: passando dalla diocesi africana all'Italia suburbicaria, l'esempio più eclatante è il celeberrimo rescritto di Hispellum (Spello, Tuscia et Umbria), città umbra alla quale Costantino e i suoi figli concessero la nuova denominazione di Flavia Constans, il privilegio di tenere le consuete festività annuali in onore dell'imperatore, in maniera simile a quanto già avveniva nel centro etrusco di Volsinii, ma soprattutto l'autorizzazione a erigere una aedes gentis Flaviae, un vero e proprio tempio del culto imperiale. Come è ben noto, secondo una tipica contraddizione costantiniana, il culto doveva rimanere immune da contagiosa superstitio, ossia da quelle pratiche rituali pagane (probabilmente i sacrifici cruenti) sulle quali il dibattito degli studiosi moderni pare ancora aperto. L'edificio sacro fu costruito nell'area di Villa Fidelia, dove recenti scavi archeologici hanno messo in luce un pre-esistente santuario extraurbano, prossimo al teatro e all'anfiteatro, in cui si celebravano i ludi. ${ }^{17}$ L'iscrizione di C. Matrinius Aurellius Antoninus mostra la fortunata carriera di un notabile ispellate, che ebbe il sacerdozio civico di pontifex gentis Flaviae, divenne coronatus Tusciae et Umbriae, curator rei publicae e patrono di Hispellum, dove organizzò l'editio di un generosissimo munus gladiatorio e di uno spettacolo teatrale. ${ }^{18}$

anni '80 del IV sec. un flamen perpetuus di Uchi Maius (Henchir Douémis, Africa Procos.), Furius Victorinus, dedica a Valentiniano II e Teodosio un edificio che parrebbe forse destinato al culto imperiale (CIL VIII 26267 = HD020939 = Uchi II 56 = SAASTAMOINEN 2010, nr. 772).

16 Aur. Vict. 40,19: dopo la rivolta di L. Domitius Alexander, vicario della diocesi d'Africa (311): Quo victo [scil. Alexandro] Maxentius Carthaginem, terrarum decus, simul Africae pulchriora vastari diripi incendique iusserat [...]; 28: dopo la vittoria di Costantino su Massenzio (312): [...] tum per Africam sacerdotium decretum Flaviae genti, Cirtaeque oppido, quod obsidione Alexandri conciderat, reposito exornatoque nomen Constantina inditum. Sulla ridenominazione di città secondo l'onomastica dinastica dei Costantinidi vd. GREGORI/FILIPPINI 2013, 534, n. 23.

17 Rescritto di Hispellum (datazione: 333-335 o 337): CIL XI 5265 = ILS 705 = EAOR II, 20 (G.L. GREGORI) = EDR136860 (24-11-2014: E. ZUDDAS). La bibliografia sul rescritto è enorme: per ulteriori rimandi cfr. CeCConi 2012; Zuddas 2012; Gregori/FilipPini 2013, 533-534, nn. 19-21. Per la datazione vd. TABATA 1995 (fine 333); BARNES 2011, 20-23, 167 (luglio 337, durante il periodo di 'interregno' seguito alla morte di Costantino); CECConi 2012, 275-276. Area sacra di Villa Fidelia (Spello): SENSI 1998; CAMERIERI/MANCONi 2010, 31-37.

18 C. Matrinius Aurellius Antoninus di Hispellum: CIL XI $5283=$ EAOR II, 21 (G.L. GREGoRI) = EDR123166 (04-10-2013: A. CANnUCCIARI): C(aio) Matrinio Aurellio / C(ai) f(ilio) Lem(onia) Antonino $v$ (iro) p(erfectissimo) / coronato Tusc(iae) et Umb(riae) / pont(ifici) gentis Flaviae / abundantissimi muneris sed et / praecipuae laetitiae theatralis editori / aedili quaestori duumviro / iterum q(uin) $q$ (uennali) i(ure) d(icundo) huius splendissimae / coloniae curatori r (ei) p(ublicae) eiusdem / colon(iae) 
Un pontifex Flavialis, ossia un sacerdote addetto al culto della gens Flavia costantiniana, è attestato anche a Roma, nel cuore del conservatorismo pagano d'Occidente: il cursus di L. Aradius Valerius Proculus, senatore pagano e membro illustre del casato degli Aradii Valerii, prefetto urbano nel 337, registra tale pontificato nella sezione preliminare, riservata agli incarichi sacri, elencandolo dopo l'appartenenza agli amplissima collegia, ossia ai sacerdozi tradizionali di augur, pontifex maior (di Vesta) e quindecemvir sacris faciundis. ${ }^{19}$

D’altra parte un segno caratteristico di contraddizione costantiniana (o perlomeno di un certo imbarazzo di fronte alle forme greco-orientali del culto imperiale) può essere visto in una precisa modifica semantica della titolatura imperiale in lingua greca, voluta da Costantino intorno al 324-325: BENET SALWAY ha riconosciuto un ten-

et primo principali ob meritum / benevolentiae eius erga se / [ple]bs omnis urbana Flaviae / Constantis patrono / dignissimo. L'iscrizione onoraria per Matrinius andrà datata dopo il rescritto di Hispellum, quindi dopo il periodo 333-337 (vd. supra n. 17): la fortunata carriera di questo notabile può collocarsi ragionevolmente a cavallo della metà del IV sec., tra i regni di Costantino, Costante e Costanzo II. Per l'iscrizione onoraria di un altro coronatus Tusciae et Umbriae (EDR135070 [04-09-2014: E. ZUDDAs]), proveniente dalla città umbra di Carsulae e pubblicata di recente, vd. Roscini/ZuDDAS 2014; cfr. ZUDDAS 2013.

19 L. Aradius Valerius Proculus signo Populonius (PLRE I 747-749) ebbe una notevolissima carriera senatoria sotto Costantino e i suoi figli: dopo vari governatorati provinciali fu proconsul Africae e contestualmente vicarius Africae (331-333), membro di primo ordine del comitato imperiale presso la corte di Costantinopoli (comes ordinis primi intra Palatium, 333-336), quindi prefetto urbano di Roma (337-338: l'ultimo prefetto nominato da Costantino nel marzo 337, cfr. CHASTAGNoL 1962, 96102, nr. 40), console ordinario (340) e nuovamente prefetto urbano (sotto Magnenzio, 351-352). In occasione della prima prefettura urbana ricevette una lettera di elogio, indirizzata da Costantino al Senato e pervenuta tramite un'iscrizione onoraria del Foro di Traiano: AE 1934, 158 = CIL VI $40776=$ LSA 2685 = EDR073236 (08-09-2015: A. FERRARO). Il sacerdozio di pontifex Flavialis è registrato nelle due iscrizioni onorarie per Proculus, provenienti dalla sontuosa domus Valeriorum del Celio e databili c.a. 340: la dedica della corporazione dei suarii et confecturarii: CIL VI 1690, cfr. pp. 3173, 3813, $4735=$ ILS 1240 = LSA 1396 = EDR076346 (17-10-2015: A. FERRARO); la dedica della città di Puteoli: CIL VI 1691, cfr. p. 4735 = LSA 1397 = EDR134898 (04-06-2014: S. ORLANDI); cfr. anche l'iscrizione frammentaria CIL VI 1694, cfr. p. 4736 = LSA 1400 = EDR134899 (09-12-2014: S. ORLANDI). Forse esso compariva anche nella dedica votiva, frammentaria, posta alla Magna Mater e ad Attis dallo stesso Proculus, nel ruolo straordinario di proconsul et vicarius Africae, per il restauro del tempio delle divinità frigie in Cartagine: CIL VIII 24521 = CCCA V 94 = HD022151 (28-01-2009: F. FERAUDI) = SAASTAMOINEN 2010, nr. 691; cfr. ORLANDI 2011, 434-435, ma esso potrebbe, più verosimilmente, essere stato conferito a Proculus in un tempo posteriore al governatorato africano (331-333). Non si hanno altre attestazioni del sacerdozio romano di pontifex Flavialis: il confronto con il sacerdozio ispellate di pontifex gentis Flaviae suggerisce di interpretarlo analogamente come un sacerdozio legato alla gens Flavia di Costantino, come ritiene TROMBLEY 2011, 30; non pare invece condivisibile l'ipotesi di JöRG RÜPKE (RÜPKE/GLOCK 2005, II 778, nr. 707; RÜPKE 2011/2013, 270), secondo cui il pontifex Flavialis sarebbe forse un sodalis Flavialis (piuttosto che un flamen Flavialis), ossia un membro del collegio sacerdotale votato al culto della gens Flavia di Vespasiano, ben attestato in epoca alto-imperiale; corretta ma non chiarificatrice in merito alla questione la traduzione priest of the Gens Flavia di CARLOS MACHADO (LSA 1396, 1397, 1400). 
tativo di „neutralizzare“ il valore sacrale originario del titolo Augustus nel passaggio

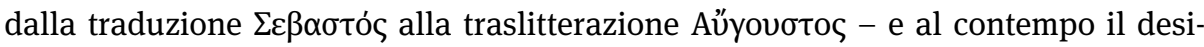
derio di marcare l'inizio di una nuova èra. Tale fenomeno, ben documentato dalla documentazione papirologica, si riflette anche nella denominazione di un ópxıрєù

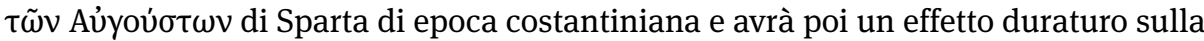
titolatura ufficiale degli imperatori cristiani. ${ }^{20}$

Un esempio delle cerimonie sacre cui sovrintendeva il sommo sacerdote provinciale può essere fornito dal cosiddetto Feriale Campanum, che già THEODoR MoMmSEN interpretava come il calendario delle festività religiose, ancora tradizionalmente pagane, della provincia Campania: esso fu esposto il 22 novembre 387 presso l'anfiteatro di Capua su ordine imperiale (feriale dom(i)norum [...] iussione dom(i) norum); secondo GIOvanNi CECCONI le autorità che presiedettero alla pubblicazione di tale documento ufficiale furono il consularis Campaniae Felix e il sommo sacerdote Romanus Iunior, che contestualmente presiedeva l'assemblea provinciale campana (administrante Romano Iun(iore) sacerdote). ${ }^{21}$

Per tornare dall'Italia all'Africa, il sommo sacerdozio federale, pur comportando onerosissime spese per le editiones di spettacoli (munera), era considerato un incarico di eccezionale prestigio e continuava a suscitare l'ambizione dei più ricchi notabili africani: a una vera e propria competizione allude infatti l'iscrizione onoraria dedicata dalla provincia Africa, ossia dal concilium africano, all'ex-proconsole Iulius Festus Hymetius, che all'epoca di Valentiniano I (366-368) aveva rinvigorito l'aspirazione al sacerdotium provinciale, rendendolo più appetibile. Egli aveva probabilmente ridotto

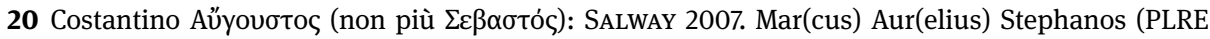
I 853; RizaKis/Zoumbaki/Lepenioti 2004, 126, Laconia nr. 187; cfr. CAMia /KantiRÉa 2010, 393),

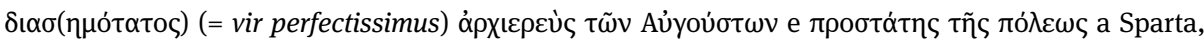
provvide all'erezione di una statua onoraria (AE 1931, 6 = ROBERT 1948, 21 = SEG 11, 810, dal teatro di Sparta), dedicata dalla città al proconsul Achaiae Publilius Optatianus signo Porphyrius (PLRE I 649; RIZAKIS/ZOUMBAKI/LEPENIOTI 2004, 433-434, Laconia nr. 656), il cui proconsolato si data c.a. 325-329 (cfr. DAVENPORT 2013, 232-233). Pochi anni prima, in epoca tetrarchica, il sommo sacerdote civico di

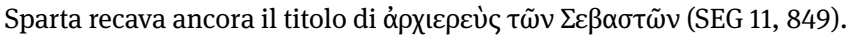

21 Feriale Campanum (Capua, Campania; datazione: 22 novembre 387): CIL X 3792 = ILS 4918 = InscrIt XIII.2, p. 282-283 = EAOR VIII.1, 47 (S. Evangelisti) = EDR005626 (09-03-2013: L. CHIOFFI/M. FogLIA); cfr. Mommsen 1913; CeCConi 1994, 101-106; FrAschetti 1999, 299-300; Trout 2001. Administrante Romano Iun(iore) sacerdote / feriale dom(i)norum / III Nonas Ian(uarias) vota / III Idus Febr(uarias) Genialia / Kal(endis) Mai(i)s lustratio ad flumen / Casilino / III Idus Mai(as) rosaria amp(h)it(h)eatri / VIII Kal(endas) Aug(ustas) lustratio ad flumen / ad iter Dianae / VI Kal(endas) Aug(ustas) profectio ad iter Averni / Idus Oct(obres) vendemia Acerusae / iussione dom(i)norum Felix votum / sollicite solvit X Kal(endas) Decembr(es) / Valentiniano III et Eutropio (consulibus). Come prima festività dell'anno il Feriale (1. 3) registra, al 3 gennaio, i consueti vota (pro salute Imperatorum). Agli imperatori si allude, chiamandoli domini, senza però nominarli: nell'autunno 387 la situazione del collegio imperiale era infatti particolarmente complessa, dopo l'invasione dell'Italia da parte di Magno Massimo e la fuga di Valentiniano II a Tessalonica presso Teodosio. 
le spese previste per le grandi celebrazioni festive connesse con il sommo sacerdozio, dissipando il timore degli alti costi. ${ }^{22}$

Una costituzione dello stesso Valentiniano del 372, posta ad apertura della sezione De spectaculis del libro XV del Codex Theodosianus, ribadisce infatti che nella competenza dei governatori provinciali non rientrava, in nessun caso, la scelta della città in cui si dovessero tenere le editiones di magistrati e sacerdotes, ma che ai governatori ancora spettava di individuare quali notabili avrebbero dovuto affrontare gli oneri economici connessi (expensis ac sumptibus). ${ }^{23}$ A proposito di tali enormi spese, potenzialmente dirompenti degli assetti socio-economici provinciali, il legislatore interviene talora a porre dei limiti: così Teodosio II nel 409, rivolgendosi ai governatori al fine di tutelare le ricchezze e le proprietà, delle città come dei notabili, dal rischio di bancarotta, fissa a due solidi il tetto delle expensae ludorum, ma al contempo ammette delle categorie esenti da tale massimale (exceptis alytarchis syriarchis agonothetis itemque asiarchis et ceteris), in particolare i sommi sacerdoti federali dei кoเvó di Siria e d'Asia. ${ }^{24}$

22 Iulius Festus Hymetius (PLRE I 447), proconsul Africae negli anni 366-368, circa dieci anni più tardi fu onorato dall'assemblea della provincia Africa Proconsularis per varie benemerenze, tra cui [...] quod studium / sacerdotii provinciae restituerit / ut nunc a conpetitoribus adpetatur / quod antea formidini fuerit, come risulta dall'iscrizione onoraria romana CIL VI 1736 (cfr. p. 4747) = ILS 1256 = LSA 1439 = EDR130289 (07-10-2013: S. ORLANDI), 11. 11-14. Datazione: 376 o 378 (376?). Per l'interpretazione del brano nel senso di riduzione degli onera economici connessi al sacerdotium vd. il commento di H. DESSAU (ILS 1256); si tenga anche presente che l'assunzione del sommo sacerdozio non dipendeva esclusivamente dall'ambizione dei singoli notabili, ma conservava, al contempo, un aspetto liturgico di fondo. Su Hymetius cfr. MAzzARINo 1966, 2, 250-251. A distanza di parecchi anni dal suo proconsolato e dopo una temporanea caduta in disgrazia sotto Valentiniano I, Hymetius ricevette l'onore di due statue dorate, poste rispettivamente a Cartagine, capitale della provincia, e a Roma; l'assemblea provinciale comunicò le proprie deliberazioni in merito agli imperatori Valente, Graziano e Valentiniano II.

23 Cod. Theod. 15,5,1 (SC 531, 376-377: Imppp. Valentinianus, Valens et Gratianus AAA. ad Probum praefectum praetorio: Treviri, 25 aprile 372): magistratus et sacerdotiorum editiones, quae aut in civitatibus aut certe in his debent exigi, quas delegit antiquitas, non in potestate iudicum sint, qui plerumque, dum popularem plausum alienis spoliationibus aucupantur, ea, quae in competenti loco sollers diligentia praeparavit, ad alteram urbem transferri praecipiunt, sed in eorum arbitrio maneant, quorum expensis ac sumptibus procurandae sunt. A tale costituzione fa riferimento un rescritto di Valente finalizzato alla regolamentazione degli spettacoli relativi all'asiarchia (vd. infra n. 76): cfr. CECCONI 1994, 94-95; LENSKI 2002, 270-271.

24 Cod. Theod. 15,9,2 (Impp. Honorius et Theodosius AA. Anthemio praefecto urbi [in realtà Anthemius era praefectus praetorio Orientis]: Costantinopoli, 25 febbraio 409): cunctos iudices admonemus, ut ludorum quidem, quibus moris est, intersint festivitati et oblectamentis favorem eliciant populorum, verum expensarum non excedant duorum solidorum librata impendia, nec inconsulta plausorum insania curialium vires, fortunas civium, principalium domus, possessorum opes, rei publicae robur evellant: exceptis alytarchis syriarchis agonothetis itemque asiarchis et ceteris, quorum nomen votiva festivitatis sollemnitas dedicavit. 


\section{I sommi sacerdoti dal punto di vista del legislatore: le fonti giuridiche (IV-VI sec.)}

Un rapido spoglio della normativa raccolta nelle due grandi codificazioni tardoantiche permette di inquadrare meglio, dal punto di vista giuridico, il ruolo e le funzioni del sommo sacerdozio, già esemplificati dai vari casi concreti, presentati dalla documentazione epigrafica.

Innanzi tutto il sommo sacerdozio viene esplicitamente riconosciuto come sacerdotium, con un termine giuridico-sacrale pregnante, che non intende cancellare l'aspetto religioso dell'incarico: nel 336 Costantino, trattando dell'esclusione dei figli illegittimi dai diritti di successione ereditaria, ricorda il sacerdotium tra le dignità più prestigiose e cita come esempi la presidenza delle assemblee federali di Phoenice e di Syria ([...] sacerdotii, id est phoenicarchiae vel syriarchiae).$^{25}$ Il fatto che la syriarchia, connessa con la vivace dimensione festiva provinciale, fosse un incarico ancora importante e ambito (pur essendo assai costoso) è testimoniato dall'antiocheno Libanio e, ancora nella seconda metà del V sec., dalle disposizioni emanate dall'imperatore Leone nel $465 .^{26}$

25 Cod. Theod. 4,6,3 (Idem A. [Costantino] ad Gregorium: letta a Cartagine, 21 luglio 336): senatores seu perfectissimos, vel quos in civitatibus duumviralitas vel quinquennalitas vel flamonii vel sacerdotii provinciae ornamenta condecorant, placet maculam subire infamiae et peregrinos a Romanis legibus fieri, si [...]; cfr. Cod. Iust. 1,5,27 (Const. A. ad Gregorium: letta a Cartagine, 21 luglio 336): senatores seu perfectissimos, vel quos in civitatibus duumviralitas vel sacerdotii, id est phoenicarchiae vel syriarchiae, ornamenta condecorant, placet maculam subire infamiae et alienos a Romanis legibus fieri, si [...]. La medesima costituzione di Costantino è riportata sia dal Codex Theodosianus (dove si parla, genericamente, di flamonium civico e di sacerdotium provinciale), sia dal Codex Iustinianus (dove compare un'interessante variante esplicativa: come esempi di sacerdotium si nominano phoenicarchia e syriarchia); lo stesso documento è poi citato da Giustiniano nella novella 89 sui figli illegittimi

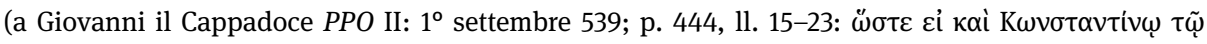

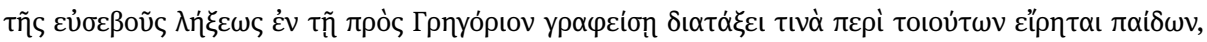

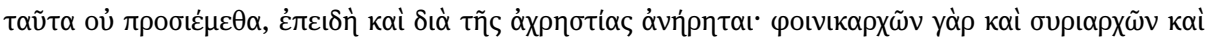

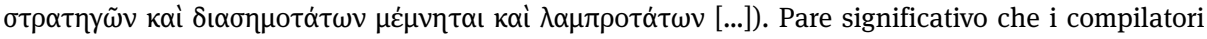
giustinianei abbiano selezionato tale costituzione: il medesimo interesse per il sommo sacerdozio

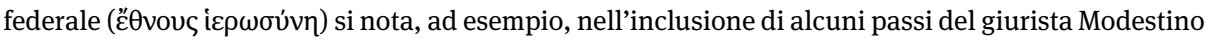
nei Digesta, relativamente alle particolari esenzioni previste per i sommi sacerdoti in carica (partic.

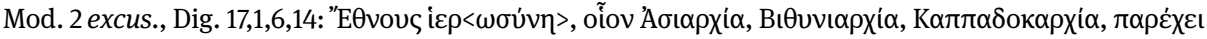

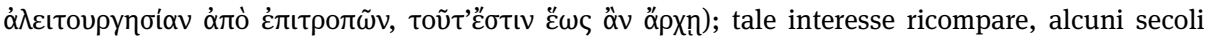

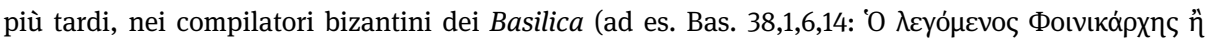

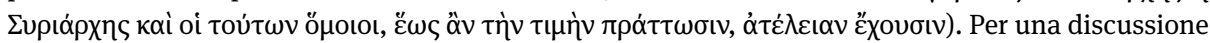
di questi passi vd. recentemente VITALE 2014, 272-276.

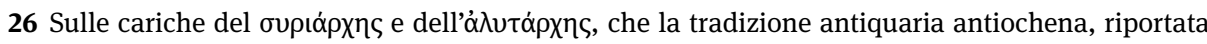
dal cronografo Ioannes Malalas (VI sec.), ricollega all'organizzazione liturgica delle grandi feste quadriennali di Zeus Olympios, vd. le discussioni di Schenk von STAUfFenBerg 1931, 412-443;

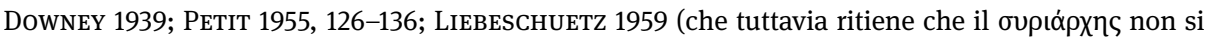
occupasse tout court delle feste Olympia, ma soltanto delle venationes); LIEBESCHUETZ 1972, 141-144; 
Sotto il profilo giuridico-fiscale il sommo sacerdozio rientra nella categoria dei munera patrimonalia, ossia delle prestazioni liturgiche regolamentate sulla base del patrimonio dei soggetti e non della loro persona (munera personalia sive corporalia, per i quali sono previste immunità ed esenzioni derivanti dalla condizione giuridicosociale del soggetto, pro qualitate personarum, ad esempio l'appartenenza alla classe senatoria). ${ }^{27}$ In quanto munus patrimoniale esso spetta pertanto, in maniera quasi naturale, ai notabili più abbienti delle singole comunità oppure della provincia, ovvero ai più insigni tra i curiales. ${ }^{28}$ Il legislatore chiarisce però che non si tratta di un munus obbligatorio, che possa essere imposto contro la volontà dei soggetti: esso dovrebbe essere cercato spontaneamente dagli aspiranti e non potrebbe, almeno a rigore di diritto, assumere quei connotati coercitivi che la prassi concreta della vita politica locale sembra volergli attribuire con vari pretesti, suscitando così il timore e lo scontento dei designati inviti per quegli oneri patrimoniali, assai ingenti, che sono legati all'esercizio del sacerdozio. Alcune costituzioni imperiali mostrano come il principio generale della libera voluntas dei candidati dovesse essere (teoricamente)

cfr. REMIJSEN 2015, 89-110. Sull'importanza dell' $\alpha \lambda \nu \tau \alpha \rho x i \alpha$ si veda la notizia di Malalas (chron. 12,44:

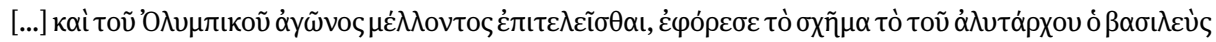
$\Delta เ о \kappa \lambda \eta \tau \iota \alpha$ ós), secondo cui lo stesso Diocleziano, durante il soggiorno antiocheno nell'estate del 300,

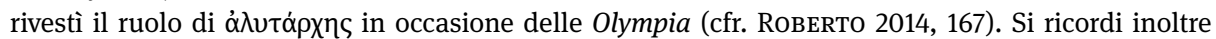
che il fisco imperiale forniva un importante finanziamento all'organizzazione delle feste Olympia di Antiochia. Nel 383 Teodosio emana un provvedimento riguardante la syriarchia, che ne sottolinea il carattere di munus non obbligatorio: Cod. Theod. 12,1,103 (vd. infra n. 29). Dieci anni più tardi lo stesso imperatore abolisce un precedente tentativo di imporre alle proprietà senatorie una collatio annuale, volta a cofinanziare la syriarchia: Cod. Theod. 6,3,1 (Imppp. Theodosius, Arcadius et Honorius AAA. Aureliano praefecto Urbi: Costantinopoli, 27 febbraio 393). Nel 409 Teodosio II esenta gli alytarchae e i syriarchae dal tetto di spesa decretato per le expensae ludorum: Cod. Theod. 15,9,2 (vd. supra n. 24). Nel 465 invece Leone proibisce ai notabili antiocheni di occuparsi delle grandi festività, avocandone d'autorità la gestione, organizzativa ed economica, e assegnandola ai più alti funzionari imperiali di Antiochia: Cod. Iust. 1,36,1 (Leo A. Pusaeo PP.: Costantinopoli, 9 novembre 465), secondo cui la liturgia della syriarchia, insieme all'amministrazione dei relativi sovvenzionamenti imperiali, passerà sotto il controllo diretto del consularis di Syria I e parimenti quella dell'alytarchia sotto il comes Orientis; da entrambe le funzioni saranno dunque esclusi, d'ora in poi, i curiales siriaci.

27 Cod. Iust. 10,42,8 (Diocletianus et Maximianus AA. et CC. Longino): nec protostasiae vel sacerdotii vel decaprotiae munera corporalia sunt, sed tantum patrimonii esse non ambigitur. Per l'interpretazione del documento in riferimento alla tassa di leva (protostasia) e alla sua oscillazione tra le categorie dei munera personalia e patrimonalia nel IV sec. vd. MAZZARINo 1951/2002, 232-237. In generale sui munera civilia vd. GRELLE 1999. Per il tentativo, effettuato dai notabili di Smirne in sede di ekklesia, di

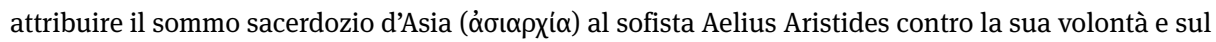
ricorso di Aristides al tribunale del proconsole d'Asia vd. recentemente MAROTTA 2013.

28 Cod. Theod. 12,1,174: vd. infra n. 30. I curiales potranno accedere al sommo sacerdozio provinciale solo dopo aver assolto tutti i munera civilia e ricoperto tutte le magistrature municipali presso la propria civitas: cfr. Cod. Theod. 12,1,77 (SC 531, 310-313: Idem AAA. [Valentiniano, Valente e Graziano] ad Probum vicarium Urbis: Treviri, 23 febbraio 372). 
mantenuto a fondamento giuridico del munus (così afferma Teodosio riguardo alla syriarchia nel 383). ${ }^{29}$

Ma talora (e forse non di rado) questo principio individuale doveva cedere, in via eccezionale, a un principio comunitario, ossia alla necessitas richiesta dalla publica utilitas (così si esprime lo stesso Teodosio nel 385). In questo caso il legislatore tiene però conto delle grandi spese previste dall'organizzazione dei giochi (agonothesia) e predispone delle forme di compensazione per quei curiales che, avendo già rivestito tutti gli honores municipali, fossero quindi costretti ad assumersi l'onere di tale ulteriore prestazione: essi avrebbero poi goduto, ad esempio, del rango onorario di ex comitibus, che comportava l'immunità perpetua dalla tassazione municipale applicata ai decurioni. ${ }^{30} \mathrm{Nel} 428$, pur in un periodo di incombente crisi politico-militare, Valentiniano III arriverà persino a riconoscere l'indennità dalla tassa di leva (praebi-

29 Cod. Theod. 12,1,103 (SC 531, 316-317: Idem AAA. [Graziano, Valentiniano II e Teodosio] ad Proculum comitem Orientis: Salamariae [Selymbriae, SEECK], 27 luglio 383): voluntate propria unusquisque syriarchiae munus suscipere debet, non necessitate imposita; cfr. LIEBESCHUETZ 1972, 141-142.

30 Cod. Theod. 12,1,109 (Idem AAA. [in realtà non più Graziano, ma Valentiniano II, Teodosio e Massimo] Cynegio praefecto praetorio: [senza luogo], 26 aprile 385): nec cogi ad agonothesiam volumus invitos et ad eum statum cuncta referenda sunt, in quo inveniuntur. atque ideo curiales, qui universa persolverint nihilque iam vel ex honoribus reliquum habeant, quod debere videantur, dumtaxat huius ac similium pro qualitate generis functionum, postquam patriae cuncta reddiderint quae publica poscit utilitas, etsi praesentare forsitan nolunt, tamen propter personarum condicionem praestare cogendi sunt, ut concessa sibi generaliter atque in perpetuum ex comitibus dignitate laetentur, osculum quoque his in provincia iudicantum et consessus indultus sit. Il conferimento del rango di ex comitibus (probabilmente l'equiparazione ai comites tertii ordinis) e la conseguente immunità dalla tassazione municipale rimanda al grave problema dell'abbandono delle curiae da parte dei notabili: i decurioni, dopo aver rivestito la magistratura di duumvir, tentavano di sottrarsi ai propri obblighi fiscali, abbandonando la civitas originaria e trasferendosi altrove, come segnala il richiamo dei curiales all'assunzione del sommo sacerdozio provinciale e dei loro figli alle sedi originarie in Cod. Theod. 12,1,174 (SC 531, 336-339: Idem AA. [Onorio e Teodosio II] Euchario proconsuli Africae: Ravenna, 10 marzo 412): duumvirum impune non liceat extollere potestatem fascium extra metas propriae civitatis. curiales etiam sacerdotio provinciae, sed et filios reddi praecipimus propriae civitati. D'altra parte lo stesso Costantino aveva previsto l'esenzione di sacerdotales, flamines perpetui e duumvirales dalle liturgie annonarie e dagli inferiora munera: vd. Cod. Theod. 12,5,2 (SC 531, 340-343: Idem A. [Costantino] ad concilium provinciae Africae: proposita a Cartagine, 21 maggio 337); cfr. già Cod. Theod. 12,1,21 (Idem A. [Costantino] ad Felicem praefectum praetorio: Viminacium, 4 agosto 335). In ogni caso, dopo il consueto svolgimento dell'elezione del sommo sacerdote provinciale, era necessario provvedere, in sede di curia municipale, alla designazione dei membri più degni e idonei, dal punto di vista patrimoniale, ad subeunda patriae munera: cfr. Cod. Theod. 12,1,148 (SC 531, 328329: Idem AA. [Arcadio e Onorio] Theodoro praefecto praetorio: Milano, 28 settembre 395 [in realtà 397-399, SEECK]): cum super ordinando sacerdote provinciae publicus esset ex more tractatus, idem nostra auctoritate decretum est, ut ad subeunda patriae munera dignissimi et meritis et facultatibus eligantur nec huiusmodi nominentur, qui functiones debitas implere non possint. Il fatto che anche i sacerdotales tendessero poi a lasciare le proprie comunità di origine emerge pure dal dossier di costituzioni onoriane analizzato da CHASTAGNOL 1988b (vd. infra n. 35). 
tio tironum) ai sacerdotales della provincia Africa Proconsularis, in virtù delle grandi spese da essi sostenute per i giochi. ${ }^{31}$

D’altra parte una costituzione di Onorio al proconsul Africae, datata al 400, sembra emblematica: essa ribadisce che, secondo un vetus mos, i figli dei sommi sacerdoti non possono essere costretti, contro la propria volontà, a rivestire il sacerdotium, ma al contempo lascia intendere come si consideri assolutamente necessario che vi siano sempre dei candidati idonei, pronti ad assolvere il munus. Libera voluntas individuale e necessitas generale paiono dunque elementi contrastanti eppure sempre presenti all'interno di un binomio instabile. ${ }^{32}$

A proposito della funzione di portavoce degli interessi provinciali svolta dai sommi sacerdoti in rappresentanza del concilium, una costituzione di Costanzo II del 358 asserisce chiaramente che il sacerdos provinciae deve essere prescelto esclusivamente tra i membri della corporazione degli advocati..$^{33} \mathrm{E}$ il ruolo dei sacerdotes quali avvocati difensori della provincia fu tenuto presente dalle chiese d'Africa, quando il Concilio di Cartagine del 407 espresse la richiesta di nominare dei propri avvocati per la tutela degli interessi ecclesiastici, i quali intercedessero presso l'autorità imperiale more sacerdotum provinciae. ${ }^{34}$

31 Cod. Theod. 7,13,22 (SC 531, 104-107: Impp. Theodosius et Valentinianus AA. Volusiano praefecto praetorio: Ravenna, 25 febbraio 428): mansura in saeculum auctoritate praecipimus proconsularis provinciae non eandem sacerdotalium, quae est de ceteris, in praebendis tironibus habendam esse rationem. non inique si quidem ea potissimum ab hoc officio provincia videtur excepta, quae omnium intra africam provinciarum obtinet principatum cuiusque maioribus sacerdotes fatigantur expensis, in quarum solacium indemnem esse convenit dignitatem. Il provvedimento di esenzione va inserito nel quadro dei problemi di esazione fiscale della provincia Africa tra 428 e 429: cfr. la legazione provinciale inviata alla corte di Valentiniano III e la risposta ufficiale in Cod. Theod. 12,1,186 (Idem AA. [Teodosio II e Valentiniano III] Celeri proconsuli Africae: Ravenna, 27 aprile 429]); si tenga anche presente che nel 428 il re vandalo Genserico preparava notoriamente la migrazione dalla Spagna e l'invasione del Nord Africa: cfr. TRAINA 2007, 131-148, partic. 136-137 per la questione fiscale.

32 Cod. Theod. 12,1,166 (SC 531, 334-335: Idem AA. [Arcadio e Onorio] Pompeiano proconsuli Africae: Milano, 30 giugno 400): iuxta veterem morem Mecilianus legatus adstruxit, ut sacerdotum filii inviti ad sacerdotium non cogantur. antiquam igitur consuetudinem laudabilitas tua praecipiat custodiri, ita ut neque ullus indebite teneatur et tamen idonei sacerdotes deesse non possint. Sulle crescenti responsabilità giuridico-fiscali attribuite dallo Stato alle classi dirigenti municipali tra epoca altoimperiale e Tarda Antichità vd. GANGHoffer 1963; LANGHAMmer 1973; NEeSEn 1981; HoRSTKOtTe 1988; DRECOLL 1997.

33 Cod. Theod. 12,1,46 (SC 531, 294-297: Idem. A. [Costanzo II] ad Martinianum vicarium Africae: Mursa, 27 giugno 358): a solis praecipimus advocatis eorumque consortio dari provinciae sacerdotem. [...]. Dopo tale precetto di ordine generale si ribadisce che gli advocati non hanno mai avuto alcun diritto a excusationes dai munera civilia, tantomeno dal sommo sacerdozio provinciale. In senso contrario sembrerebbe invece andare Cod. Theod. 12,1,152 (Idem AA. [Arcadio e Onorio] Africano praefecto urbi: Costantinopoli, 3 agosto 396): ne quis ex corpore togatorum provinciales suscipiat functiones [...], laddove con provinciales functiones si intenda il sacerdotium provinciae.

34 Conc. Carth. a. 407, par. 97 (Concilia Africae a. 345 - a. 525, CCL 149, p. 214 Munier). A tale richiesta sembra dar seguito la costituzione di Onorio del 407 (Cod. Theod. 16,2,38 [SC 497, 194-197]: 
Tre costituzioni di Onorio attestano che, nell'epoca teodosiana, i sacerdotales di tutte le province africane convenivano una volta all'anno, in ottobre, a Cartagine, capitale della provincia Africa Proconsularis, per partecipare a una solenne festività, culminante nella pompa, e alla connessa assemblea generale della diocesi d'Africa. ${ }^{35}$ Nella terza costituzione, raccolta nella sezione De paganis, sacrificiis et templis del libro XVI del Codex Theodosianus, essi sono significativamente definiti sacerdotales paganae superstitionis - un interessante indizio sul profilo giuridico-sacrale del culto imperiale tardoantico, ancora percepito come espressione della religione tradizionale. ${ }^{36}$ Nondimeno l'assunzione del sommo sacerdozio non era affatto preclusa ai cristiani, come dimostrano i casi di sacerdotes di religione cristiana e, più specificamente, di confessione donatista: pur stabilendo gravi sanzioni contro gli eretici donatisti, il legislatore non sembra considerare infatti anomalo il fatto che un cristiano possa diventare sommo sacerdote provinciale. ${ }^{37}$

Imppp. Arcadius, Honorius et Theodosius AAA. Porfyrio proconsuli Africae: Roma, 15 novembre 407), laddove si afferma che le richieste rivolte dalle chiese all'imperatore saranno notificate ai goveratori provinciali non per mezzo dei coronati (come era stato fino ad allora), ma dagli avvocati ecclesiastici, pur restando ai sacerdotes provinciae un ruolo di generale supervisione sul corretto svolgimento della procedura, a tutela degli interessi (provinciali) da loro rappresentati.

35 Cod. Theod. 12,1,145 (SC 531, 326-329: Idem AA. [Arcadio e Onorio] Ennoio proconsuli Africae: Milano, 16 maggio 395 - con riferimento a una precedente disposizione di Teodosio I); Cod. Theod. 12,1,176 (SC 531, 338-341: Idem AA. [Onorio e Teodosio II] Iuliano II proconsuli Africae: Ravenna, 23 gennaio 413); Cod. Theod. 16,10,20 (SC 497, 458-462: Impp. Honorius et Theodosius AA. [senza destinatario, ma cfr. Cod. Iust. 1,11,5: populo Cartaginiensi]: Ravenna, 30 agosto 415). Per una discussione approfondita di questi documenti vd. CHASTAGNOL 1988b, partic. 96-98 per la critica all'interpretazione di LEPELLEY 1979, 364, n. 149; cfr. il commento di R. Delmaire in SC 497, 492-494. A proposito della sede dell'assemblea (concilium) della diocesi d'Africa, CHASTAGNOL 1988b, 103-104 ha ritenuto che già sotto Graziano Cartagine potrebbe essere stata talora sostituita da Theveste, anch'essa situata in Africa Proconsularis (cfr. Cod. Theod. 1,15,10 [Imppp. Gratianus, Valentinianus et Theodosius AAA. ad Syagrium: Cartagine, 26 agosto 379]: vicario Africae aditus provinciae proconsularis inhibendus est tantumque ei consilii gratia in Thevestinam civitatem accessus pateat. [...]).

36 Acutamente CHASTAGNOL 1988b, 93 osservava: „Je n'insisterai pas ici sur le fait que ces délégués et ces grands-prêtres devaient être encore le plus souvent des païens, mais qu'il y avait également des chrétiens parmi eux, que leurs attributions étaient largement sécularisées, qu'ils avaient surtout à organiser, présider et financer des fêtes, jeux et banquets, notamment les jeux marquant la fin de la réunion annuelle, ce qui n'excluait pas le maintien d'une compétence à caractère politique“; cfr. Chastagnol/Duval 1974, 115: „Au Ve siècle, le concilium n’a réellement plus exercé de fonction proprement religieuse et n'a du reste jamais suscité des difficultés sur ce plan. Seul son chef, le sacerdos provinciae [...] a conservé aux yeux de l'opinion un caractère païen assez marqué, d'abord à cause de son nom même et du rôle qu'il avait toujours joué jusqu'au IV' siècle dans l'accomplissement des rites religieux et l'organisation des jeux [...] il n'en reste pas moins que les sacerdotes provinciae gardèrent jusqu'au règne d'Honorius un caractère païen très accentué“. Sul titulus 10 De paganis, sacrificiis et templis del Codex Theodosianus vd. DE GIovanNi 1991, 126-138.

37 Cod. Theod. 16,5,52 (SC 497, 306-310, cfr. 488-489: Idem AA. [Onorio e Teodosio II] Seleuco praefecto praetorio: Ravenna, 30 gennaio 412); Cod. Theod. 16,5,54 (SC 497, 312-317, cfr. 489-490: Idem 
La questione della liceità del sommo sacerdozio per un cristiano è posta con fermezza di principio generale - ma non senza un'irresolubile ambiguità di fondo -

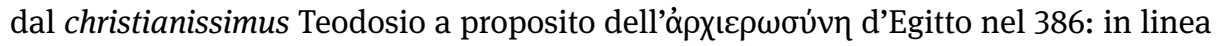
teorica dovrebbero accedere, di preferenza, al sacerdozio provinciale quei notabili pagani che non abbiano trascurato la tradizionale venerazione dei templi a motivo dell'osservanza cristiana; tuttavia, per quanto al legislatore appaia evidentemente indecoroso e quasi illicitum che la cura dei templi pagani possa essere affidata a dei cristiani, a questi ultimi non è proibito per legge di assumere quell'incarico religioso che pure, per decenza, essi dovrebbero rifiutare (quos ipsos decebat tale munus, etiamsi non prohiberentur, effugere).$^{38}$ Alla generica riprovazione morale non corrisponde pertanto un preciso divieto, codificato a livello normativo e avente vigore effettivo in quanto lex generalis: in definitiva la questione viene rimessa alla coscienza dei singoli notabili cristiani.

\section{I sommi sacerdoti dal punto di vista dei cristiani: la questione dei sacrifici e la „secolarizzazione“ del culto imperiale}

Conviene dunque chiarire un punto che risulta ambiguo e rimarrà comunque sostanzialmente contraddittorio, ossia se il sommo sacerdozio del culto imperiale, in quanto espressione dell'antica religione pagana, dovesse essere formalmente precluso ai cristiani, se non dalla legislazione imperiale, perlomeno dalla normativa canonica delle autorità ecclesiastiche.

Il problema socio-religioso del rapporto tra cristiani (nel senso di diversi cristiani, non di una categoria unica e omogenea nello spazio e nel tempo) e sacerdozio del culto imperiale è stato sintetizzato in maniera emblematica da GIOVANNI BATTISTA DE Rossi, che si domandava „come si possa conciliare il titolo di flamen perpetuus con quello di christianus“ (per affrontare la questione egli prendeva spunto dall'epitaffio del flamen africano Astius Mustelus di Ammaedara). ${ }^{39}$

\footnotetext{
AA. Iuliano proconsuli Africae: Ravenna, 14 giugno 414). Sull'entità delle pene pecuniarie previste da Onorio vd. supra n. 10.

38 Cod. Theod. 12,1,112 (SC 531, 318-321: Idem AAA. [in realtà non più Graziano, ma Valentiniano II, Teodosio e Arcadio] Florentio praefecto Augustali: Costantinopoli, 16 giugno 386): in consequenda archierosyne ille sit potior, qui patriae plura praestiterit nec tamen a templorum cultu observatione christianitatis abscesserit. quippe indecorum est, immo ut verius dicamus, illicitum ad eorum curam templa et templorum sollemnia pertinere, quorum conscientiam vera ratio divinae religionis imbuerit et quos ipsos decebat tale munus, etiamsi non prohiberentur, effugere.
}

39 DE Rossi 1878. Sull'iscrizione funeraria di Astius Mustelus, datata al 526, vd. infra n. 50. 
Un approccio 'tradizionale' al problema si trova già in un contributo di LouIS DUCHESNE, che è stato un modello autorevole per gli studiosi successivi: ${ }^{40}$ il punto di partenza per delineare la posizione normativa ufficiale della Chiesa di epoca costantiniana (o persino pre-costantiniana) sarebbe quella raccolta di canoni che la tradizione manoscritta (VI-VII sec.) ha trasmesso sotto l'intitolazione di un presunto Concilio di Elvira/Iliberris (Granada, Baetica). Nella lista dei partecipanti figura il famoso vescovo Ossio di Cordova e tale concilio è stato generalmente datato, nella storia degli studi, al primo decennio del IV sec. ${ }^{41}$

Tuttavia le recenti analisi filologiche di Josep Vilella e PERE-EnRIC BARREDA hanno messo in dubbio non soltanto l'unitarietà, ma anche l'autenticità di tale raccolta (pseudo-)iliberritana, se non la stessa storicità di un concilio tenutosi a Elvira. Una volta che si tenga conto di tali nuove acquisizioni della ricerca e nonostante le posizioni unitariste ribadite da altri studiosi, in particolare MANUEL SOTOMAYOR, pare ormai obbligatorio un approccio assai prudente a tale fonte: la raccolta di canoni, pur essendo effettivamente di origine ispanica, potrebbe infatti essersi formata variamente (e non in un solo momento) nel lungo periodo intercorso tra IV e VI sec., durante il tardo Impero romano oppure sotto il Regno visigotico. ${ }^{42}$ Accettare in maniera non problematizzata l'autenticità dei canoni e al contempo la loro datazione 'tradizionale' al principio del IV sec. comporta inevitabilmente una distorsione nell'interpretazione storica del ruolo del sacerdozio del culto imperiale e della sua precoce „secolarizzazione“, ovvero uno svuotamento dei suoi contenuti religiosi, che sarebbe avvenuto già nei primissimi anni di Costantino. ${ }^{43}$

40 Duchesne 1887; cfr. Chastagnol/Duval 1974, 109-110; Chastagnol 1978, 47; Lepelley 1979, 362-363. LEONE 2013, 88. Sull'atteggiamento delle comunità cristiane d'Africa verso le antiche festività pagane cfr. LEONE 2013, 83-119; GRAF 2015, 151-162.

41 Canoni (pseudo-)iliberritani: PL 84, 301-310; MARTínez 1961, 167-171; MARTÍNEZ/RodRíGUEZ 1984, 233-268; Reichert 1990. I canoni sono trasmessi dalla Colección Canónica Hispana e dall'Epítome Hispánico, databili tra la fine del VI e l'inizio del VII sec. Il presunto Concilio di Elvira si sarebbe tenuto nel 305-306 oppure nel 311. Su Ossio di Cordova vd. recentemente VILELLA 2013.

42 Tesi anti-unitaria: MEIGNE 1975; Vilella/BARREdA 2002; VIlELLA/BARREDA 2006; LÁZARo SÁNCHEZ 2008; VILELLA/BARREDA 2013a; Vilella/BarREDA 2013b; VIlELla 2014. Tesi unitaria: RAMOS-Lissón 1979; SOTOMAYOR 1989; SOTOMAYOR 2000; SOTOMAYOR/FERNÁNDEZ 2005; SOTOMAYOR/BERdugo 2008a; SOTOMAYOR/BERDUGO 2008b.

43 Sulla sopravvivenza del culto imperiale in Africa attraverso la sua progressiva 'secolarizzazione', ovvero il depotenziamento dell'aspetto più propriamente religioso, in particolare quello sacrificale, e sulla sua funzione di mera manifestazione di lealismo politico vd. LEPELLEY 1979, 362-369 (partic. 369: „Le culte impérial, d'autre part, avait été depuis ses origines beaucoup plus une manifestation de loyalisme politique qu'une pratique vraiment religieuse)“. Tale ricostruzione pare al contempo 'riduzionista' e modernizzante, specialmente se applicata al IV sec.; essa si basa tuttavia, per una parte significativa, sull'interpretazione 'tradizionale' dei canoni di Elvira, cfr. LEPELLEY 1979, 363: „Ces décisions sont très caractéristiques d'une époque de transition. A la veille de la conversion de Constantin, même des évêques aussi puritains et intransigeants que ceux d'Elvire ne pouvaient interdire aux chrétiens d'accomplir les charges municipales, au demeurant obligatoires pour les 
In ogni caso i canoni (pseudo-)iliberritani sono parsi particolarmente rigoristi: ${ }^{44}$ per quei cristiani, già battezzati, che avessero celebrato i sacrifici pagani durante il flaminato (o il sommo sacerdozio provinciale) si prevedeva la scomunica a vita, senza deroghe (canone 2). Coloro che invece si fossero astenuti dai sacrifici, ma avessero soltanto organizzato il tradizionale munus, ovvero lo spettacolo gladiatorio, sottostavano a due diversi provvedimenti disciplinari: per i già battezzati la riammissione nella comunità ecclesiale era permessa soltanto in caso di pericolo di morte (in finem) ed era comunque subordinata a una penitenza (canone 3); per i catecumeni l'ammissione al battesimo avveniva dopo un triennio (canone 4). Era anche contemplato il caso di cristiani che non avessero né offerto sacrifici né sovvenzionato alcuno spettacolo, ma avessero soltanto indossato le corone che contraddistinguevano i sacerdotes: costoro potevano essere riammessi in comunione dopo due anni (canone 55). Dalle differenti tipologie di sanzione sembra chiaro che la contaminazione derivante dai sacrifici pagani fosse considerata assai più grave rispetto all'allestimento dei

membres de la classe décurionale. De leur côté, les autorités municipales acceptaient que les dignitaires chrétiens se fissent remplacer pas des collègues païens pour l'accomplissement des cérémonies religieuses officielles. [...] Le plus singulier est que les évêques rigoristes d'Elvire ne considéraient pas comme une faute irrémissible pour un chrétien de recevoir le flaminat municipal ou le sacerdoce provincial: preuve que ces dignités étaient devenues, pour l'essentiel, honorifiques et politiques et que leur caractère religieux était nettement passé à l'arrière-plan, à tel point que le titulaire pouvait, sans inconvénient majeur, se dispenser des rites païens inhérents, en théorie, à ces fonctions“. Ibid., 365: „[...] ces fonctions avaient totalement perdu leur caractére religieux initial. Le concile d'Elvire tolérait, en fait, que les fidèles notables municipaux gérassent ces dignités en s'abstenant de tout rite païen, ce qui impliquait que ces sacerdoces étaient, dès avant Constantin, des fonctions civiles pour l'essentiel. La pratique suggérée à Elvire devint ensuit la règle“. Il concetto di 'secolarizzazione' viene introdotto anche da CHASTAGNOL, seppure con sfumature diverse (vd. supra n. 36); sul medesimo concetto, applicato allo spazio civico pubblico nell'Africa tardoantica, è tornato recentemente LEPELLEY 2011.

44 Si riporta il testo dei canoni 2, 3, 4, 55, ponendo tra parentesi quadre le interpolazioni seriori (comprese tutte le rubriche introduttive), secondo l'analisi filologica e linguistica di VILELLA/BARREDA 2002; VIleLla/BARREDA 2006; VILELla/BarRedA 2013b. Canone 2: [De sacerdotibus Gentilium qui post baptismum immolaverunt.] Flamines qui post fidem lavacri et regenerations sacrificaverunt, [eo quod geminaverint scelera, accedente homicidio, vel triplicaverint facinus, cohaerente moechia,] placuit eos nec in finem accipere communionem. Canone 3: [De eisdem si idolis munus tantum dederunt.] Item flamines qui non immolaverint, sed munus tantum dederint, [eo quod se a funestis abstinuerint sacrificiis,] placuit in finem eis praestare communionem, acta tamen legitima poenitentia: [item ipsi si post poenitentiam fuerint moechati, placuit ulterius his non esse dandam communionem, ne illusisse de dominica communione videantur.] Canone 4: [De eisdem si catechumeni adhuc immolant quando baptizentur.] Item flamines si fuerint catechumeni et se a sacrificiis abstinuerint, post triennii tempora placuit ad baptismum admitti debere. Canone 55: [De sacerdotibus Gentilium qui iam non sacrificant.] Sacerdotes qui tantum coronas portant nec sacrificant nec de suis sumptibus aliquid ad idola praestant, placuit post biennium accipere communionem. 
giochi oppure al rivestimento della semplice dignità sacerdotale, simboleggiata dalla corona. ${ }^{45}$

Se i canoni di Elvira rappresentano una testimonianza importante, ma difficile da contestualizzare, e richiedono pertanto di essere maneggiati con speciale cautela, un documento ufficiale della Chiesa latina d'Occidente è costituito dalla lettera inviata da papa Innocenzo I ai vescovi ispanici già riunitisi nel Concilio di Toledo (400). Trattando della questione delle ordinazioni ecclesiastiche irregolari, il pontefice chiarisce che non potevano essere ammessi nel clero cristiano quei curiali che, dopo aver ricevuto il battesimo, avessero rivestito il sommo sacerdozio del culto imperiale e celebrato le relative editiones di spettacoli, assai gradite al populus. Il monito di Innocenzo risulta assai meno intransigente dei canoni (pseudo-)iliberritani: esso sembra testimoniare che, al principio del $\mathrm{V}$ sec., vi erano cristiani di alta condizione sociale che, non di rado, divenivano coronati e provvedevano contestualmente all'organizzazione degli spettacoli; costoro non sarebbero stati scomunicati, ma soltanto esclusi dalla consacrazione come clerici e sacerdoti cristiani. Tali spettacoli, non specificati, potevano essere di tipo tanto anfiteatrale (combattimenti gladiatorii, venationes), quanto teatrale o circense. ${ }^{46}$

45 Si noti che Vilella e BARREDA (2002, 552, n. 38; 2006, 306; 2013b, 232) intendono il termine munus come generica 'offerta' religiosa presentata dal flamen/sacerdos alle divinità pagane e preferiscono tale interpretazione, suffragata dal canone 28 (in cui munera, al plurale, significa effettivamente 'offerte', presentate in questo caso al vescovo cristiano), rispetto a quella tradizionale, che invece riconosce in munus il significato tecnico di 'spettacolo gladiatorio' (DUCHESNE 1887, 169-170; cfr. SOTOMAYOR/BERDUGo 2008b, 389). L'interpretazione di VILELLA e BARREDA è stata accolta da JIMÉNEZ SÁNCHEZ 2009-2010, 274-277, in uno studio sulla fine della gladiatura nella Spagna tardoantica (sull'argomento vd. anche JimÉNEZ SÁNCHEZ c.d.s. e, più in generale, cfr. DE GIovANNI 1993, 77-94; GREGORI 2011, 27-34; 157-161). Qui si preferisce invece l'esegesi tradizionale, in considerazione del fatto che l'offerta' del sacerdote del culto imperiale consisteva, in maniera paradigmatica, proprio nell'allestimento di spettacoli, perlopiù anfiteatrali (giochi gladiatorii e venationes): in tal senso può ricordarsi, tra le molte testimonianze, l'iscrizione ispellate del coronatus Tusciae et Umbriae C. Matrinius Aurellius Antoninus (vd. supra n. 18), che fu abundantissimi muneris sed et / praecipuae laetitiae theatralis editori; si veda anche la lettera di papa Innocenzo I ai vescovi del Concilio di Toledo (vd. infra n. 46), che menziona editiones publicas celebrate dai coronati, senza tuttavia chiarire di quale tipo di spettacoli si tratti.

46 Innocent. epist. 3: PL 20, 481-494, partic. 492: [...] neque de curialibus aliquem venire ad ecclesiasticum ordinem posse, qui post baptismum vel coronati fuerint, vel sacerdotium quod dicitur sustinuerint, et editiones publicas celebraverint. Cfr. CHASTAGNOL 1974, 116. La lettera fu scritta dopo il Concilio I di Toledo (400) e indirizzata ai vescovi che vi avevano preso parte: essa sembra potersi datare c.a. 401-408. Essa tuttavia non specifica la tipologia degli spettacoli (editiones) organizzati dai coronati e non può quindi essere assunta come testimonianza a favore o contro la persistenza della gladiatura nell'Occidente tardoromano. 
Da questo punto di vista si può osservare che il sommo sacerdozio, anche dopo l'eliminazione degli aspetti sacrificali cruenti, ${ }^{47}$ manteneva ancora un nucleo originario di religiosità pagana (più o meno latente, ma eventualmente capace di riattivarsi: potremmo dire una sorta di irriducibile potenziale in stand by), che era percepito come un fossile sacrale e poteva mettere in imbarazzo dei cristiani particolarmente coscienziosi, ma che in definitiva non costituiva un deterrente per la maggior parte dei notabili municipali, desiderosi di rivestire incarichi di prestigio, anche a prescindere dal credo religioso. Si tenga comunque presente che la dimensione religiosa del sacerdozio si iscriveva in una cornice sociale più ampia: il culto era infatti indissolubilmente legato a quel corollario conviviale e festivo (il banchetto rituale che nell'antica tradizione era, allestito con le carni derivanti dai sacrifici, gli idolotiti, e i ludi di vario genere), che era proprio della città antica (civilitas) e prevedeva la partecipazione dell'intero populus, gerarchicamente ordinato. ${ }^{48}$

47 L'abolizione dei sacrifici culminanti nell'offerta di vittime animali è un argomento storico-religioso e giuridico assai complesso, che non può essere affrontato in questa sede. Basterà ricordare uno dei più duri provvedimenti legislativi dell'epoca di Costanzo II e Costante, in cui superstitio pagana e sacrificia sono strettamente associati: Cod. Theod. 16,10,2 (SC 497, 428-429: Imp. Constantius A. [in realtà Costanzo II e Costante, cfr. 16,10,3: Idem AA. [...]: vd. infra n. 48] ad Madalianum agentem vicem praefectorum praetorio: [senza luogo, né mese], accepta nel 341 - il fatto che L. Crepereius Madalianus [PLRE I 530] fosse allora vicarius Italiae suggerisce di attribuire tale provvedimento, più specificamente, a Costante: cfr. CUNEO 1997, 88-89): cesset superstitio, sacrificiorum aboleatur insania. nam quicumque contra legem divi principis parentis nostri et hanc nostrae mansuetudinis iussionem ausus fuerit sacrificia celebrare, competens in eum vindicta et praesens sententia exeratur. D'altra parte a una contagiosa superstitio allude il rescritto costantiniano di Hispellum (vd. supra n. 17), laddove notoriamente prescrive che il nuovo tempio della gens Flavia non dovrà essere „contaminato dagli inganni di alcuna contagiosa superstizione“ (CIL XI 5265, 11. 45-47: [...] ne ae/dis nostro nomini dedicata cuiusquam con/tagios(a)e superstitionis fraudibus polluatur). Per la centralità della pratica sacrificale nella religione romana vd. ScHEID 2005 (partic. 10-45 sui sacrifici celebrati dai fratres Arvales e rivolti agli imperatori viventi e divinizzati); sulla pratica sacrificale nel culto imperiale in Oriente vd. ChAniotis 2003. Per un'analisi storico-religiosa della fine dei sacrifici nella Tarda Antichità vd. Stroumsa 2005; cfr. Graf 2015, 305-322. Per un'analisi storico-giuridica della legislazione antipagana tra Costantino e Teodosio vd. SALZMAN 1987; MAZZA 1999; MAZZA 2006-2009; Bonamente 2009; Belayche 2009; Clauss 2011; BleckMann 2012; per altre fonti antiche e rimandi bibliografici vd. GREGORI/FILIPPINI 2013, 533-534, n. 21.

48 Il legame strettissimo tra dimensione religiosa e festiva all'interno del quadro civico tradizionale (la civilitas) porta il legislatore, seppure cristiano, al riconoscimento dell'importanza degli antichi templi cittadini, che pertanto non devono essere distrutti: Costante (Cod. Theod. 16,10,3 [SC 497, 430431]: Idem AA. [Costanzo II e Costante] ad Catullinum praefectum Urbi: [senza luogo], 1 novembre 346 [in realtà 342, SEECK]), pur ribadendo che ogni forma di superstitio deve essere totalmente distrutta (quamquam omnis superstitio penitus eruenda sit), prevede che i templi suburbani vengano tutelati perché proprio da essi traggono origine le feste col relativo corollario ludico (ludi, circenses, agones). Anche Onorio ritiene che la laetitia del populus, connessa con i publica vota degli anniversari imperiali, debba essere mantenuta, a patto però che non sia contaminata da sacrificia e superstitio (Cod. Theod. 16,10,17 [SC 497, 452-453]: Idem AA. [Arcadio e Onorio] Apollodoro proconsuli Africae: Padova, 
Chastagnol osservava come, nell'epoca di Onorio, i sacerdotales africani dovessero essere ancora in gran parte pagani, ma non escludeva affatto una presenza, crescente, di cristiani, per quanto il sacerdozio conservasse alcuni aspetti marcatamente legati alla tradizione religiosa ancestrale. ${ }^{49}$ Per l'epoca successiva, nell'avanzato V sec., essi sono ormai certamente e pressoché totalmente cristiani: i sacerdotales provinciae Africae sono infatti attestati fin nella piena epoca vandalica, nel primo quarto del VI sec., come mostrato da Chastagnol e Duval. ${ }^{50}$

Ma un interessante esempio di notabile cristiano nel ruolo di sacerdote civico del culto imperiale si ha già con Aelius Iulianus, notabile di Thamugadi, che compare nell'album municipale (363) come flamen perpetuus e negli anni successivi (364-366) divenne due volte curator rei publicae e infine patronus della colonia: proprio la sua tavola di patronato, adorna di un chrismon e delle lettere alpha e omega, attesta come egli dovesse essere cristiano. ${ }^{51}$ Allo stesso modo era cristiana l'intera famiglia del $\lambda ı ß u \alpha ́ \rho x \eta \varsigma$ Hesychios di Cirene, datato tra IV e V sec. ${ }^{52}$

20 agosto 399); i templi cittadini andranno dunque preservati, in quanto publicorum operum ornamenta (Cod. Theod. 16,10,15 [SC 497, 450-451]: Idem AA. Macrobio vicario Hispaniarum et Procliano vicario Quinque Provinciarum: Ravenna, 29 gennaio [agosto, SEECK] 399), mentre quelli rurali potranno essere distrutti senza suscitare troppo clamore (Cod. Theod. 16,10,16 [SC 497, 452-453]: Idem AA. ad Eutychianum praefectum praetorio: Damasco, 10 luglio 399). Sulla civilitas e la dimensione ludica tradizionale, ancora attestata dai calendari tardoantichi di IV-V sec. (Furio Filocalo, Polemio Silvio), cfr. MAZZARINo 1974, 438 (vd. supra n. 1); FRASCHETTI 1999, 96-108, 296-306 (partic. 107 e 298 su Cod. Theod. 16,10,3).

49 Vd. supra n. 36.

50 Dossier epigrafico dei sacerdotales Africae e deiflamines perpetui di epoca vandalica: CHASTAGNOL/ Duval 1974. cfr. LeONe 2013, 91-99 (epoca vandalica) e 245-254 (IV sec.). Il dossier comprende le iscrizioni del sacerdotalis Tulius Adeodatus di Cuicul (Djemila, Numidia: CIL VIII 8348 = ILCV 392); degli Astii di Ammaedara (Haïdra, Africa Proconsularis?): il vir clarissimus e flamen perpetuus Astius Vindicianus (CIL VIII 450 = ILCV 126), il flamen perpetuus c(h)ristianus Astius Mustelus (CIL VIII 10516 $=11528=$ ILCV 388), morto nel quarto anno del re vandalo Ilderico (526), e il sacerdotalis provinciae Africae Astius Dinamius (AE 1972, 691); del flamen perpetuus Iulius Honorius di Uppenna (Henchir Chigarnia, Byzacena: CIL VIII 23045a = ILCV 389B); del flamen perpetuus Minucius Apronianus di Membressa (Chouhoud el Batal, Africa Proconsularis: ILCV 389A). A tali testimonianze possono aggiungersi le cosiddette Tablettes Albertini, provenienti dall'area compresa tra Theveste e Capsa (probabilmente da una località della Byzacena), che registrano varie volte, tra 493 e 496, il nome di Flavius Geminius Catullinus, grande proprietario terriero e flamen perpetuus: cfr. CHASTAGNOL/ Duval 1974, 108-109. Sul culto imperiale nell'Africa vandalica cfr. anche MAZZARINo 1974, 437-438 (allusioni al culto del sovrano nei poemi di Draconzio e Flavio Felice).

51 Aelius Iulianus di Thamugadi: CHASTAGnol 1978, 44-48. Sull'album di Thamugadi vd. supra n. 6. D'altra parte Aelius Iulianus, curator rei publicae per la seconda volta, insieme ai flamines perpetui Flavius Aquilinus, Antonius Petronianus e Antonius Ianuarianus, provvide alla ricostruzione integrale del quadriportico del Capitolium di Thamugadi (CIL VIII 2388 = ILS 5554 = SAASTAMOINEN 2010, nr. 745; datazione: 364-366), che fu dedicato pro magnificentia saeculi di Valentiniano e Valente dal consularis Numidiae Publilius Ceionius Caecina Albinus (PLRE I34-35). Si noti come il governatore 
D’altra parte conosciamo anche alcuni casi conclamati di pagani che rivestirono il sacerdozio del culto imperiale: il vir perfectissimus T. Flavius Vibianus fu principalis e curator rei publicae di Leptis Magna e, contestualmente, duumviro di Leptis e sacerdos della Tripolitania; rivestì inoltre i sacerdozi civici di flamen e pontifex, nonché di sacerdos Laurentium Lavinatium, sacerdos Matris Deum e praefectus omnium sacrorum..$^{53}$

Altri esempi significativi possono rintracciarsi nelle roccaforti del conservatorismo pagano greco-orientale, ad esempio a Creta e in Caria: all'incirca nel secondo

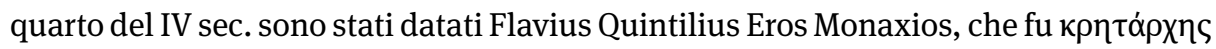

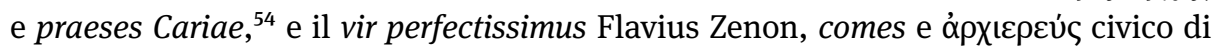
Aphrodisias. ${ }^{55}$

Albinus, pagano, avesse promosso il restauro di altri templi in Numidia, tra cui il mitreo di Cirta (ILAlg II.1, 541) e il tempio di Nettuno a Lambaesis (CIL VIII 2656): vd. GREGORI/FILIPPINI c.d.s.

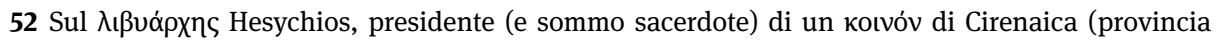
Lybia Superior), donatore di mosaici cristiani a Cirene, e sulla sua famiglia vd. REYNolds 1959, 100; SEG 18, 745-746 = SEG 30, 1785; cfr. DEININGER 1965, 35, n. 4.

53 T. Flavius Vibianus signo Heraclius di Leptis Magna: IRT 567-568 = CCA V, 49-50 = TANTILLo/BIGI 2010, 422-427, nrr. 56-57 (datazione: prima metà del IV sec.); cfr. ZudDAs 2013, 106.

$54 \mathrm{Fl}$ (avius) Quint(ilius) Eros Monaxios (PLRE I 608), governatore di Caria di rango perfectissimus

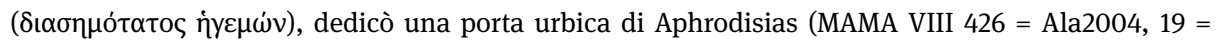
PH257488 = IAph2007, 12.1001) all'Augusto Costanzo II e a un Cesare (preferibilmente Giuliano, 355-360, piuttosto che Gallo, 351-354: cfr. ConTI 2004, nr. 32). Nella dedica egli ricorda di essere

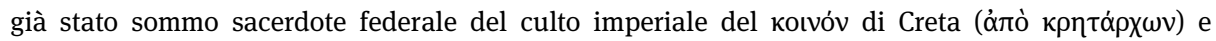

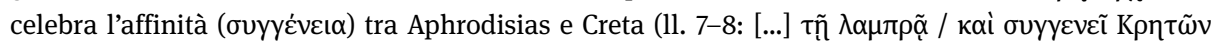

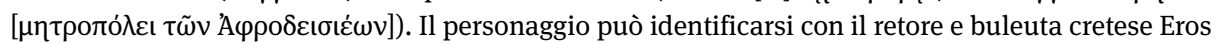
(PLRE I 283, Eros 2), un corrispondente di Libanio che fu nominato governatore provinciale (o’ $\rho \chi \omega v$ ) nel 359 (SEECK 1906, 128, Eros: destinatario della epist. 94 Wolf, cfr. epist. 95,8-9 Foerster): tale identificazione permetterebbe di restringere ulteriormente la cronologia del suo governatorato in Caria c.a. 359-360. ChANiotis 2008, 250-252 ha inoltre proposto di riconoscerlo nel Fl(avius) Er(os?)

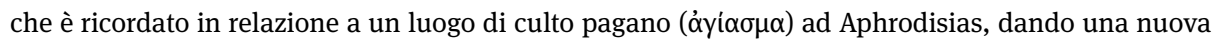
lettura dell'iscrizione votiva di un certo Polychronios, che si dichiara cognato (o genero?) di una innominata somma sacerdotessa civica del culto imperiale (MAMA VIII $457=$ PH257051 = IAph2007,

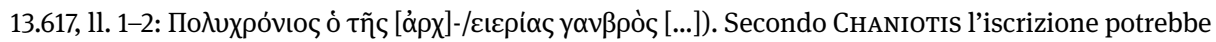
datarsi al IV sec. avanzato anziché al III. Sulla persistenza della religione pagana a Creta nel IV-V sec. vd. GREGORI/FILIPPINI c.d.s. (con rimandi bibliografici).

$55 \mathrm{Fl}$ (avius) Zenon (PLRE I 992) è attestato sia ad Aphrodisias, dove dedica alla patria due oggetti/ monumenti non meglio identificati, entrambi pertinenti al Cortile Est delle Terme di Adriano (le iscrizioni sono poste su una colonna marmorea, probabilmente destinata a sorreggere una statua: SEG 32, 1105 = Ala2004, 11 = PH257046 = IAph2007, 5.301; e su un blocco architettonico: SEG 32, 1106 = Ala2004, 12 = PH257047 = IAph2007, 5.302; la seconda dedica è effettuata post mortem dai figli, secondo le volontà testamentarie paterne), sia a Roma, dove dedica ben cinque statue di divinità pagane (dediche iscritte sui plinti: IG XIV 1268-1271 = IGUR IV 1594-1598 = PH189243-189247), i cui frammenti sono stati rinvenuti nell'Ottocento sull'Esquilino (non in un solo punto), in contesti di reimpiego, genericamente databili alla prima metà del IV sec. (il cd. „Gruppo dell'Esquilino“, ora alla Ny Carlsberg Glyptothek di Copenhagen: vd. MoLtesen 1990; MoLtesen 2000; cfr. VoRSTER 2004, 


\section{I sommi sacerdoti nell'epigrafia dell'Oriente greco: Asia Minore e Grecia}

Come necessaria premessa metodologica conviene subito osservare che nell'Oriente ellenofono di epoca alto-imperiale la denominazione dei dignitari del culto impe-

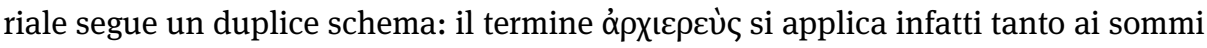
sacerdoti civici (senza ulteriori specificazioni di competenza, se non, eventualmente, quella generica di $\alpha \rho x เ \varepsilon \rho \varepsilon v ่ \varsigma \tau \tilde{\omega} v \Sigma \varepsilon \beta \alpha \sigma \tau \tilde{\omega} v)$, quanto ai sommi sacerdoti federali, nel cui titolo compare però l'indicazione del relativo koıvóv (piuttosto che della provincia romana in quanto entità politico-amministrativa: si tenga ben presente questi due concetti giuridici non sono necessariamente coincidenti), ad es. $\alpha \rho x ı \rho \varepsilon v ่ \varsigma ~ \tau \tilde{n} \varsigma ~ A \sigma i ́ \alpha \varsigma$

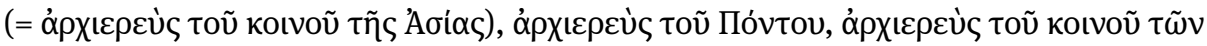
$\Gamma \alpha \lambda \alpha \tau \tilde{\omega} v$ etc. (con diverse possibili varianti). In parallelo un altro termine, parimenti ufficiale, designa il sommo sacerdote federale in quanto presidente dell'assemblea

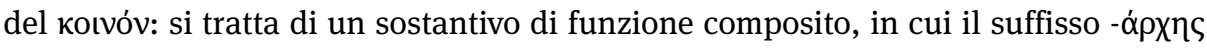

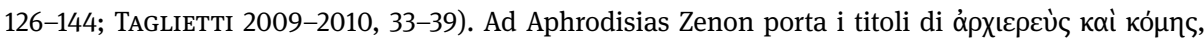

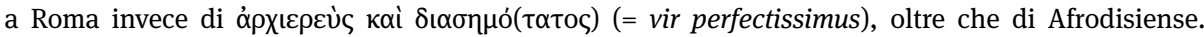
Il titolo di comes e il gentilizio „di rango“ Fl(avius) sono stati considerati da RouechÉ/ERIM 1982, 106-107 (cfr. commento di Charlotte RouEchÉ ad Ala2004, 11-12) come elementi indicativi per una datazione approssimativa all'epoca di Costantino e/o dei Costantinidi, intorno agli anni 324-350 (sull'organizzazione della comitiva imperiale in tre ordines in epoca costantiniana cfr. CHASTAGNOL 1960, 412). Il titolo di ápxıعрús è stato inteso dagli editori della PLRE I 992 (Zenon 8) come sommo sacerdote del culto imperiale della provincia Caria, carica che sarebbe teoricamente in linea con il rango di vir perfectissimus (vd. supra n. 8); sembra tuttavia più plausibile l'esegesi di RouECHÉ/ERIM 1982, 114-115 nel senso di sommo sacerdote civico di Aphrodisias, accolta anche da CHANIOTIS 2008, 249-250 e FrIJA 2012, 55, 257, nr. 308. Non sembra invece altrettanto persuasiva l'ipotesi di RouECHÉ/ ERIM 1982, 113-115 (cfr. anche ERIM/REYNOLDS 1989), secondo cui Flavius Zenon, come anche

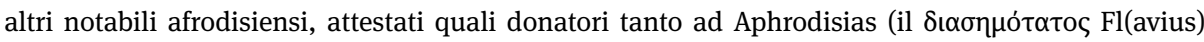
Andronikos: Ala2004, 13 = IAph2007, 2.113; [Fl(avius)?] Palladius: Ala2004, 252 = IAph2007, 5.119), quanto a Roma (il medesimo Fl(avius) Andronikos: IGUR IV 1592-1593; Fl(avius) Chryseros: IGUR IV 1599-1603), sarebbero stati scultori o perlomeno proprietari di botteghe di scultura, riconducibili alla fase tardoantica della cosiddetta Scuola di Aphrodisias (cfr. SQUARCIAPINO 1943; SQUARCIAPINO 1983;

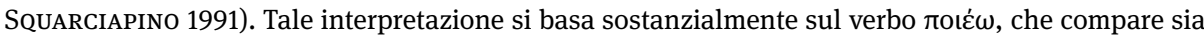

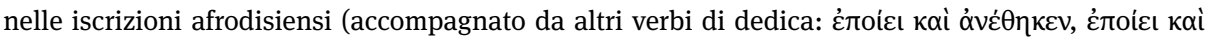

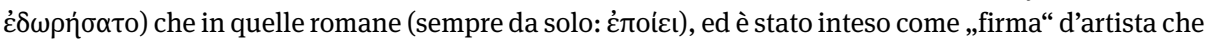
avesse materialmente „fatto“ l'opera scultorea. Nuove scoperte epigrafiche ad Aphrodisias potranno forse chiarire meglio la questione. A proposito delle manifestazioni del culto imperiale tardoantico ad Aphrodisias si può ricordare come un illustre funzionario pagano, Flavius Eutolmios Tatianos (PLRE I 876-878), praefectus praetorio Orientis di Teodosio (388-392), avesse consacrato le statue di Onorio, Arcadio e Valentiniano II (Ala2004, 25, 26, 27 = IAph2007, 5.217, 4.10, 4.11) „,con la tradizionale

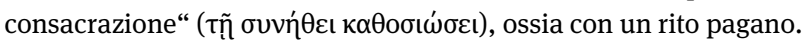




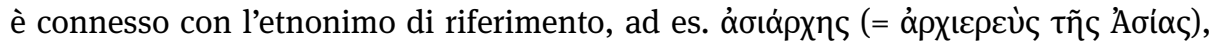

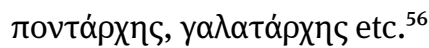

L'analisi della documentazione epigrafica relativa all'Oriente può aprirsi con un caso per certi aspetti paradigmatico. Un'iscrizione di epoca tetrarchica, recentemente pubblicata da ELENA MiRANDA, proviene dall'area sacra del kotvóv dei Motaleis (Dağmarmara), una comunità di villaggio situata sull'altopiano di Uzunpınar nel territorio della città di Hierapolis di Frigia (Pamukkale): tale area è stata indagata dai colleghi Tullia RitTi e GiusepPe Scardozzi, membri della Missione Archeologica Italiana di Hierapolis (MAIER) diretta da FRANCESCO D'ANDRIA. ${ }^{57}$

L'architrave di un edificio monumentale, verosimilmente destinato al culto imperiale, reca una dedica all'imperatore ( $\alpha$ ư ( $\theta \varepsilon$ có) Massimiano (il cui nome è stato successivamente eraso): la datazione al 313 è fornita dalla menzione del terzo consolato di Costantino e Licinio. L'incisione del testo fu disposta dal governatore [Fl(avius)?] Domitius Asklepiodotos e realizzata a cura del sacerdote (ísعúc) Aeb(utius) Flaccus Apphianos. Oltre ai dati preziosi, già discussi dall'editrice, riguardanti la data di morte dello stesso Diocleziano, la damnatio memoriae di Massimiano e la cronologia di un nuovo praeses Phrygiae, l'iscrizione chiarisce l'articolata sequenza di ruoli che soggiaceva alla costruzione (o ricostruzione) di un luogo sacro legato al culto imperiale. A un sollecito del governatore doveva corrispondere l'iniziativa di Apphianos, che era non soltanto sacerdote dei Motaleis, ma anche buleuta di Hierapolis ed esponente di una famiglia importante di

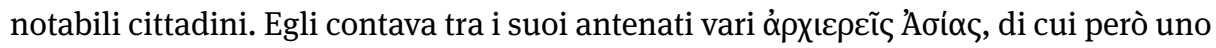

56 Denominazione dei sommi sacerdoti civici: FRIJA 2012, 71-74 (provincia Asia). Denominazione dei sommi sacerdoti/presidenti delle assemblee federali: Vitale 2014 (Oriente ellenofono). Analisi

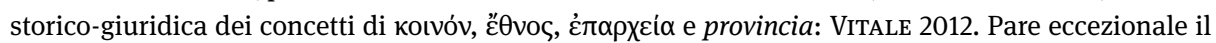

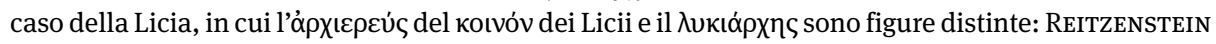
2011.

57 Dedica di un edificio a Diocleziano e al divus Massimiano presso i Motaleis (Hierapolis, Phrygia; datazione: 313): MirandA DE MARTINo/RitTi/ScARdozzi 2012, 699-703, nr. 9 (E. MirandA);

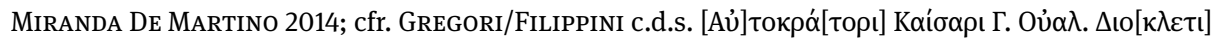

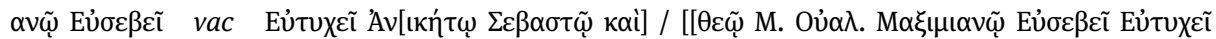

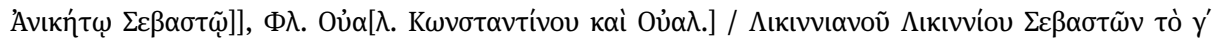

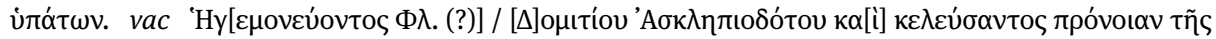

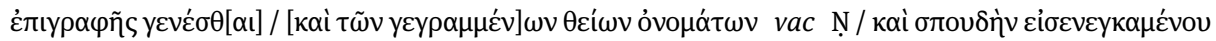

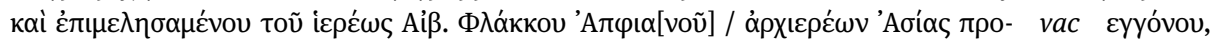

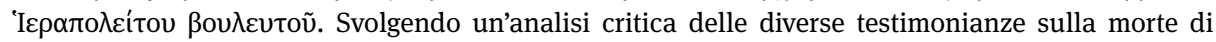
Diocleziano, MiRANDA DE MARTino 2014, 74-76 ritiene che l'iscrizione dei Motaleis sia stata posta nella prima metà del 313, entro giugno-luglio; RoBERTo 2014, 254-255 pensa alla primavera del 313, probabilmente tra marzo e aprile. Sul territorio dei Motaleis (la Motalis) e la loro area sacra vd. Miranda De Martino/Ritti/Scardozzi 2012, 687-693 (G. ScARdozZi/T. RitTi); cfr. SCARDOZZI 2014, 100. Sugli scavi di Hierapolis vd. recentemente D’ANDRIA/CAGGIA/ISMAELLI 2012. 
soltanto ci è già noto: Aebutius Flaccus, sommo sacerdote federale presso il tempio di Kyzikos in epoca tardo-adrianea. ${ }^{58}$

Si noti, en passant, che Hierapolis, al principio del IV sec., non si trovava più da lungo tempo nella provincia Asia, bensì nella provincia tardoantica denominata Phrygia: su tale importante dato di storia amministrativa si tornerà tra breve. In ogni caso, nella prima metà del 313 il governatore provinciale e il sacerdote locale provvidero al restauro di vari monumenti nella stessa area sacra, tra cui questo tempio e anche un altro edificio, non distante, dedicato agli dèi dei Motaleis. ${ }^{59}$

Una situazione parzialmente analoga si era verificata, pochi anni prima, nella vicina Laodikeia al Lykos (Goncalı presso Denizli): gli scavi del tempio A (il cosiddetto Sebasteion), un tetrastilo su alto podio, sono stati condotti dalla missione archeologica della Pamukkale Üniversitesi (Denizli) diretta da CELAL ŞıMŞEK e hanno portato alla scoperta di un ricco dossier epigrafico di epoca tetrarchica, attualmente in corso di pubblicazione a cura di Francesco GuIzzI. ${ }^{60}$ All'inizio del IV sec. il tempio fu restaurato a cura del praeses provinciae Phrygiae Septimius Dionysios e furono allora poste nell'area santuariale alcune imponenti dediche ai sovrani, Diocleziano e Massimiano, che vennero così ad affiancare le divinità titolari del tempio, Apollo e Artemide. Si noti che in quegli anni Laodikeia era diventata capitale della nuova provincia Phrygia, istituita tra 301/302 e 305, nella quale rientrava anche Hierapolis. ${ }^{61}$ Una

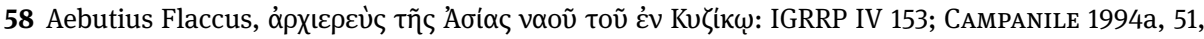
nr. 29. Tale personaggio è stato identificato da MIRANDA 2002 con P. Aebutius Flaccus di Hierapolis,

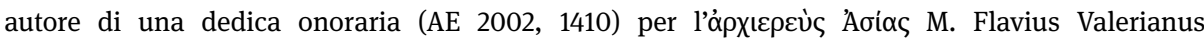
Terentullianus (vd. CAMPanile 2006, 531-531, nr. 204a = 20c), o comunque con un suo congiunto; entrambi sono certamente antenati di Aeb(utius) Flaccus Apphianos. Gli Aebutii sono peraltro largamente attestati nell'epigrafia funeraria (II-III sec.) delle necropoli di Hierapolis. Tra i discendenti di Aeb(utius) Flaccus Apphianos deve infine porsi il buleuta Aeb(utius) Eupolis Apphianos (forse suo figlio?), che fu sovrintendente ai lavori di restauro del teatro di Hierapolis, completati nel 352 (tale dossier epigrafico è in corso di pubblicazione a cura di TulLIA RITTI: vd. infra n. 79).

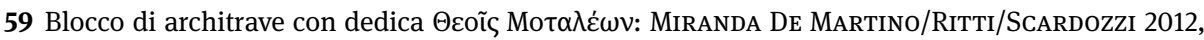
698, nr. 7 (T. RITTI); l'iscrizione originaria (II-III sec.) è stata ritoccata nel IV sec. Un altro frammento

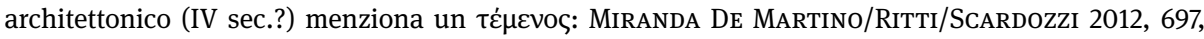
nr. 5 (T. RITTI).

60 Dossier epigrafico del tempio A di Laodikeia: GuIzzi c.d.s. Per la conoscenza di tali importanti documenti desidero ringraziare il collega Francesco Guizzi. Sul praeses Septimius Dionysios cfr. anche ŞıмŞEK/GUIzZI 2012, 517. Tra i funzionari imperiali attestati nel dossier compare anche il praeses Phrygiae [Fl(avius)?] Domitius Asklepiodotos come dedicante di un'iscrizione onoraria per un Augusto, probabilmente Galerio: lo stesso governatore operò dunque tanto nel villaggio dei Motaleis (313), quanto nella capitale Laodikeia (c.a. 305-311), attuando un programma di restauro degli edifici sacri che pare conforme alle direttive generali dei sovrani. Sugli scavi di Laodikeia vd. recentemente ŞıMŞEK 2014 (partic. 227-245 sul tempio A).

61 Lo sdoppiamento della provincia Phrygia-Caria (vd. infra n. 74) nelle due province autonome di Phrygia (capitale Laodikeia) e Caria (capitale Aphrodisias) va collocato, in termini generali, tra l'inverno 301/302 e il maggio 305: nel novembre 301 è infatti ancora attestato Fulvius Asticus (PLRE 
dedica votiva in versi, rinvenuta nel portico del tempio A e già pubblicata da ŞıMŞEK

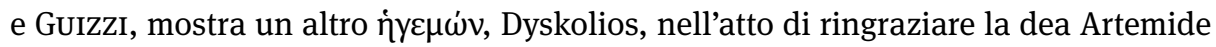
Lochia - l'incarico di tale governatore è databile sotto Licinio (313-323). ${ }^{62}$

Un caso simile riguarda Antiochia di Pisidia (Yalvaç): nel 310, quando Galerio aveva istituito la nuova provincia Pisidia, il suo primo praeses, Valerius Diogenes, subito provvedeva alla monumentalizzazione di Antiochia, prescelta come capitale, e la dotava di un tempio del culto imperiale. ${ }^{63}$ Si noti che lo stesso Diogenes si impegnava poi con grande zelo nelle persecuzioni anti-cristiane decretate negli anni seguenti da Massimino Daia. ${ }^{64}$

Ma qual è stato il ruolo dei sommi sacerdoti del culto imperiale in questi anni di restaurazione della religione tradizionale da parte dei Tetrarchi e, al contempo, di durissime misure repressive contro i cristiani? Alcune famiglie sacerdotali paiono avere una posizione durevole di preminenza in tale contesto, greco e microasiatico, di inizio IV sec. - ad esempio nell'Asklepieion di Epidauro due statue del dio guaritore

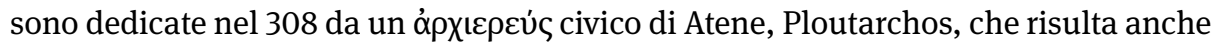

I 119) come praeses attivo in entrambe le province, mentre Aurelius Marcellus figura come praeses provinciae Cariae in un'iscrizione onoraria da lui dedicata al primo collegio di Tetrarchi (c.a. 293-305) ad Alicarnasso (CIL III 449 = ILS 635). Per un aggiornamento su entrambi i governatori vd. RouechÉ 1981; Barnes 1982, 156-157; Roueché 1996; cfr. Miranda De Martino 2014, 77. Si ricordi come, parallelamente rispetto ad Aurelius Marcellus, Septimius Dionysios (vd. supra n. 60) compaia come praeses provinciae Phrygiae nel dossier del tempio A di Laodikeia (c.a. 286-305): vd. GuizzI c.d.s.

62 Epigramma votivo di Dyskolios (Laodikeia, Phrygia; datazione: 313-323): ŞıMŞEK/GUIzzI 2012 = AE 2012, 1537; cfr. Manganaro 2013; Jones 2014a, 34. Il praeses Phrygiae Dyskolios è stato identificato dagli editori con l'omonimo alto funzionario (PLRE I 275, Dyscolius 1) di Licinio, attestato tra 317 e 324 (probabilmente nel 323) dal dossier papirologico dello scholasticus Theophanes di Hermoupolis (PLRE I 907): la carica di Dyskolios nel 323 deve interpretarsi come vicarius Orientis (ipotesi ROBERTS-TURNER, quindi ŞıMŞEK-GUIzZI) anziché come semplice governatore di Syria (ipotesi JonEs-MARTINDALE); egli avrà governato la Phrygia prima di assumere tale vicariato. Dyskolios è inoltre identificabile con un omonimo allievo (PLRE I 275, Dyscolius 2) del filosofo neoplatonico Giamblico.

63 Sul praeses Pisidiae Valerius Diogenes (PLRE I 257) vd. il dossier epigrafico (AE 1999, 1611-1620) analizzato da Christol/Drew-BeAR 1999; Christol 2013; Christol 2014. In particolare la dedica su architrave AE 1999, 1611, rivolta da Diogenes ai tetrarchi (Massimiano, Massimino, Costantino, Licinio), sembra pertinente a un edificio destinato al culto imperiale. Su Antiochia di Pisidia vd. DREW-BEAR/TaşLIALAN/Thomas 2002.

64 Sul ruolo avuto da Diogenes nella persecuzione anti-cristiana di Massimino Daia vd. l'iscrizione funeraria (ILS 9480 = MAMA I 170 = SGO III nr. 14/06/04a = PH274935) di M. Iul(ius) Eugenios (PLRE I 293; PCBE III, E. 1), buleuta di Laodikeia Katakekaumene (Ladık, Pisidia), che era stato funzionario dell'officium di Diogenes e venne da lui perseguitato in quanto cristiano al tempo di Massimino. Eugenios lasciò allora l'officium e, dopo un breve soggiorno a Laodikeia Katakekaumene, ne divenne vescovo per ben venticinque anni (c.a. 313/315-338/340): vd. WischMEYER 1990; FILIPPINI c.d.s. (con rimandi bibliografici). Sulla persecuzione di Massimino in Oriente (novembre 311 - maggio 313) vd. CASTRItius 1969; GRANT 1975; Filosi 1987; MitChell 1988; ARENA 2008. 
essere sacerdote di Asklepios Soter e ípo sonaggio pare discendere un casato ateniese che tra IV e V sec. presenterà membri

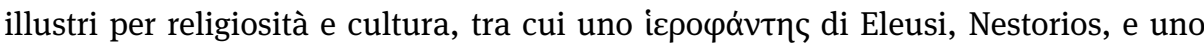
scolarca dell'Accademia neoplatonica, Ploutarchos. ${ }^{66}$ D'altra parte non è chiaro se nell'Atene del IV sec. vi fosse anche un altro sacerdote, un flamen, votato al culto imperiale. ${ }^{67}$

Sul fronte della tradizione pagana ancestrale possiamo trovare altre importanti famiglie sacerdotali in Asia Minore: ad Akmoneia (Ahat Köyü, Phrygia) gli Äávatoı, i cosiddetti „immortali“, presentano ben tre generazioni di $\pi \rho \tilde{\omega} \tau o \iota ~ \alpha ́ \rho x เ \varepsilon \rho \varepsilon \tilde{\varsigma}$ civici. L’ara funeraria di Athanatos Epitynchanos (I), che fu iniziato ai misteri ( $\mu \nu \eta \theta \varepsilon i ́ \varsigma)$ dalla

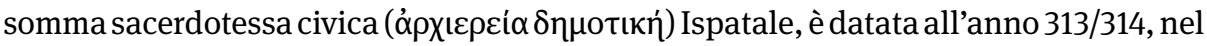
periodo immediatamente successivo alla vittoria di Licinio su Massimino (primaveraestate 313). ${ }^{68}$ Il documento sembra alludere al clima sanguinoso delle recenti perse-

65 Entrambe le dediche di Ploutarchos ad Asklepios (epigramma votivo: IG IV² 1, 436; breve iscrizione in prosa: 437) sono datate all'anno $185^{\circ}$ (हैточ $\rho \pi \varepsilon^{\prime}$ ) dell'éra locale di Epidauro (=308), il cui computo

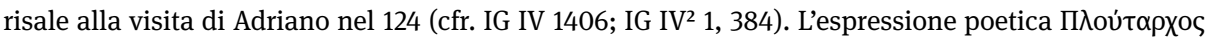

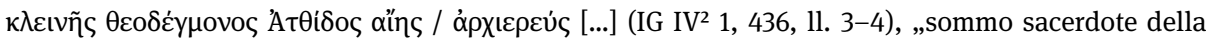

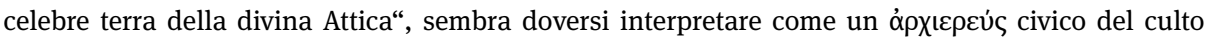
imperiale della città di Atene (cfr. infra n. 124): si noti che in epoca alto-imperiale tale sacerdozio era di durata vitalizia (cfr. CAMIA 2011, 137-138).

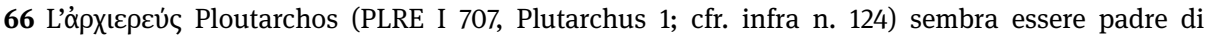

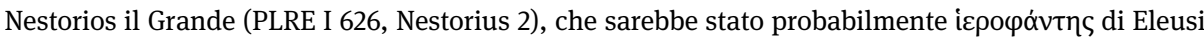
(CLINTon 1974, 43, nr. 36) e amico dell'imperatore Giuliano (vd. infra n. 117), e quindi bisnonno dello scolarca Ploutarchos (PLRE I 708, Plutarchus 5), attivo tra la fine del IV e il secondo quarto del V sec. (sull'Accademia neoplatonica tra IV e VI sec. cfr. CHIARAdONNA 2013; JonEs 2014b, 126-131 con rimandi bibliografici).

67 La questione rimane dubbia e dipende dall'interpretazione della parte destra, ormai perduta (e conosciuta tramite la sola tradizione antiquaria), dell'iscrizione tardoantica che attesta il restauro della porta di ingresso all'Acropoli, effettuato a proprie spese da Fl(avius) Septimius Marcellinus, ex-

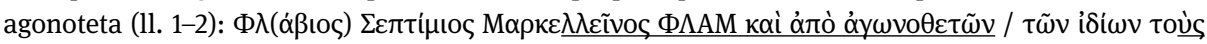

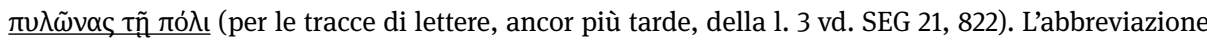
$\Phi \Lambda \mathrm{AM}$ è stata intesa in vario modo dagli editori: Boeckh (CIG I 521) pare interpretarlo come un cognome, $\Phi \lambda \alpha \mu(\grave{\eta} v)$; Dittenberger (IG III, 398) come un sacerdozio, $\varphi \lambda \alpha \mu(\grave{\eta} v)$; Kirchner (IG II/III ${ }^{2}$ 3.1, $5206=$ PH7520) si limita a riportare le posizioni precedenti, cui aggiunge l'ipotesi di Graindor $\Phi \lambda \alpha \mu$ (ivıo)). Si noti che Kirchner data, correttamente, l'iscrizione al IV sec. (sul gentilizio „di rango“ $\mathrm{Fl}$ (avius) vd. supra n. 55), diversamente dai suoi predecessori (III sec. sulla base del gentilizio Septimius). Da ultimo Sironen (IG II/III ${ }^{2}$ 5, $13291=$ PH345520) propone invece la diversa lettura

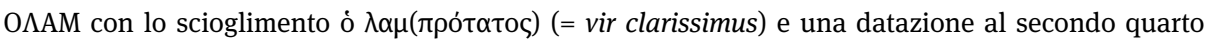
del IV sec. TRombley 2011, 39 accoglie l'esegesi di Marcellinus come flamen e agonoteta e sottolinea l'associazione tra culto imperiale e organizzazione di giochi. Mancano tuttavia termini di confronto: non sono infatti attestati altri flamines né in Attica né in altre parti della Grecia, salvo presso le colonie romane in epoca alto-imperiale (ad es. Corinto: cfr. CAMIA 2011, 153-154).

68 Ara funeraria di Epitynchanos (I) da Otourak presso Akmoneia (di cui tre lati sono iscritti: A-C): RAMSAY 1897, 566-568, nrr. 467-469; CUMONT 1913, 158-163, nr. 136; GRÉGOIRE 1933, 49-56 (= SEG 
cuzioni, laddove si dice che la stessa Ispatale aveva riscattato molti uomini da crudeli

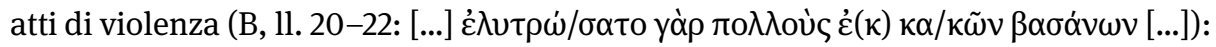
secondo HENRI GRÉGOIRE si tratterebbe di cristiani, dapprima perseguitati da Massimino e quindi riabilitati da Licinio, e tale frase avrebbe forse inteso salvaguardare il monumento funerario da eventuali ritorsioni da parte cristiana. ${ }^{69}$ Epitynchanos

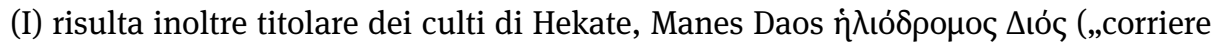

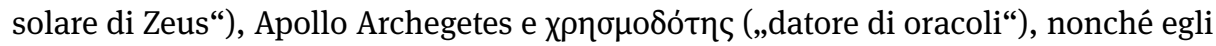
stesso detentore del carisma profetico per concessione degli dei immortali (A, 11.

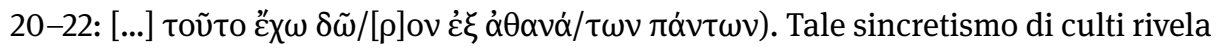
alcuni tratti tipici della teosofia mitraica e orfica. ${ }^{70}$ Anche un epigramma funerario di sapore neoplatonico, rinvenuto nell'alta valle del fiume Tembris (Phrygia) e dedicato al profeta oracolare Epitynchanos, un astrologo capace di prevedere il futuro, è stato

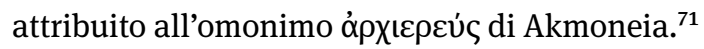

43, 943B = PH272540); MAMA VI, List p. 148, nr. 152*; MERKELBACH/STAUBER 1999, 159-162; SGO III nr. 16/31/10 (Prosainschrift); cfr. Mitchell 1993, II, 47, 64; HiRschmann 2003; Belayche 2011, 254. L'iscrizione B reca la data dell'anno $398^{\circ}$ (ह̌́touৎ тọn') della provincia Asia (= 23 settembre 313 / 22 settembre 314), calcolato secondo l'èra sillana (pace di Dardano, 85 a.C.). Il monumento funerario con le sue tre iscrizioni, contestuali e coeve, è stato dunque dedicato dopo i decisivi eventi politici della primavera-estate 313, che determinarono il dominio di Licinio sulla diocesi d'Oriente (vittoria di Licinio su Massimino a Campo Ergeno: 30 aprile 313; Licinio entra a Nicomedia: maggio 313; l'editto di Nicomedia garantisce la tolleranza per i cristiani: 13 giugno 313; Massimino muore a Tarso: agosto-

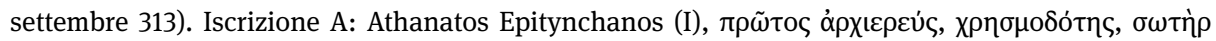

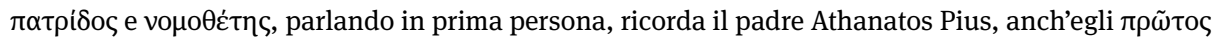

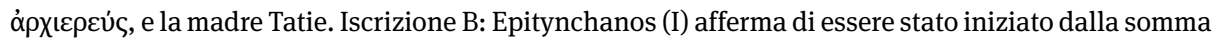
sacerdotessa Ispatale (che, secondo GRÉGOIRE 1933, 52, potrebbe essere forse sua moglie); l'ara di Epitynchanos (I) è stata consacrata da Diogas e da un altro Epitynchanos (II, probabilmente figlio di Diogas), con la moglie Tation e i figli Onesimos, Alexandros, Asklas e Epitynchanos (III). Iscrizione C:

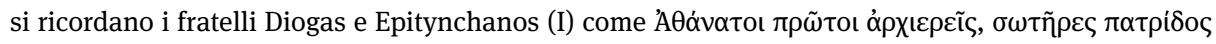

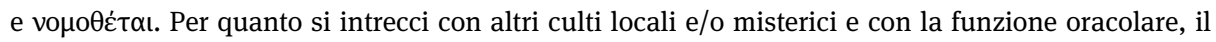
sommo sacerdozio rivestito da Pius, Ispatale, Epitynchanos (I) e Diogas ad Akmoneia è interpretato come sommo sacerdozio civico del culto imperiale: FRIJA 2012, 55-56, 269, nrr. 424-426. Si tratta probabilmente di un sacerdozio di durata vitalizia.

69 GRÉGOIRE 1933, 52-53 (l'ara funeraria ha in effetti subito violenti colpi di martello, specialmente sui rilievi figurati, nonché l'incisione di una croce cristiana). Mitchell 1993, II, 47, n. 274 ritiene inoltre che Ispatale avesse sottratto i cristiani alle torture dei persecutori inducendoli all'apostasia. All'opposto RAMSAY 1897, 567 aveva ipotizzato che Ispatale avesse salvato dei correligionari pagani dalle violenze cristiane.

70 Analisi storico-religiosa del documento: HIRSCHMANn 2003 (elementi misterici mitraici e orfici); cfr. le ancor utili osservazioni di GRÉGOIRE 1933, 49-56 (aspetti cultuali traco-daco-frigi, interrelati con il culto imperiale di epoca tetrarchica).

71 Epigramma del profeta e astrologo Epitynchanos da Doğanarslan (alta valle del Tembris, non lontano dal territorio di Akmoneia): RAMSAY 1897, 790-791, nr. 3; IGRRP IV 607; PH268892; SEG 43, 943; MerKelbach/Stauber 1999, 162-164; SGO III nr. 16/31/10 (Epigramm); OBRYK 2012, 108-112, nr. D8; cfr. MitcheLL 1993, II, 47. L’epigramma è stato datato c.a. 313 per via dell'identificazione tra il 
Passando dalla provincia Phrygia alla Caria, un'altra influente famiglia di sacerdoti e notabili è attestata a Stratonikeia (Eskihisar presso Yatağan) e nei vicini templi di Zeus a Panamara e di Hekate a Lagina, i più importanti santuari federali dei Carii. I fratelli e sacerdoti M. Sempronius Auruncius Theodotos e Sempronia Auruncia Arriana, che finanziarono generosamente le grandi festività religiose locali, si distinsero per opere di evergetismo civico e, non a caso, nel 312 ospitarono in città l'Augustus Iovius Massimino con le sue truppe. I Sempronii Auruncii di Stratonikeia si proclamano orgogliosamente „figli e nipoti e pronipoti di sacerdoti e di sommi sacerdoti e di asiarchi““, ${ }^{72}$ con una formula in parte simile a quella usata da Aebutius Flaccus Apphianos di Hierapolis, sacerdote presso i Motaleis. Tra i loro antenati è noto come

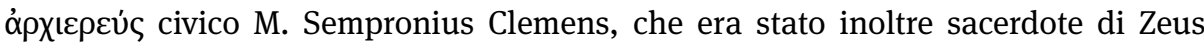
Chrysaoreios e di molte altre divinità, ma soprattutto sembra essere il più influente notabile cittadino nella prima età severiana: ${ }^{73}$ nel secolo che intercorre tra Clemens e i suoi pronipoti, non siamo però in grado di segnalare altri membri della famiglia

defunto e l'omonimo ảpxıєрєúৎ di Akmoneia. Sull'ispirazione neoplatonica della politica religiosa di Massimino vd. FILOSI 1987.

72 Iscrizione dei fratelli Sempronii Auruncii dal santuario di Zeus a Panamara: SIG $900=$ IK 21, 310 + IK 22.2, p. 35 = PH261930 (datazione: 311-313 [312?]). I fratelli M. Sem(pronius) A(u)runc(ius) Theodotos e Semp(ronia) A(u)runc(ia) Arriana, figli di (Sempronius Auruncius) Arrianus, dispongono l'incisione di una stele commemorativa nel portico già allestito dal padre per accogliere le stele e la

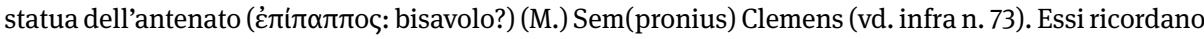

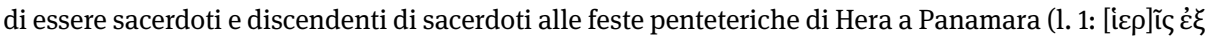

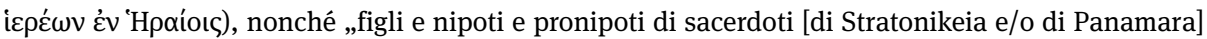

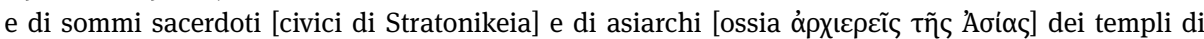

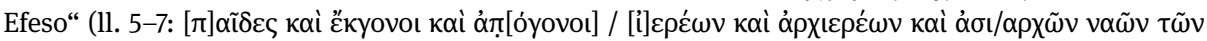

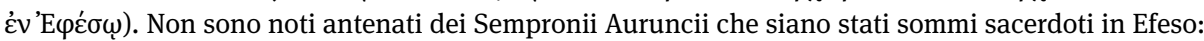
la menzione di „templi“, al plurale, indicherebbe in linea generale un arco temporale successivo

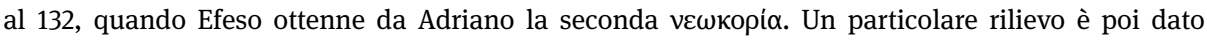
(1l. 20-27) al fatto di aver generosamente accolto in città l'imperatore Massimino (ll. 23-25: ’ $\theta \varepsilon$ เótns

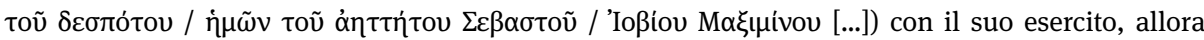

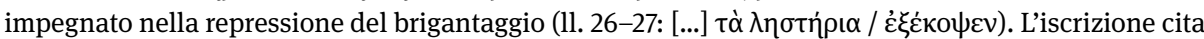
infine (1l. 49-54) come mistagogo Mar(cus) Aur(elius) [- - -]ios, figlio di Diophantos, filosofo e membro del Museo (di Alessandria). La datazione dell'iscrizione al 312(-313?), assai probabile, deriva dalla presenza di Massimino in Caria (databile tra gennaio e luglio 312) nel quadro dei suoi spostamenti tra Asia Minore e Siria (cfr. BARNES 1982, 65-68, partic. 66): inoltre l'iscrizione di Kolbasa (vd. infra n. 83) mostra come Massimino inviasse il suo rescritto alla città da Sardis, capitale della provincia di Lydia, limitrofa alla Caria, il 6 aprile 312 (vd. MitcheLl 1988, 118-119; MitcheLl 1993, II, 64-65).

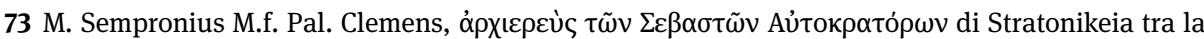
fine del II e il primo quarto del III sec.: FRIJA 2012, 265, nr. 385. Oltre al sacerdozio del culto imperiale Clemens assunse quelli di varie divinità federali dei Carii e/o locali di Stratonikeia: Zeus Panamaros, Hekate, Zeus Chrysaoreios, Zeus Narasos, Zeus Londargos, Zeus Kapetolios (Iuppiter Capitolinus), Asclepio, Hygeia, Hestia (cfr. IK 21, 16, 289, 291, 293). Anche il figlio M. Sempronius Clemens Iulius

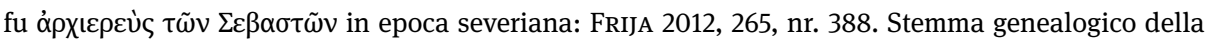
famiglia: IK 21 pp. 154-155. 
come sommi sacerdoti civici, tanto meno come asiarchi, e dobbiamo ammettere le lacune delle ricostruzioni genealogiche. Nonostante ciò si può rilevare la grandissima importanza che tali notabili attribuivano al fatto di poter contare dei sommi sacerdoti

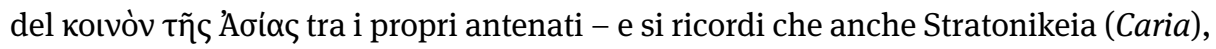
in maniera analoga a Hierapolis (Phrygia), non apparteneva più alla provincia Asia sin dalla metà del III sec.

L'estensione della grande provincia Asia di epoca alto-imperiale si era infatti notevolmente ridotta, una prima volta intorno alla metà del III sec., quando venne istituita la doppia provincia Phrygia-Caria (c.a. 249-250), ${ }^{74}$ e nuovamente tra la fine del III e l'inizio del IV sec., in conseguenza del generale riordino giuridico-amministrativo varato da Diocleziano, quando altri territori già appartenenti all'Asia furono redatti nella forma di tre nuove province: Lydia, Hellespontus, Insulae. La „piccola“ Asia tardoantica rientrò allora nella dioecesis Asiana, che intorno al 310 comprendeva otto province. ${ }^{75}$

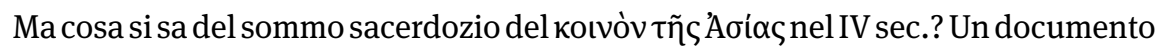
ufficiale di straordinaria importanza è rappresentato dal rescritto inviato dall'imperatore Valente al proconsul Asiae Festus, probabilmente nel 372: esso è riprodotto in versione bilingue (originale latino e traduzione greca) da un'iscrizione monumentale dell'Embolos di Efeso e tratta dell'organizzazione dei ludi connessi all'asiarchia. ${ }^{76}$ Il

74 La provincia Phrygia-Caria fu creata da Filippo l'Arabo o Decio c.a. 249-250 con lo smembramento delle regioni sud-orientali della grande provincia Asia di epoca alto-imperiale; resta incerto se la capitale della nuova doppia provincia fosse allora diventata Aphrodisias (ipotesi Roueché: cfr. le perplessità di HAENSCH 1997, 297, n. 199) o piuttosto Laodikeia al Lykos, come sembrano suggerire alcuni indizi numismatici ed epigrafici (sia editi che ancora inediti): sull'intera vicenda storico-amministrativa cfr. VITALE 2012, 85-88 (con rimandi bibliografici). Un cinquantennio più tardi la doppia provincia fu suddivisa in due province autonome, Phrygia e Caria: questa ulteriore trasformazione amministrativa avvenne in epoca dioclezianea, tra 301/302 e 305 (vd. supra n. 61).

75 Alla fine del primo decennio del IV sec., oltre alle sei province già afferenti alla grande provincia Asia alto-imperiale - Asia tardoantica (capitale Efeso), Phrygia (Laodikeia al Lykos), Caria (Aphrodisias), Lydia (Sardis), Hellespontus (Kyzikos), Insulae (Rodi) - la dioecesis Asiana comprendeva anche la doppia provincia Lycia-Pamphylia (Myra e Perge) e la Pisidia (Antiochia: vd. supra n. 63). Nel corso del IV sec. intervennero altri cambiamenti: intorno al 324/325 (sulla data vd. FILIPPINI c.d.s.) la Phrygia venne sdoppiata in Phrygia I o Pacatiana (Laodikeia al Lykos) e Phrygia II o Salutaris (Synnada); nel 371-372 venne istituita e attribuita alla dioecesis Asiana la Lycaonia (Iconium). Cfr. BARNES 1982, 156159, 215, 219; FeISSEL 1998, 93-95; ChRISTOL/DREW-BEAR 1999, 39-42.

76 Rescritto di Valentiniano I, Valente e Graziano a Festus da Efeso (Asia; datazione: 372-375 [372?]): AE 1906, 30 (solo testo latino) = FIRA ${ }^{7}$ I, 97 = GRÉGoIRE 1922, 29-31, nr. $100=$ AввоTт/JoHNSON 1926, 503-505, nr. 158 = IK 11.1, 43 + Add./Corr. p. 3 = PERGAMI 1993, 601-603 = PH250659 = HD016883; cfr. MAZZARINO 1942/1990, 22; CECCONI 1994, 94-95; LENSKI 2002, 270-271. Il destinatario (PLRE I 334335, Festus 3) fu proconsul Asiae per oltre un quinquennio negli anni 372-378 e viene generalmente identificato con l'omonimo magister memoriae di Valente (c.a. 369) e autore del Breviarium. Al rescritto originale in latino (11. 1-14) segue la traduzione in greco (1l. 15-30). Non fu incisa in antico la subscriptio del rescritto, che avrebbe conservato la data di emissione del documento; la cronologia, 
rescritto stabilisce che la scelta della città nella quale debbano tenersi i giochi federali (editiones), non dipenderà dall'arbitrio del governatore, ma le quattro città aventi il titolo di metropolis nella provincia Asia li ospiteranno a turno secondo un calendario quadriennale fisso, in modo che non manchi mai il coronatus provinciae e ognuna delle quattro città abbia il tempo necessario per trovare un editor. ${ }^{77}$ Anche ai notabili di altre città minori viene parimenti concesso il diritto di assumere le popolari cariche di asiarcha e alytarcha, a patto di organizzare i giochi a Efeso e soprattutto di aver precedentemente assolto tutte le responsabilità liturgiche (munera) che li legano alla propria curia di origine: soltanto a queste condizioni potranno finalmente rivestire la suprema carica federale e quindi ottenere la senatoria dignitas, grazie alla quale resteranno nella propria città nella condizione privilegiata di honorati. ${ }^{78}$

già posta al 372-375 per la composizione del collegio imperiale, sembra potersi forse circoscrivere al 372 (seconda metà dell'anno?): il rescritto fa infatti riferimento (1. 3: [...] [exe]mplo Illyri[c]i a [d]que Italarum urbium [...]) a un precedente (e recente) provvedimento legislativo degli stessi imperatori, relativo alle città della prefettura del pretorio d'Italia e Illirico, che può riconoscersi nella costituzione Cod. Theod. 15,5,1 (25 aprile 372, vd. supra n. 23), inviata al prafectus praetorio Italiae Illyrici et Africae Sex. Claudius Petronius Probus (PLRE I 736-740). A proposito delle elevate spese legate all'asiarchia, si ricordi che nel 409 Teodosio II esentava gli asiarchae dal tetto di spesa decretato per le expensae ludorum: Cod. Theod. 15,9,2 (vd. supra n. 24).

77 IK 11.1, 43, ll. 1-6: [DD]D(omini) nnn(ostri) Auggg(usti) Valentinianus, Valens, Gratianus. [hab(e)], Feste [car(issime) n]ob(is). / honorem Asiae ac totius provinci[a]e dignitatem, quae ex iudicantis pendebat arbitrio, [exe]mplo Illyri[c]i a[d]que Italarum urbium recte perspexi[mus] / esse firmatum. nec enim utile videbatur, ut [po]npa conventus publici unius arbitrio gereretur, qu[a]m consuet[u]dinis instaurata deberet solemnitas / exhibere. ex sententia denique factum est, quod divisis officiis per quattuor civitates, quae metropolis apu[d] Asiam nominantur, lustralis cernitur edi[tio] / constituta, ut dum a singulis ex[h]ibitio postulatur, non desit provinciae coronatus nec gravis cuiquam erogatio sit futura, cum servatis vicibus qu[in]/to anno civitas praebeat editorem. [...] Per brevità si riporta qui e alla nota successiva il solo testo originale, latino, del rescritto di Valente, al quale però, per una raggiungerne una comprensione storica (in senso più ampio, non soltanto giuridica) più approfondita, andrà sempre affiancata la traduzione (e interpretazione) greca: essa esprimeva infatti il forte interesse „campanilistico“ della classe dirigente efesina per un documento ufficiale che confermava i privilegi della città e in ogni caso rappresentava, come un vero e proprio „testo a fronte“, il necessario filtro di accesso al documento per la maggioranza del pubblico ellenofono. Si tenga anche presente il luogo di pubblicazione prescelto: la grande iscrizione proviene infatti dall'Ottagono della Kuretenstrasse (Embolos), uno degli spazi pubblici più rappresentativi della vita politica cittadina: sul significato della pubblicazione monumentale di documenti amministrativi nel contesto topografico di Efeso vd. FEISSEL 1999b.

78 Ibid., 1l. 6-14: [...] nam et il[lu]d quoque libenter admisimus, quod in minoribus municipiis generatis, quos popularis animi gloria maior / attollit facultatem tribui edendi mun[er]is postulasti, videlicet ut in metropoli Efesena al[ia] e civi<ta>te asiarchae sivi alytarchae procedant ac s[ic] / officiis melioribus nobilitate contend[an]t. unde qui desideriis sub s(a)eculi nostri felicitate ferv[entib]us gaudiorum debeamus f[om]enta [p]raestare, c[ele]/brandae editionis dedimus potestat[e]m, adversum id solum voluntatem contrariam re[feren]tes, ne suae civitatis obliti eius, in qua ediderin[t] / munera, cu[ria]e socientur, Feste karissime ac iucundissime. lauda<ta> ergo experientia tua n[os]tri potius praecepta sequatur arbitrii, ut omn[es], / qui ad hos h[on]ores transire festinant, c[u]nctas primitus civitatis 
Alcuni elementi ricordano in parte il contesto storico-sociale del sacerdotium africano del IV-V sec., già analizzato (vd. supra par. 2), e meritano di essere evidenziati: il rescritto riflette il vivace clima di competizione che caratterizza la provincia Asia anche in epoca tardoantica, una competizione per il sommo sacerdozio federale (definito honorem Asiae ac totius provinciae dignitatem) che mobilita sia le varie città della provincia (compresi i minora municipia), sia le loro ambiziose classi dirigenti;

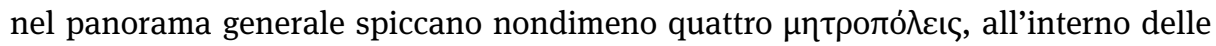
quali Efeso sembra mantenere una posizione di relativa preminenza (un documento coevo mostra la medesima competizione nella provincia Bithynia, dove le due rivali Nikomedeia e Nikaia sono entrambe metropoleis e partecipano alle cerimonie ufficiali della bithyniarchia); ${ }^{79}$ emerge infine il timore del legislatore per il fenomeno

suae restituant functiones, $u[t$ p]eractis curiae muneribus a [d h]onorem totiu[s] / provinciae debiti fabore festinent percepturi postmodum, si tamen voluerint senato[r]iam dignitatem, <ita tam>en, ut satisfacientes legi in locis s[uis] / alteros dese<r>ant substitutos. ceterum nequaquam ad commodum credimus esse iustitiae, ut expensis rebus suis laboribusque transactis / veluti novus tiro ad curiam transeat alienam, cum rectius honoribus fultus in sua debeat vivere civitate.

79 Quali erano intorno al 372 le quattuor civitates, quae metropolis apu[d] Asiam nominantur (1. 4; cfr.

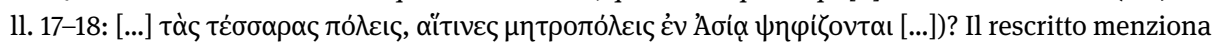

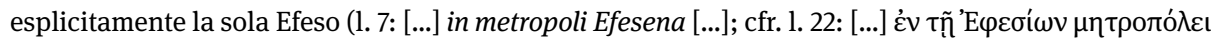
$\mu$ óvn [...]), ma dovremmo pensare che le altre tre fossero Smirne, Pergamo e probabilmente Tralles: sono queste infatti le uniche città a rientrare nei limiti territoriali della provincia Asia tardoantica tra quelle dodici della grande Asia alto-imperiale che in vari momenti, tra II e III sec., arrivarono a ottenere

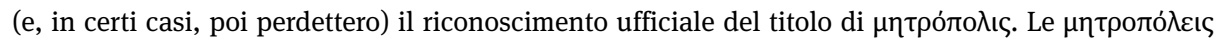
di epoca alto-imperiale, distribuite secondo la successiva appartenenza alle province tardoantiche, sono: Asia, 4 metropoli (Efeso, Pergamo, Smirne, Tralles); Phrygia, 2 metropoli (Laodikeia al Lykos, Hierapolis); Caria, 3 metropoli (Mileto, Aphrodisias, Stratonikeia); Lydia, 2 metropoli (Sardis, Philadelpheia); Hellespontus, 1 metropoli (Kyzikos). Si noti come il rescritto preveda che i notabili provenienti dalle città minori (1. 6: [...] in minoribus municipiis generatis [...]; cfr. 11. 20-21: [...] toù

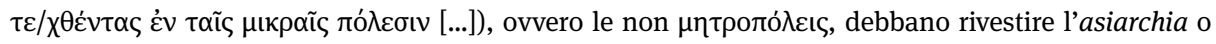
l'alytarchia necessariamente in metropoli Efesena (1. 7) e la traduzione greca sottolinei „nella sola metropoli di Efeso“ (1. 22) - in tal caso restano dunque escluse le altre tre. Una lettera di Valentiniano e Valente a Nikaia (c.a. 364-375, forse 364-367 per l'assenza del co-imperatore Graziano) conferma alla città il rango di metropolis e menziona la visita ufficiale del bithyniarches: il documento è trasmesso dagli Atti del Concilio di Calcedone (451), Actio XIV, in ACO II 1, 3, 61 [420]; cfr. MILlar 2006, 135; Destephen 2013, 218-220. Per una discussione della complessa questione del valore polisemico,

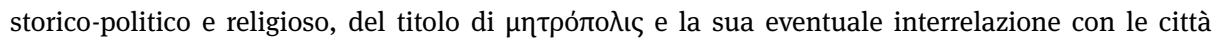

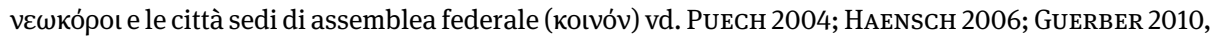
79-213. La fonte primaria per stabilire l'appartenenza amministrativa delle singole città alle rispettive province tardoantiche è il Synekdemos di Hierokles (VI sec.: cfr. JonEs 1971, 514-521 su Hierokles e Giorgio Ciprio; 522-552 per le tabelle riassuntive delle singole province). Si noti che Tralles, pur avendo ottenuto il titolo sotto Caracalla, lo aveva già perduto entro la metà del III sec. (probabilmente sotto Macrino: vd. PUECH 2004, 368, con rimandi alle fonti epigrafiche), salvo recuperarlo in seguito,

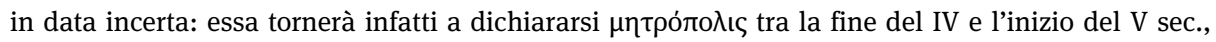

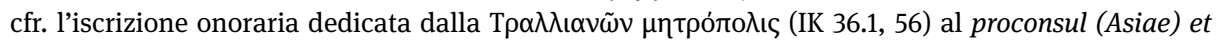
praefectus praetorio Orientis Fl(avius) Caesarius (PLRE I 171), databile c.a. 395-397 (Caesarius PPO I, 
dell'abbandono delle curiae cittadine da parte dei più ricchi notabili municipali (i primores), cui si tenta di porre un freno con la concessione di particolari privilegi giuridico-fiscali. ${ }^{80}$

In ogni caso colpisce la differenza quantitativa tra le dodici metropoli attestate

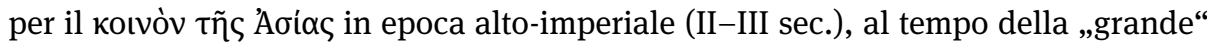
provincia Asia, e le sole quattro metropoli del kotvóv all'epoca di Valente, nella „piccola“ Asia tardoantica prodotta dal drastico ridimensionamento dioclezianeo: ${ }^{81}$ su questa significativa differenza, che attiene da un lato all'estensione della provincia romana e dall'altro alla composizione interna del koıvóv greco, e sulla tempistica delle trasformazioni giuridico-amministrative intercorse tra Diocleziano e Valente si tornerà più avanti (vd. infra par. 6.2).

\section{I sommi sacerdoti nelle „riforme religiose“ di Massimino Daia e Giuliano: sacerdozi, koıvó e provinciae nell’Asia Minore del IV sec.}

\subsection{La „riforma“ di Massimino Daia tra innovazione e restaurazione}

Le connessioni più volte riscontrate con la politica religiosa di Massimino Daia impongono di chiedersi quale fosse il ruolo giocato dalle classi dirigenti locali nella persecuzione del 311-313: le fonti cristiane attribuiscono l'iniziativa alle città d'Asia Minore e d'Oriente e ai loro rispettivi koıvó, sollecitati in tal senso (subornatis legationibus) dallo stesso Massimino e pronti a inviare petitiones, con la richiesta di autorizzare l'espulsione dei cristiani. ${ }^{82}$ Tale dato è risultato confermato dal dossier epigrafico di

cos. 397) o, meglio, 400-403 (PPO II). Per quanto fosse una città appartenente fin da epoca remota alla regione storica della Caria, al principio del IV sec. Tralles non fu ascritta alla provincia Caria, bensì all'Asia: a conferma del dato trasmesso da Hierokles vd. le iscrizioni locali in onore di tre proconsules Asiae del IV-V sec. (IK 36.1, 152 per Caelius Montius [c.a. 347-348], 44 per Flavius Magnus [c.a. 356-358], 56 per il succitato Caesarius: per un aggiornamento prosopografico sulla carriera dei

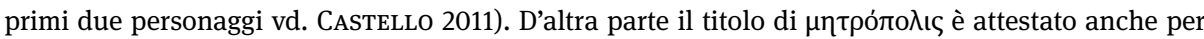
Hierapolis di Frigia già nella prima metà del III sec., come risulta da alcuni documenti epigrafici inediti, attualmente in corso di pubblicazione a cura di TulLIA RITTI, e ricompare poi nell'iscrizione di dedica a Costanzo II dal secondo ordine della frontescena del teatro, incisa a restauro completato e datata al 352 (cfr. RITTI 2006, 124-126, nr. 25, cui seguirà a breve un'edizione integrale con ampio commento in RITTI c.d.s.). Desidero ringraziare con viva sincerità TulLIA RiTTI per avermi informato di tale preziosa documentazione.

80 Sui privilegi riservati agli ex-sommi sacerdoti federali in quanto honorati vd. supra par. 2.

81 Sulle dodici metropoli di epoca alto-imperiale vd. supra n. 79.

82 Lact. mort. pers. 36,3: Redit ille [scil. Maximinus] securus et fit qualis in Syria et in Aegypto fuit. Imprimis indulgentiam Christianis communi titulo datam tollit, subornatis legationibus civitatum quae peterent, ne intra civitates suas Christianis conventicula extruere liceret, ut suasu coactus et impulsus 
Arykanda e Kolbasa, ${ }^{83}$ due comunità allora ascritte alla provincia Lycia-Pamphylia e facenti parte del koเvóv unificato dei Licii e dei Panfilii. ${ }^{84}$

facere videretur quod erat sponte facturus. Lattanzio colloca questi primi provvedimenti anti-cristiani di Massimino subito dopo l'editto di tolleranza emanato da Galerio a Serdica, con la conseguente scarcerazione dei cristiani a Nicomedia (35,1-2: 30 aprile 311), quindi la morte di Galerio (35,3-4: maggio 311), la rapida marcia di Massimino dall'Oriente alla Bitinia, con la mossa propagandistica dell'abolizione del census (36,1), e gli accordi tra Licinio e Massimino per la spartizione dei territori greco-orientali $(36,2)$. Rientrato nei suoi possedimenti (la diocesi d'Oriente), Massimino per prima cosa revoca l'editto di Galerio. Sulle petitiones delle città e i rescripta di Massimino vd. Eus. HE 9,2; 9,4,2; 9,7,1-2;9,7,11-14 (rescritto a Tyros); cfr. CASTRITIUs 1969, 48-62.

83 Iscrizione di Arykanda (Aykiriçay): CIL III $12132=13625 \mathrm{~b}=$ OGIS $569=$ TAM II.3, 785 = GRÉGoIRE 1922, 95-97, nr. 282 = SEG 38, 1443 = MITCHELL 1988, 110-111 = AE 1988, 1047 = AE 1995, $38=$ IK 48, $12=$ HD009581. Iscrizione di Kolbasa (Kuşbaba): Mitchell 1988, 108-109 = AE 1988, 1046 = AE 1995, $38=$ HD009578 = HORSLEY 2007, 240-243, nr. 338. Per entrambi i documenti vd. la messa a punto di ARENA 2008. L'iscrizione di Kolbasa riporta il rescritto latino di Massimino Colbassensibus (subscriptio, 1. 16), emesso a Sardis il 6 aprile 312, in risposta a una petitio di Kolbasa non conservata. L'iscrizione di Arykanda trasmette la parte finale del medesimo testo latino di Massimino, privo però di subscriptio, seguito dalla petitio (in greco) indirizzata agli imperatori Massimino, Costantino e Licinio dall' $\varepsilon$ $\theta$ vo

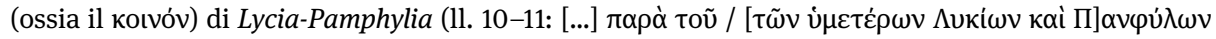

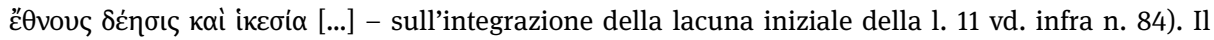
fatto che i rescritti di Massimino, indirizzati a singole città oppure a interi kotvó, riproducessero un medesimo testo standard, è dimostrato dal confronto con il rescritto alla città di Tyros, capitale della provincia Phoenice, trasmesso in versione greca da Eus. HE 9,7,11-14. Massimino acconsentiva alle richieste avanzate dalle petitiones, autorizzando le comunità a espellere i cristiani dal proprio territorio e promettendo come ricompensa generose concessioni (probabilmente esenzioni fiscali relative al census: vd. supra n. 82; cfr. ARENA 2008).

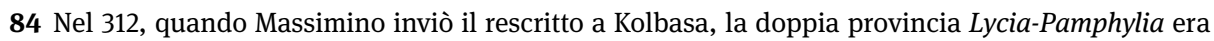
ancora indivisa, come è attestato da Cod. Theod. 13,10,2 (Idem A. [in realtà non Costantino, bensì Massimino o Licinio] ad Eusebium v.p. praesidem Lyciae et Pamfyliae: [senza luogo], $1^{\circ}$ giugno 313; vd. infra n. 90), che sembra doversi attribuire proprio a Massimino (sulla datazione e l'attribuzione della costituzione vd. ARENA 2008; cfr. MirAnda De MARTino 2014, 75). La Lycia-Pamphylia sarà suddivisa in due province intorno alla metà del IV sec. al più tardi (ma forse lo era già nel 324/325, come sembrerebbe potersi dedurre dalle sottoscrizioni del Concilio di Nicea e dal Laterculus Veronensis: per il problema cronologico legato all'interpretazione delle fonti cfr. BARNES 1982, 156, 219; IK 43, pp. 134135 [J. Nollé]): Arykanda verrà allora a trovarsi nella provincia Lycia, Kolbasa invece nella Pamphylia (fonte Hierokles: vd. supra n. 79). Il fatto che Arykanda si trovasse nella „sub-provincia“ licia della

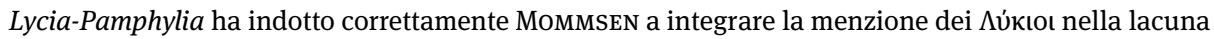

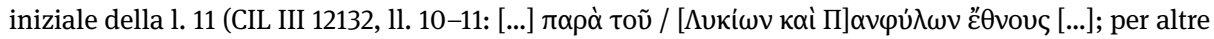

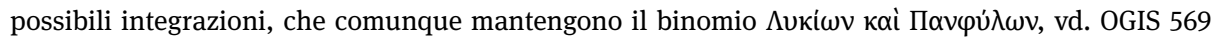
con il commento di H. DeSSAU; SEG 38, 1443 [D. FeISSEL - K.A. WoRP]; IK 48, 12 [S. Şahin]): in questo periodo Licii e Panfilii prendevano dunque parte a un solo kotvóv unificato, che nel 312 aveva inviato una petitio ufficiale a Massimino. Tale elemento risulta innovativo rispetto al passato e va considerato con particolare attenzione: in epoca alto-imperiale Licii e Panfilii, pur trovandosi accomunati entro la cornice giuridico-amministrativa di una sola doppia provincia (come ancora avveniva nel 312-313, nonostante la generale tendenza al ridimensionamento delle province nel grande riordino amministrativo di epoca dioclezianea), avevano mantenuto l'organizzazione interna in due kotvó ben 
Per quanto riguarda l'aspetto più propriamente religioso di questa restaurazione dei culti tradizionali, Lattanzio osserva che Massimino, novo more, volle nominare i sommi sacerdoti del culto imperiale in ogni città (novo more sacerdotes maximos per singulas civitates singulos ex primoribus fecit), reclutandoli tra i primores, facendoli assistere dai veteres sacerdotes e incaricandoli della repressione anti-cristiana; al di sopra di questi sommi sacerdoti civici erano posti infine, per ogni provincia, i sommi sacerdoti federali, selezionati tra i notabili di più alto rango (etiam provinciis ex altiore dignitatis gradu singulos quasi pontifices superponeret). ${ }^{85}$

distinti, uno per i Licii e un altro per i Panfilii (cfr. Vitale 2012, 263-290; Vitale 2014); tale distinzione per etnie rimase infatti in vigore quando, all'inizio del regno di Vespasiano (c.a. 70-71), venne istituita la Lycia-Pamphylia (con l'attribuzione della regione panfilia alla pre-esistente provincia Lycia, redatta nel 43: cfr. ADAK/WiLson 2012; CAMPANILE 2015). Ancora sotto l'imperatore Tacito (275-276)

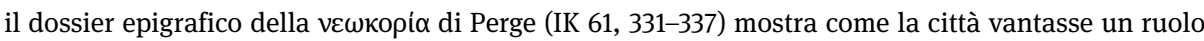
di preminenza all'interno del koıvóv di Panfilia. Quando si passò dunque dai due kotvó separati a un solo kotvóv unificato? Tale importante provvedimento amministrativo, già attestato nel 312, dovrà collocarsi sotto Diocleziano (283-305), Galerio (305-311) oppure Massimino (311-313): pur non avendo dati positivi per restringere il campo cronologico, sembrerebbe plausibile ipotizzare che l'unificazione dei koเvó fosse, in qualche modo, legata alla „riforma religiosa“ (politico-amministrativa e religiosa) di Massimino, nella quale il sommo sacerdozio federale, restituito in ogni provincia, avrebbe avuto un ruolo fondamentale. Nella seconda metà del IV sec., insieme allo sdoppiamento della provincia Lycia-Pamphylia (o dopo di esso), sembra che tornassero a dividersi anche i due kotvó: un riferimento al кoเvóv dei Licii pare riscontrabile nella costituzione Cod. Theod. 9,38,9 (Impp. Arcadius et Honorius AA. ad Caesarium PPO: Costantinopoli, 31 agosto 396), con cui Arcadio abrogava un precedente provvedimento del padre Teodosio, volto a punire i Lycii con la privazione di honores e dignitates e databile al 392, subito dopo la caduta in disgrazia del praefectus praetorio Orientis di origine licia, Flavius Eutolmios Tatianos (vd. MecelLa 2015; cfr. supra n. 55). Da ultimo, un'iscrizione onoraria di Limyra (Lycia) per Teodosio Seniore, padre dell'imperatore, risulta dedicata dalla provincia Lycia, ossia dall'assemblea federale dei Licii : il suo editore, MichaEL WöRRLE, ha proposto di datarla c.a. 384-387, cfr. FEISSEL-WöRRLE 2015, 271.

85 Lact. mort. pers. 36,4-6: 4. Quibus annuens novo more sacerdotes maximos per singulas civitates singulos ex primoribus fecit, qui et sacrificia per omnes deos suos cotidie facerent et veterum sacerdotum ministerio subnixi darent operam, $<$ ut $>$ Christiani neque <conventicula $>$ fabricarent neque publice aut privatim coirent, sed comprehensos suo iure ad sacrificia cogerent vel iudicibus offerrent. 5. Parumque hoc fuit, nisi etiam provinciis ex altiore dignitatis gradu singulos quasi pontifices superponeret, et eos utrosque candidis clamidibus ornatos iussit incedere. 6. Facere autem parabat quae iam dudum in

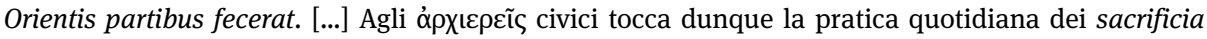
consacrati a tutte le divinità e viene inoltre espressamente demandato il compito di individuare e reprimere le comunità cristiane, arrestandone gli adepti per poi costringerli a compiere i sacrificia oppure per consegnarli ai tribunali dei governatori provinciali. Per svolgere questo non facile ufficio di polizia, potranno avvalersi della collaborazione degli altri sacerdoti municipali (i cosiddetti veteres sacerdotes, „vecchi“ nel senso di „tradizionali/ancestrali“, ma anche con una sfumatura semantica che li contrappone volutamente al novus mos di azione/competenza che caratterizza

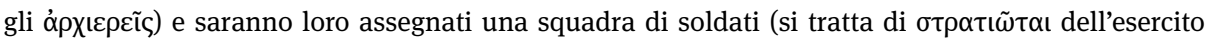
imperiale, non di gendarmi municipali) e una scorta di guardie del corpo (come attesta Eusebio: $\mu \varepsilon \tau \grave{\alpha}$

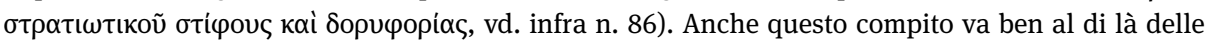


Eusebio parla, più sinteticamente, della ricostruzione dei templi e della nomina di „sacerdoti degli idoli“ in ogni luogo e città e, al di sopra di essi, di un sommo sacer-

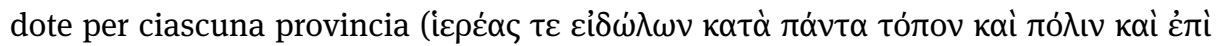

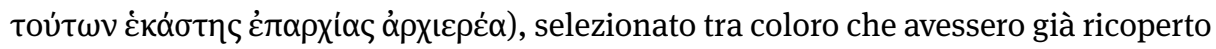

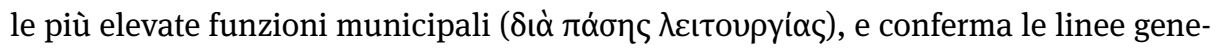
rali di tale assunto. ${ }^{86}$ Allo stesso modo StePhen Mitchell ha richiamato un suggestivo brano della Vita di san Theodotos di Ankyra, in cui il praeses Galatiae Theoteknos invita il martire cristiano Theodotos all'apostasia e gli propone di diventare

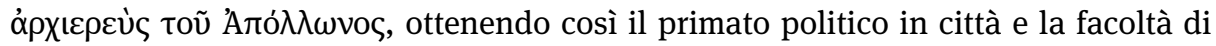

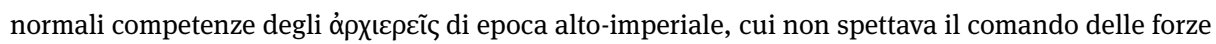

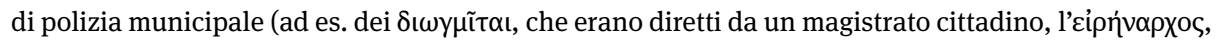
come avviene durante l'arresto del vescovo Policarpo di Smirne nel Martyrium Polycarpi 6-7: cfr.

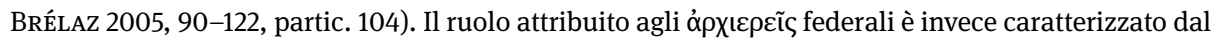
termine di paragone quasi pontifices, che sembra riferirsi a una funzione di supervisione generale sui culti, analoga a quella esercitata in Roma (e nelle colonie romane) dal collegio pontificale, custode e garante delle norme rituali. Sarebbe questo un dato nuovo: non risulta infatti che in precedenza

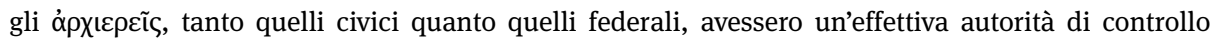
sugli altri culti e sacerdozi municipali. Tale gerarchizzazione dei sacerdozi, in cui un ruolo apicale direttivo sia conferito al sommo sacerdozio del culto imperiale, sembrerebbe dunque un'innovazione peculiare del programma religioso ideato da Massimino. Lattanzio conclude affermando che, con tali provvedimenti preliminari, Massimino si preparava a scatenare un'aperta persecuzione in Asia Minore, come già aveva fatto in Oriente (Siria-Palestina ed Egitto).

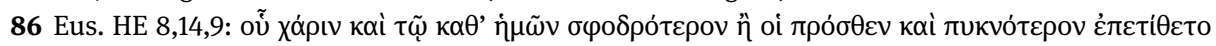

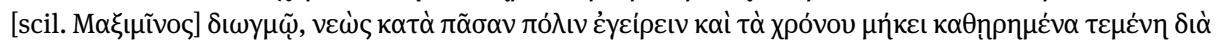

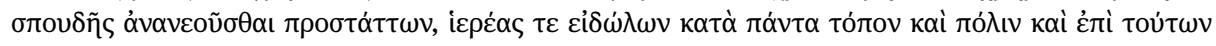

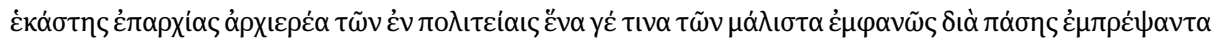

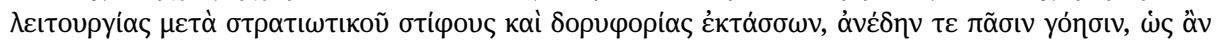

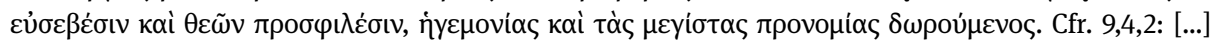

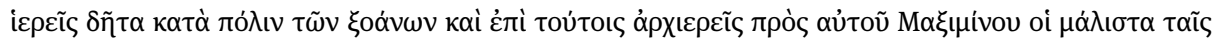

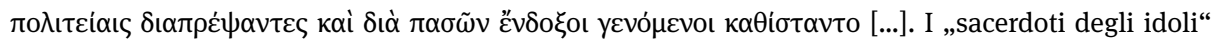

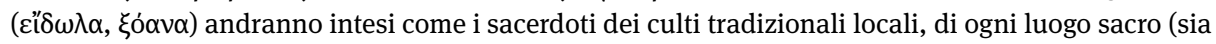
urbano che extra-urbano): sotto questo profilo essi costituiscono il parallelo eusebiano dei veteres sacerdotes lattanziani. Eusebio invece non parla espressamente dei sommi sacerdoti civici del culto imperiale (definiti da Lattanzio sacerdotes maximos per singulas civitates), a meno che non si riferisca

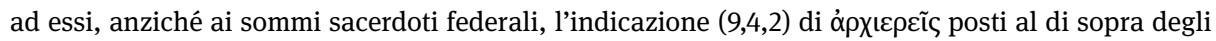

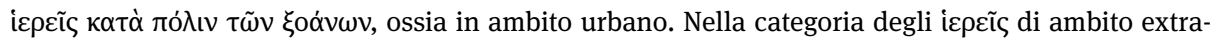
urbano (ad es. presso i grandi e piccoli santuari rurali) può essere annoverato lo ícęúc Aebutius Flaccus Apphianos, attivo presso i Motaleis (vd. supra par. 5). Eusebio riferisce d'altra parte degli

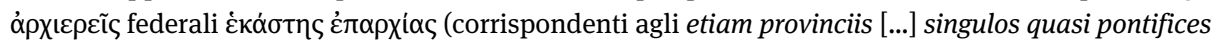
di Lattanzio); le fonti cristiane sono concordi sull'appartenenza di questi sommi sacerdoti allo strato più elevato e influente delle classi dirigenti cittadine (ex primoribus / ex altiore dignitatis gradu / $\tau \tilde{\omega} v$

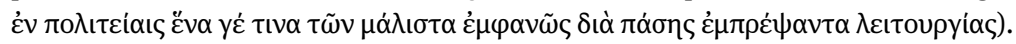


sovrintendere all'elezione dei sacerdoti e di rappresentare la patria presso i governatori e gli imperatori. ${ }^{87}$

Ma l'espressione lattanziana che ha suscitato maggiore interesse nella storia degli studi è novo more (Lact. mort. 36,4), „secondo una nuova usanza“, in cui l'aggettivo novus esprime, in negativo, l'anomala difformità rispetto a una tradizione consolidata: per questo motivo quasi tutti gli studiosi hanno interpretato il passo come attestazione di una cosiddetta „riforma religiosa“ varata da Massimino Daia. ${ }^{88}$ Tale interpretazione è stata però recentemente rigettata da Nicole BELAYCHE, che, richiamando vari esempi epigrafici di dignitari del culto imperiale di epoca precedente (I-III sec.), ha dimostrato da un lato, giustamente, che né gli Äávoto di Akmoneia né tantomeno i Sempronii Auruncii di Stratonikeia, talora ricordati come casi esemplari di sacerdoti impegnati nella persecuzione anti-cristiana, sono di per sé identificabili con i sommi sacerdoti federali, introdotti etiam provinciis da Massimino. Dall'altro lato però, esprimendo un giudizio di sostanziale scetticismo sulle fonti cristiane, ha preferito concludere, in maniera alquanto drastica, che non vi sarebbe stata alcuna novità nelle misure prese dal tetrarca e che la presunta „riforma“ non sarebbe altro che un mito storiografico. ${ }^{89}$

In realtà i resoconti di Lattanzio ed Eusebio, pur essendo ideologicamente orientati in senso avverso a Massimino, sembrano potersi integrare e confermare a vicenda,

87 Esortazione di Theoteknos a Theodotos in Vita S. Theodoti Ancyrani 26: [...] a̋p

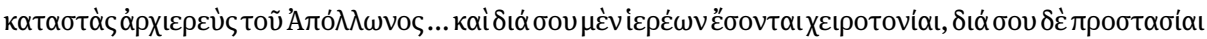

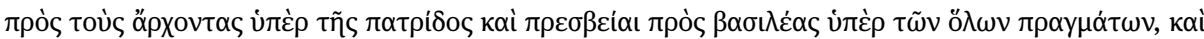

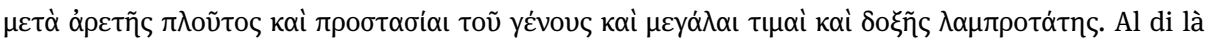
di un problema testuale di tipo filologico (una lacuna?), il sommo sacerdozio compare qui associato al culto di Apollo, mostrando un intreccio che può spiegarsi alla luce dell'introduzione del culto dei sovrani presso i luoghi sacri tradizionali in epoca tetrarchica (i Tetrarchi diventano oúvvooı $\theta \varepsilon o i$ delle antiche divinità: vd. supra n. 13), ad es. presso il tempio A di Laodikeia, intitolato ad Apollo e Artemide (vd. supra n. 60). La descrizione delle competenze politiche dell'ỏpxıєpєús nella Vita $S$. Theodoti suggerisce che debba trattarsi di un sommo sacerdote del culto imperiale, probabilmente di livello federale a giudicare dal ruolo di rappresentante degli interessi generali della provincia presso governatori e imperatori. Sul brano cfr. Mitchell 1982, 108-109; Mitchell 1988, 118, che identifica il praeses Galatiae Theoteknos (PLRE I 908, Theotecnus 1) con l'omonimo curator rei publicae di Antiochia di Siria e poi governatore provinciale (PLRE I 908, Theotecnus 2), che ebbe un ruolo organizzativo fondamentale nella persecuzione di Massimino.

88 „Riforma religiosa“ di Massimino: CASTRItiUs 1969; GRANT 1975; Mitchell 1982; Mitchell 1988; NichOLSON 1994. Per la storia degli studi sulla questione (da Tillemont ai contributi più recenti) cfr. BELAYCHE 2011, 236-239.

89 Belayche 2011. Si noti tuttavia che i Sempronii Auruncii, pur dichiarando di essere discendenti

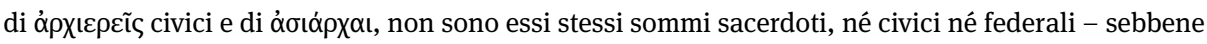
avessero accolto con munificenza l'esercito di Massimino a Stratonikeia, non furono gratificati, a

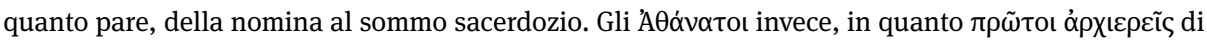
Akmoneia, potrebbero essere stati, in effetti, tra quei sommi sacerdoti civici nominati (o confermati) da Massimino per singulas civitates. 
fornendo un quadro attendibile del contesto storico: da una parte essi rivelano alcuni significativi elementi di continuità tra gli indirizzi religiosi di Massimino e quelli dei Tetrarchi, specialmente di Diocleziano, in particolare la cura nel restaurare i templi caduti in rovina e nel rinvigorire sacerdozi e culti ancestrali pagani, sia in contesti urbani che rurali - questi aspetti religiosi della restauratio imperii dioclezianea, in cui il culto dei sovrani si innesta nella dimensione locale dei culti tradizionali, dando loro nuova linfa vitale, trovano ampio riscontro nella documentazione epigrafica, sia africana che greco-orientale, basti ricordare i casi emblematici dei sacerdotes Modestii di Thubursicu (vd. supra par. 2) e dello íعрús Aebutius Flaccus Apphianos presso i Motaleis (vd. supra par. 5).

Il programma politico-religioso di Massimino intendeva dunque reinsediare, ridinamizzare (redynamiser, per usare un termine adottato dalla BELAYCHE, che sembra molto appropriato al caso) e al contempo, aggiungerei, rifunzionalizzare tre categorie di sacerdozi, ponendole in una nuova interrelazione gerarchica: a) i sacerdoti delle divinità locali, in ogni luogo sacro di ambito urbano o extra-urbano; b) i sommi sacerdoti civici del culto imperiale, in ogni città; c) i sommi sacerdoti federali del culto imperiale, per ciascuna provincia tardoantica. In tale cornice al sommo sacerdozio del culto imperiale veniva attribuita una funzione catalizzatrice e direttiva.

La questione terminologica non è priva di effettivo significato storico e riguarda l'applicazione del concetto di „riforma“ in campo religioso al mondo tardoantico, un mondo certamente diverso dall'Europa del Cinquecento. „Riforma“ dovrà intendersi, nel caso di Massimino, prevalentemente come „rivoluzione“ o „restaurazione“? Il linguaggio adottato dalle fonti antiche risente senza dubbio del diverso orientamento ideologico di ciascuna: l'ostile Lattanzio (novo more) condanna la politica religiosa di Massimino, connotandola in senso negativamente rivoluzionario; al contrario, dal punto di vista dello stesso imperatore, la sua opera non sarà stata altro che la legittima prosecuzione della grandiosa restauratio inaugurata dal dominus et parens noster Diocleziano..$^{90}$ Per quanto riguarda la storiografia dei moderni, può essere utile ricordare, come termine di paragone, la valutazione data da SANTO MAZZARINo sulla politica religiosa e, insieme, sulla politica socio-economica dei due personaggi che maggiormente hanno caratterizzato il IV secolo con le sue intrinseche contraddizioni:

90 L'eco di tale richiamo all'exemplum legittimante di Diocleziano, ancor vivo seppure ritiratosi dalla vita politica attiva, è riscontrabile nel provvedimento sull'esenzione dei Licii-Panfilii dal census, datato al 313, che deve attribuirsi allo stesso Massimino (Cod. Theod. 13,10,2 [vd. supra n. 84]): plebs urbana, sicut in orientalibus quoque provinciis observatur, minime in censibus pro capitatione sua conveniatur, sed iuxta hanc iussionem nostram inmunis habeatur, sicuti etiam sub domino et parente nostro Diocletiano seniore Augusto eadem plebs urbana inmunis fuerat. Si ricordi come il tempio (ri)costruito presso i Motaleis dal sacerdote Aebutius Flaccus Apphianos nel 313 (durante il dominio di Massimino sull'Asia Minore) fosse significativamente dedicato ai primi Augusti e fondatori della tetrarchia, ovvero a Diocleziano, vivente, e al divus Massimiano (vd. supra n. 57 Sui termini riforma, restaurazione e reazione nella panegiristica di V sec. vd. DESTEPHEN 2015.). 
il „rivoluzionario“ Costantino e il „restauratore“ (di spiriti dioclezianei, ma non privo di idee innovative) Giuliano. ${ }^{91}$ E proprio alla restauratio di Giuliano, contro alcune interpretazioni in chiave „reazionaria“, MARIO MAZZA ha giustamente riconosciuto una prospettiva politica „riformatrice“ .92

In ogni caso, diversamente dalla BELAYCHE, penserei che l'elemento innovativo all'interno del programma di restaurazione politico-religiosa di Massimino potrebbe

91 MAZZARINo 1962, 666-668: „Costantino non limitò la sua rivoluzione al campo religioso. [...] ruppe i legami con tutta la tradizionale economia monetaria del principato. Diocleziano era ancora legato alla tradizione monetaria del III secolo: egli aveva difeso il denarius, ormai moneta divisionale a corso forzoso; [...] Costantino trasse le conclusioni del tentativo dioclezianeo, ma con una mentalità del tutto nuova. Se si voleva fondare il sistema monetario sulla solida base della moneta di metallo pregiato, bisognava (ed era in ciò la novità rivoluzionaria) abbandonare la moneta divisionale al suo destino: essa avrebbe avuto non il valore che lo Stato le attribuiva, che Diocleziano aveva disperatamente difeso nel suo edictum de pretiis - ma piuttosto il valore reale che il suo rame aveva, nel mercato, in rapporto con l'oro. [...] Poche volte, nella storia dell'Occidente, si è compiuta una rivoluzione economica così radicale. [...] Con Costantino tutto ciò scompare: l'imperatore rivoluzionario abdica alla difesa del denarius; d'ora in poi, la vita economica sarà dominata dall'effettivo rapporto tra il solidus aureo e la moneta divisionale. Crolla il potere di acquisto del denario di rame, crollano la piccolissima borghesia e il proletariato. Si crea una nuova società, in cui i detentori di oro, unici, possono effettivamente controllare la vita dello Stato; i detentori della moneta di rame sono rovinati“. A proposito di Giuliano, Mazzarino (713) parla di: ,[...] un tipico richiamo alla tradizione giuridica romana (auctoritas), che egli sempre contrapponeva alla tendenza rivoluzionaria della legislazione di Costantino [...]“. E ancora, 714-715: „,...] la sua politica religiosa reazionaria era destinata ad un grave insuccesso [...]. Ma anche in questo caso, bisogna tener presente, com’è noto, che Giuliano ha cercato di restaurare il paganesimo in forme nuove, con una gerarchizzazione dei sacerdoti che in certo modo voleva imitare l'organizzazione gerarchica della chiesa cristiana. [...] Voleva essere un paganesimo nuovo, adatto alla diffusione tra le masse, ma sempre percorso dall'antico spirito ellenista“; 724725: „Con l'impresa persiana, anche la sua politica religiosa era fallita. [...] Restava la sua politica economica: non per il suo estremo tentativo di sostituire il calcolo nella moneta divisionale (la 'sua' siliqua, moneta della povera gente) al calcolo in solidi, moneta di Costantino; ma per il suo generale indirizzo di deflazione e riduzione dei prezzi. Questo è il duplice volto della sua grandiosa personalità: aristocratica nel ritorno alla religione e alla cultura degli Elleni ('ellenismo'), ma conscia dell'importanza degli umili e degli oppressi nella conservazione della res publica. Egli, l'eroe della res publica, e Costantino, l'imperatore isoapostolo di cui avversava la memoria, sono i dominatori del quarto secolo. La antitesi fra il nipote e lo zio è la chiave per intendere la storia dell'impero romano“. 92 MAzZA 1986, 49, n. 15; 51-53: „È fondamentalmente sbagliato, e sostanzialmente antistorico, considerare Giuliano un 'restauratore', un 'reazionario' che vuole riportare indietro le lancette di un preteso orologio della storia [...]; è un errore che sorge dalla nostra prospettiva di moderni, che sappiamo, o pretendiamo di sapere, come sarebbero andate le cose [...] e che siamo abituati, nel nostro inveterato storicismo, a giustificare il già avvenuto in quanto puramente avvenuto. $\grave{E}$ questa distorsione prospettica che rende tanto difficile il giudizio su Giuliano. In realtà Giuliano è il difensore di un sistema di valori culturali, religiosi e politici, ed insieme delle strutture economiche ad essi correlati. Può essere utile adesso smettere la moda, tra positivisti confessionali e neostoricisti pragmatici, di insistere sul conservatorismo e sul tradizionalismo di Giuliano. [...] Ciò su cui preme insistere [...] è appunto sull'originalità e sulla complessità di questo programma politico e culturale e la sua organica connessione con la filosofia religiosa dell'epoca“. 
riconoscersi proprio nella decisa volontà di nominare direttamente, dall'alto, quei sommi sacerdoti che erano abitualmente eletti „dal basso“, ossia dalle singole città e dagli organismi federali, e di conferire loro un'autorità di controllo, fino ad allora inedita, sulla dimensione locale e provinciale. ${ }^{93}$ Per quanto attiene alle procedure formali, giuridico-amministrative, questo sembrerebbe un tentativo autocratico di trasformare i dignitari civici e federali in funzionari imperiali, selezionati tra i notabili più affidabili e leali, e imposti dall'autorità centrale alle varie comunità. E un secondo fattore di innovazione potrebbe intravedersi nell'espressione „per ciascuna provin-

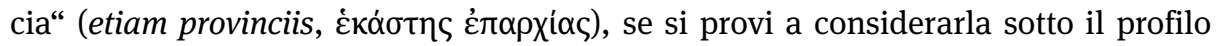
giuridico-amministrativo, tenendo conto delle specifiche relazioni intercorrenti tra $\mathrm{i}$ кoเvó e le provinciae tardoantiche nell'ordinamento territoriale dioclezianeo. ${ }^{94}$

\subsection{Aotópx $\alpha$ t fuori dalla provincia Asia: Euethios di Laodikeia e Makarios di Mileto}

Per quest'ultimo ragionamento si può prendere spunto da un pregevole monumento funerario conservato nel Museo Archeologico di Denizli-Hierapolis: un grande sarcofago marmoreo a colonnette del tipo Sidamara, databile approssimativamente alla metà del III sec. e proveniente dalla Necropoli Ovest di Laodikeia al Lykos. ${ }^{95}$ Il sarcofago ha un coperchio a forma di k $\lambda$ ívn, sul cui materasso è adagiata una coppia di sposi, e non presenta una sua iscrizione funeraria originaria, ma sul bordo del materasso, in una posizione non predisposta all'incisione e pertanto in un momento successivo alla prima utilizzazione del sarcofago stesso, è stata graffita una linea di scrit-

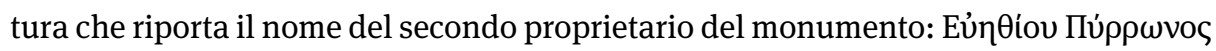

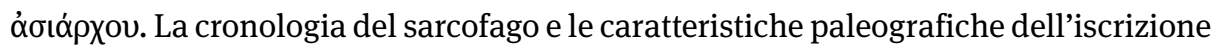

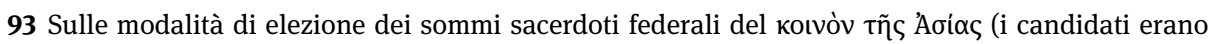

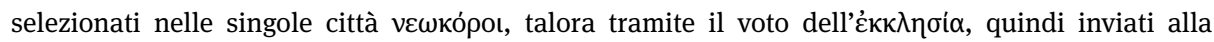

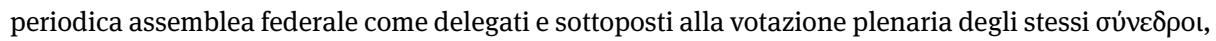
per poi essere assegnati ai vari templi federali del culto imperiale) vd. Campanile 1994b. Per le differenze procedurali in ambito federale tra epoca alto-imperiale e Tarda Antichità cfr. LARSEN 1955, 106-161. La procedura di elezione e/o designazione dei sommi sacerdoti civici non è altrettanto chiara (vd. FrIJA 2012, 76-82), ma si può supporre che, come avveniva per l'attribuzione di altre importanti magistrature e sacerdozi di ambito cittadino, vi avesse un ruolo attivo (variamente da città a città)

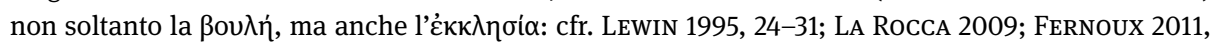
347-388.

94 In questo senso vd. NichoLson 1994, 9: „It is not impossible that one of Maximinus' motives was to introduce a new system of priesthoods which he considered better adapted to the administrative structure devised by Diocletian“; SCROFANI 2005, 204.

95 Sarcofago a colonnette da Laodikeia: ŞIMŞEK 1997; cfr. ŞıMŞEK 2007, 317-319.
} 
suggeriscono una datazione tarda, certamente non anteriore alla fine del III sec., ma che potrebbe, ugualmente, collocarsi più avanti nel corso del IV sec. ${ }^{96}$

L'áoı́ápxns Euethios figlio di Pyrrhon non è sfuggito al recente aggiornamento di Domitilla Campanile, che ha proposto un parallelo onomastico databile all'ultimo quarto del III sec., ${ }^{97}$ ma per un'epoca successiva si può ricordare, come esempio ancor più attinente, una dedica votiva cristiana da Attouda (Hisarköy, Phrygia I), città non lontana da Laodikeia, in cui compare una coppia di $\lambda \alpha \mu \pi \rho o ́ \tau \alpha \tau o$ (clarissimi), Euethios e Theodora, databili al IV-V sec. - quest'ultimo Euethios, senatore,

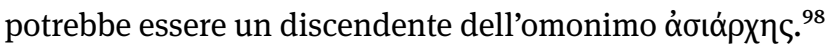

Si sono già discussi i casi di sacerdoti locali di Hierapolis (Aebutius Flaccus Apphianos) e Stratonikeia (i Sempronii Auruncii), che vantavano una discendenza da varie generazioni di sommi sacerdoti federali d'Asia, pur provenendo da città che non facevano più parte, da lungo tempo, della provincia Asia: a maggior ragione

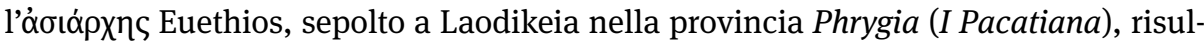
terebbe fuori contesto rispetto alla provincia Asia per come essa ormai si configurava nel IV sec., dopo il riassetto dioclezianeo.

Un altro caso assai interessante, relativo alla provincia Caria, mostra l'attività

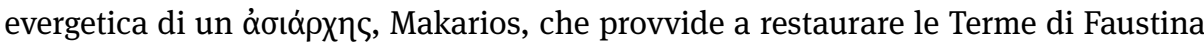
a Mileto: un prezioso dossier epigrafico, costituito da quattro epigrammi celebrativi e affiancato da altre iscrizioni metriche contestuali, dichiara che la generosa iniziativa di Makarios, intrapresa insieme alla moglie Eucharia in ottemperanza della promessa

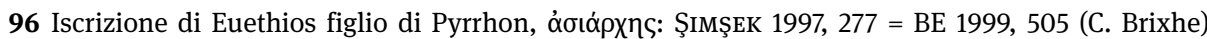

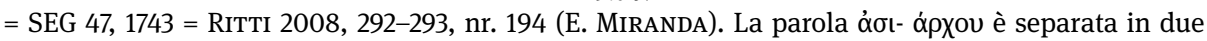
parti, essendo stata incisa, per ragioni di spazio disponibile, ai lati della mano della defunta. Si noti come l'editrice più recente del documento, ElENA Miranda, abbia espresso un motivo di perplessità riguardo al titolo di óoıópxns (p. 292): [...] in epoca tarda la provincia [Asia] fu smembrata in più parti; di conseguenza la citazione del titolo di asiarca fa dubitare della genuinità dell'epigrafe. Proprio questo documento, unitamente ad altri, farebbe piuttosto dubitare della premessa del ragionamento, ossia che lo smembramento della provincia in epoca dioclezianea avrebbe dovuto necessariamente

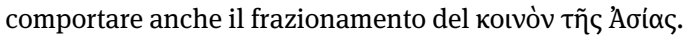

97 L'óotópxnৎ Euethios: CAMPANILE 2006, 538, nr. 211, che nota la relativa rarità del nome Euethios e ipotizza un qualche legame con Valerius Euethios, che intorno al 282/283 (sotto Caro, Carino e Numeriano) compare come ह̌ di Ovacık, relativo a problemi di brigantaggio nell'area di Termessos di Pisidia (cfr. BRÉLAz 2005, 308-319, partic. 312-313); costui potrebbe forse identificarsi con l'omonimo funzionario di epoca tetrarchica, Valerius Euethios (PLRE I 291), attestato come rationalis Aegypti c.a. 302-304. Si noti però come l'áoı́́pxๆৎ di Laodikeia non rechi il gentilizio Valerius (o, comunque, non abbia sentito la necessità di metterlo in evidenza).

98 Stele marmorea di Attouda con ex voto contrassegnato da croci: MAMA VI 86 (Pl. 16) = PH257919:

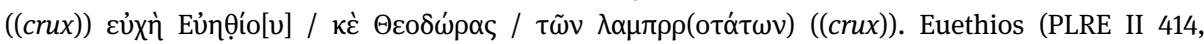
Euethius 2) e Theodora (PLRE II 1085, Theodora 5) sono datati ipoteticamente al V sec. dagli editori della PLRE. 


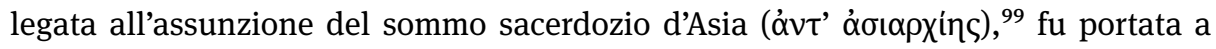
termine dal „dispensatore di giustizia“ ( Tatianos; ${ }^{100}$ un ulteriore restauro sarebbe stato effettuato, circa cent'anni più tardi, da un ricco benefattore locale, Hesychios figlio di Hesychios. ${ }^{101}$ Nella storia degli studi ai

99 Dossier epigrafico di Makarios dalle Terme di Faustina (quattro epigrammi: a-d): IvMilet I.9, 339 (A. Rehm) = PH252540; RoBERT 1948, 129, 134; IvMilet VI.1, pp. 112-114, 212-213 (P. Herrmann); SGO I nr. 01/20/16. Makarios è celebrato in ciascuno dei quattro epigrammi: a) il testo, frammentario nelle prime linee, si conclude ricordando che Makarios ha rinnovato le terme in contraccambio

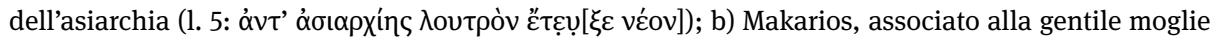
Eucharia, in contraccambio dell'asiarchia ha donato un sommo motivo di orgoglio alla città (1. 4: ơv '’

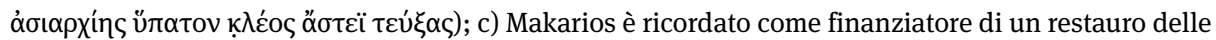

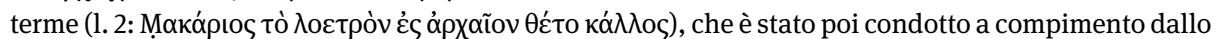

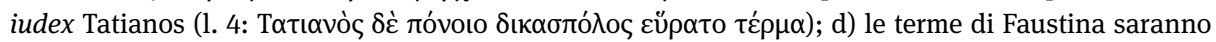
chiamate d'ora in poi terme di Makarios.

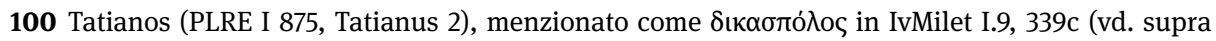
n. 99), è celebrato anche da un altro epigramma dalle Terme di Faustina: IvMilet I.9, 340 (A. Rehm); IvMilet VI.1, pp. 114, 213 (P. Herrmann); SGO I, nr. 01/20/17. Il suo ruolo di „dispensatore di giustizia“ è stato correttamente interpretato come governatore di Caria dagli editori della PLRE e datato probabilmente al IV sec.: la cronologia del personaggio può ulteriormente restringersi se si accetta l'identificazione, assai verosimile, con Antonius Tatianos, governatore di Caria di rango clarissimus

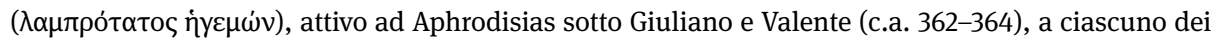
quali dedica una statua onoraria (per Giuliano, c.a. 362-363: Ala2004, 20 = PH257540 = ConTI 2004, nr. 33 = IAph2007, 8.405 = CoNTI 2004, nr. 33; per Valente: Ala2004, 21 = PH257541 = IAph2007, 8.406). Charlotte Roueché (Ala2004, comm. III.11-15) ha notato come Antonius Tatianos sia il primo governatore di rango clarissimus attestato per la Caria: il suo predecessore, forse diretto, Flavius Quintilius Eros Monaxios (c.a. 359-360) infatti è ancora un vir perfectissimus (cfr. supra n. 54). Il governatore Tatianos delle Terme di Faustina non può invece essere identificato con il praeses Cariae Tatianos (PLRE II 1053-1054, Tatianus 1; cfr. RouechÉ in Ala2004, comm. IV.8-15), attestato nella prima metà del V sec. ad Aphrodisias, dove restituì una statua onoraria per il nonno Flavius Eutolmios Tatianos (caduto in disgrazia nel 392: cfr. supra nn. 55 e 84), apponendovi un epigramma celebrativo (Ala2004, 37 = IAph2007, 5.218 = SGO I nr. 02/09/24). Se dunque il praeses Cariae (Antonius) Tatianos

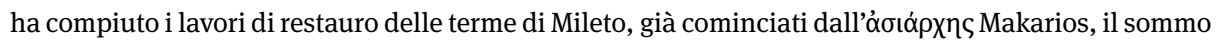
sacerdozio federale di quest'ultimo dovrebbe datarsi poco prima del governatorato di Tatianos, forse negli ultimi anni di Costanzo II (c.a. 359-360).

101 Il notabile milesio Hesychios figlio di Hesychios (PLRE I 429, Hesychius 3), advocatus, è stato datato genericamente tra IV e V sec. dagli editori della PLRE. La sua attività di restauro delle Terme di Faustina è attestata da tre epigrammi celebrativi: 1) IvMilet I.9, 341 (A. Rehm); RoBERT 1948, 129, 134; IvMilet VI.1, pp. 117, 213 (P. Herrmann); SGO I nr. 01/20/19; 2) IvMilet I.9, 342 (A. Rehm); IvMilet VI.1, pp. 117, 213 (P. Herrmann); SGO I nr. 01/20/18; 3) IvMilet I.9, 343 (A. Rehm); IvMilet VI.1, pp. 117, 213-214 (P. Herrmann); SGO I nr. 01/20/20. Il primo epigramma contiene i dati biografici e cronologici salienti: l'omonimia con il padre, il ruolo come advocatus presso l'ufficio del prefetto del pretorio, il titolo di $\varphi$ í $\lambda$ oৎ dell'imperatore, il fatto di aver provveduto, grazie a un finanziamento imperiale, al restauro delle terme dopo un periodo di cent'anni (dal precedente restauro?). Egli potrebbe essere identificato con l'advocatus milesio Hesychios (PLRE II 555, Hesychius 13), databile tra la seconda metà del V e l'inizio del VI sec.: costui fu marito di Philosophia (PLRE II 878) e padre dello storico

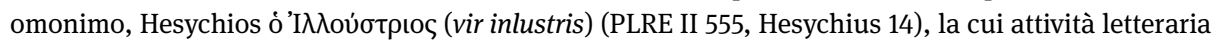


molti indizi, paleografici, contenutistici e prosopografici, che suggeriscono di considerare i primi due personaggi come contemporanei e di porre entrambi nel corso del IV sec. (probabilmente in epoca giulianea) e il terzo nella seconda metà del V sec., si è spesso opposto il pregiudizio secondo cui Makarios dovrebbe necessariamente collocarsi nella seconda metà del III sec., prima della riorganizzazione territoriale dioclezianea $^{102}$ (ma, seguendo coerentemente tale ragionamento, bisognerebbe risalire alla prima metà del III sec., ossia prima della fondazione della provincia Phrygia-Caria) -

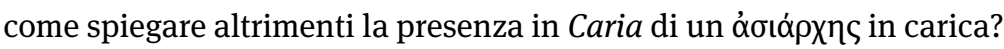

In realtà la questione potrebbe spiegarsi, più semplicemente, ipotizzando che il

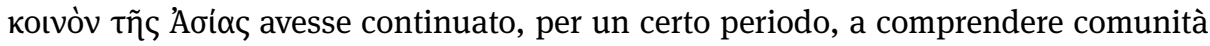
frigie e carie, come Laodikeia e Mileto, anche dopo lo smembramento della provincia romana Asia, avvenuto in due fasi tra la metà del III sec. (istituzione della provincia Phrygia-Caria) e l'inizio del IV sec. (separazione di Phrygia e Caria; istituzione di altre province: Lydia, Hellespontus, Insulae). D'altro canto non sono finora attestati, a mia conoscenza, dei sommi sacerdoti federali per quelle nuove provinciae che sorsero all'epoca di Diocleziano sui territori ex-asianici: in altre parole, non sono documen-

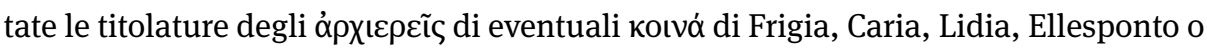
delle Isole, né tantomeno degli stessi dignitari in quanto presidenti delle assemblee

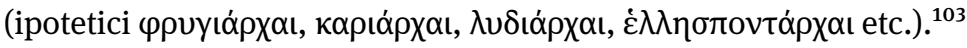

Per quanto tempo sarebbe perdurato questo „prolungamento di funzione“ del

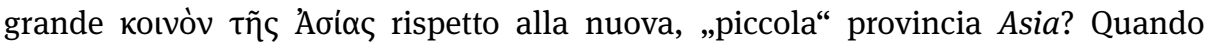
sarebbe avvenuto il ridimensionamento del koเvóv, commisurato infine alla taglia ridotta della provincia? Un terminus ante quem è costituito dal già ricordato rescritto di Valente al proconsul Asiae Festus (c.a. 372-375) in tema di asiarchia (vd. supra par. 5), che lascia intravedere un quadro ristretto del koเvóv, ormai limitato a sole quattro metropoli: intorno al 370 la trasformazione amministrativa doveva pertanto essere già avvenuta. ${ }^{104}$ Un altro termine di confronto può trovarsi nell'attività di un kotvóv autonomo dei Carii, riconoscibile in alcuni documenti epigrafici di Aphrodisias: esso è attestato tra l'ultimo quarto del IV sec., in epoca teodosiana, e l'inizio del VI sec. e

si pone nella prima metà del VI sec. (cfr. KALDELLIS 2005a, partic. 399-400 per gli epigrammi delle terme di Mileto).

102 Cfr. il commento di R. MERKelbaCh e J. StAUbeR a SGO I nr. 01/20/16 (p. 133): „Die Erwähnung der Asiarchie zeigt, dass Makarios wohl noch um das Ende des 3. Jahrh. n.Chr. anzusetzen ist, weil Milet später nicht mehr zu Asia gehörte, sondern zu Caria,,.

103 L'unica eccezione a questa generale mancanza di documentazione è rappresentata dalla nomina

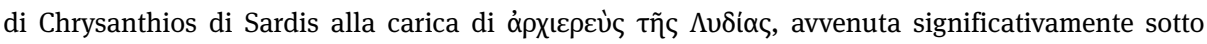
Giuliano: vd. infra par. 6.3. Fuori da tale contesto geografico microasiatico sono invece attestati, ad

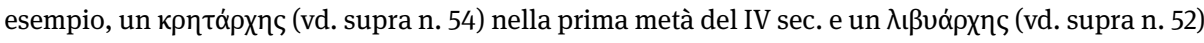
tra IV e V sec.

104 Cfr. supra nn. 76-78. 
non sembrerebbe comunque risalire a un periodo anteriore alla metà del IV sec. ${ }^{105}$ Un terminus post quem è dato infine dall'attività dell'óoı́xpxns Makarios a Mileto, che è sembrata databile agli ultimi anni di Costanzo II (c.a. 359-360) o all'inizio del regno di Giuliano (c.a. 361). Questi indizi suggeriscono che il ridimensionamento del

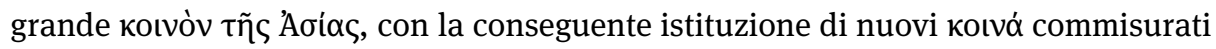
alle singole provinciae, sia stato decretato dall'autorità imperiale (almeno per quanto attiene al koเvóv dei Carii) nell'arco del decennio 360-370, non necessariamente in un unico momento, sotto l'imperatore Giuliano (361-363) oppure sotto Valente (364378): la prima soluzione sembrerà la più verosimile, come appare dalle fonti relative alla cosiddetta „riforma religiosa“ di Giuliano (vd. infra par. 6.3). ${ }^{106}$

105 Un rotvóv dei Carii con sede assembleare nella metropoli Aphrodisias è attestato come dedicante delle iscrizioni onorarie, poste dai Kã $\tilde{\varsigma}$ (in senso etnico/federale collettivo), per alcuni personaggi illustri tra l'ultimo quarto del IV e la fine del V sec.: Ala2004, 23 = IAph2007, 5.216 per l'Augusta Aelia Flavia Flaccilla (PLRE I 341-342), moglie di Teodosio I (379-386); Ala2004, 36 = IAph2007, 4.310 = SGO I nr. 02/09/04 per Anthemios (PLRE II 93-95), praefectus praetorio Orientis (405-414); Ala2004, 63 = IAph2007, 15.360 = SGO I, nr. 02/09/18 per Fl(avius) Palmatus (PLRE II 824), consularis Cariae e agens vices vicarii Asiae (fine V - inizio VI sec.: cfr. Ala2004, 62 = IAph2007, 8.410). A queste tre iscrizioni va

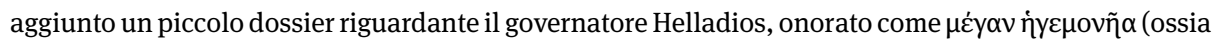
praeses Cariae) dai Kõp๕s (MAMA VIII 531 = Ala2004, 16 = IAph2007, 1.131.ii = SGO I nr. 02/09/14), il

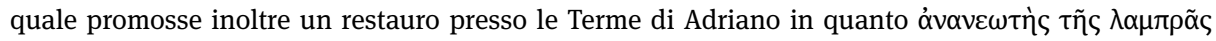
$\mu \eta \tau \rho о \pi ́ ́ \lambda \varepsilon \omega \varsigma$ (Ala 2004, 17 = IAph2007, 4.120; cfr. anche l'iscrizione frammentaria Ala2004, $18=$ IAph2007, 5.118). CHARLOTTE RouechÉ (Ala2004, comm. II 35-37) ha ipotizzato di collocare Helladios nella prima metà del IV sec., non escludendo una sua identificazione con il funzionario Aur(elius) Helladios (PLRE I 412), attestato nel 325 nel ruolo di governatore provinciale o vicario di area ignota, e quindi ha considerato tali documenti come le più antiche testimonianze di un kotvóv autonomo dei Carii e del ruolo di Aphrodisias come relativa metropoli federale. Tuttavia la cronologia del governatorato di Helladios e il suo stesso rango (perfectissimus o clarissimus?) restano tuttora incerti per mancanza di elementi datanti. Tantomeno può considerarsi sicura l'eventuale identificazione tra questo Helladios e il governatore di Caria [Hella?]dios(?) Ioannes (PLRE I 459 con datazione generica al IV-V sec.), avanzata dagli editori della PLRE sulla base di una ricostruzione onomastica di LouIs ROBERT: tale ipotesi prosopografica si basa infatti sulla problematica lettura dell'iscrizione MAMA

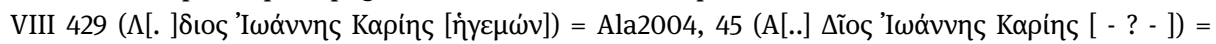
IAph2007, 6.5, per la cui discussione approfondita vd. l'analisi della RouECHÉ (Ala2004, comm. IV.16 e 35). Non potendo pertanto considerare il caso di Helladios per lo stabilimento di una cronologia relativa, la prima attestazione di un koเvóv dei Carii che possa datarsi con certezza resta la dedica all'imperatrice Aelia Flaccilla (c.a. 380), che costituisce dunque un terminus ante quem.

$106 \mathrm{Al}$ di là dei termini cronologici già indicati (ante c.a. 380: vd. supra n. 105), si può ipotizzare in quale particolare congiuntura politica venne istituito il kotvóv dei Carii? Anche in questo caso si può trovare forse un indizio che punterebbe verso l'epoca giulianea: l'ultimo praeses Cariae di rango perfectissimus è attestato sotto Costanzo II e il Cesare Giuliano, c.a. 359-360 (Flavius Quintilius Eros Monaxios: vd. supra n. 54), mentre il primo praeses di rango clarissimus è databile già sotto Giuliano Augusto, c.a. 362-363 (Antonius Tatianos: vd. supra n. 100). Se l'innalzamento di rango del governatorato della provincia Caria avesse un qualche legame con l'istituzione di un кoเvóv dei Carii, le due trasformazioni giuridico-amministrative potrebbero attribuirsi a Giuliano e datarsi, contestualmente, c.a. 361-362. Ulteriori spunti di riflessione potranno derivare dalla preziosa 
Secondo la ricostruzione qui presentata, si sarebbe mantenuta in epoca diocle-

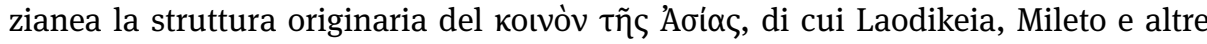
comunità avrebbero continuato a far parte, pur trovandosi ormai collocate in altre provinciae (Phrygia, Caria etc.): sarebbe questa una conferma della tesi, avanzata di recente da MARco Vitale, della polivalenza semantica dei termini provincia,

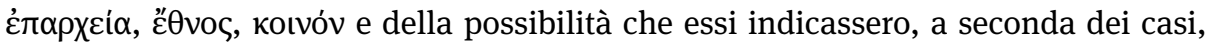
sia le „province“ romane in senso strettamente tecnico-amministrativo, sia delle „sub-province“ interne, sia gli organismi federali di rappresentanza, senza che peraltro queste entità giuridiche fossero necessariamente tra loro coincidenti. ${ }^{107} \mathrm{Si}$ può dunque ipotizzare che l'ordinamento dioclezianeo non prevedesse - nell'Asia Minore occidentale, in particolare nella ex-provincia Asia - di moltiplicare i koıvó nella stessa misura delle nuove, più piccole, provinciae (o, perlomeno, non prevedesse di farlo subito) - al contrario, nello specifico contesto microasiatico, quello stesso indirizzo di

documentazione epigrafica, attualmente in corso di pubblicazione (RITTI c.d.s.), relativa al teatro di Hierapolis: due iscrizioni distinte, che attestano opere di restauro effettuate in diverse parti dell'edificio teatrale e di altri edifici limitrofi, mostrano come nel 352 il praeses locale (di Phrygia Pacatiana), Fl(avius) Antonius Iulianus (cfr. PLRE I 471), fosse di rango perfectissimus, mentre in un periodo di poco successivo (c.a. 354-358) un suo successore, Ael(ius) Helladios [- - -]demos, fosse già di rango clarissimus. Tale Helladios potrebbe forse identificarsi con l'Helladios governatore di Caria (vd. supra n. 105), a patto di considerare i governatorati di Caria e di Phrygia Pacatiana come due tappe distinte all'interno della carriera del personaggio. In ogni caso, l'elevazione di rango della provincia Phrygia Pacatiana è avvenuta sotto Costanzo II, tra 352 e 354-358: proprio all'interno di questa forcella di tempo, nel 354, si colloca l'epigramma onorario (SEG 36, $1198=$ SEG 47, 1735 = SGO I nr. 02/12/06 $=\mathrm{AE} 2007,1397$ ) per il vicarius Asiae Flavius Magnus (PLRE I 535), promotore di un abbellimento del teatro, in cui la città di Hierapolis si autodesigna come „Madre della Frigia“ (

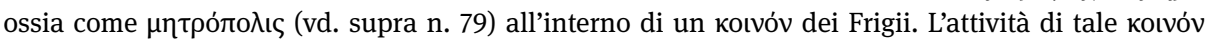
risulta da una lettera di Libanio ( $674 \mathrm{~W}=764 \mathrm{~F}$ ), indirizzata nel 362 al vicarius Asiae Caesarius (SEECK 1906, 98-99, Caesarius IV; PLRE I 168-169, Caesarius 1), nella quale si afferma che i Frigii (un kotvóv unitario o due koเvó separati per le due province Phrygia Pacatiana e Phrygia Salutaris?) avevano allora proclamato come proprio benefattore Iulianus, un ex-governatore provinciale (praeses di Phrygia Pacatiana o Phrygia Salutaris?) a cui erano succeduti molti altri praesides (

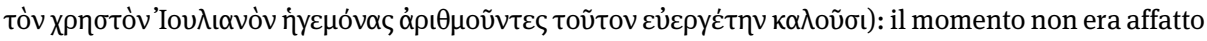
casuale, dato che questo Iulianus (SEECK 1906, 189-190, Iulianus II; PLRE I 470-471, Iulianus 12) era lo zio materno dell'imperatore Giuliano e deteneva in quel periodo l'alto incarico di comes Orientis. Questi dati rinforzano l'ipotesi, sopra formulata rispetto alla Caria, che possa esserci un legame tra l'innalzamento di rango della provincia e l'istituzione di un kotvóv autonomo: nel caso della Caria questo pare essersi verificato sotto Giuliano, per la Phrygia (almeno la Pacatiana) invece sotto Costanzo

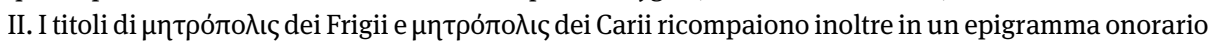
di Aphrodisias (Ala2004, nr. 32 = IAph2007, nr. 3.4.ii = SGO I nr. 02/09/02), databile genericamente alla seconda metà del IV sec. (cfr. RouEchÉ, Ala2004 comm. III.35-37), laddove si dice che la „Madre della Frigia“ (Hierapolis oppure Laodikeia al Lykos) ha inviato come omaggio alla „Madre della Caria“ (Aphrodisias) la statua di un funzionario, il „giusto“ Alexandros, forse un vicarius Asiae. Per una discussione storica e prosopografica approfondita di tali documenti vd. RitTi c.d.s.

107 Vitale 2012; cfr. VitALE 2014. 
governo che preferì mantenere integra la doppia provincia Lycia-Pamphylia, sembra aver promosso l'unificazione dei due kotvó dei Licii e dei Panfilii. ${ }^{108}$

E d'altra parte l'innovazione che Massimino Daia avrebbe tentato di introdurre,

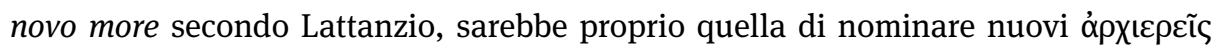
federali per le singole provinciae dioclezianee (etiam provinciis): un tentativo che, all'epoca di Massimino, sarebbe stato effimero e non avrebbe forse prodotto un esito rilevante, ma che sarebbe stato ripreso, circa cinquant’anni più tardi, da Giuliano.

\subsection{La „riforma“ di Giuliano e la prosopografia degli ảpxıعрєĩ federali del 362-363}

Per sostenere questa interpretazione amministrativa della „riforma“ di Massimino si può trovare un supporto indiretto se, come già hanno fatto studiosi illustri, si cercano elementi di continuità nella riforma religiosa progettata, nel 362, dall'imperatore Giuliano. ${ }^{109}$ E proprio nella breve ma significativa parentesi giulianea possono trovarsi numerosi termini di confronto: lo stesso Giuliano, spesso onorato come restitutor sacrorum e templorum, ${ }^{110}$ dimostra infatti di voler nominare direttamente i nuovi

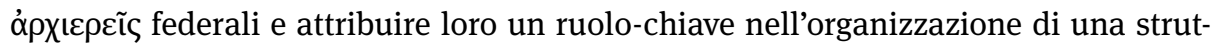

108 Sull'unificazione dei kotvó dei Licii e dei Panfilii, avvenuta sotto Diocleziano, Galerio o Massimino, e già attestata nel 312, vd. supra n. 84.

109 Il problema della politica religiosa di Giuliano è connesso a doppio filo con la formazione filosofica dell'imperatore, la sua concezione culturale di Ellenismo e i tentativi del neoplatonismo di III-IV sec. (Plotino, Porfirio, Giamblico) di produrre una teorizzazione politica capace di influenzare i sovrani; su questi temi la bibliografia è assai vasta. Più specificamente sulla „riforma religiosa“ e sull'auspicata „Chiesa pagana“ di Giuliano vd. Asmus 1895; Косн 1927-1928; BIDEZ 1930/1965, 261-272; ATHANASSiadi 1981, 161-190; MAZZA 1986; Nicholson 1994; Fowden 1998, 543-548; MaZZA 1998/2009; Olszaniec 1999a e 1999b; SCrofani 2005; CaLtabiano 2009; SCRofani 2010.

110 Nelle iscrizioni onorarie per Giuliano compare significativamente il concetto sacrale di restauratio: egli è infatti celebrato come restitutor sacrorum a Thibilis (El Announa, Numidia: ILAlg II.2, 4674 = CoNTI 2004, nr. 176), come restitutor libertatis et Romanae religionis a Casae (El Mahder, Numidia: CIL VIII $4326=18529=$ ILS $752=$ CoNTI 2004, nr. 167) e soprattutto come restitutor templorum a Berytos (Phoenice: AE 1907, $191=$ DIETZ $2000=$ AE 2000, $1500=$ HD023840 = ConTI 2004, nr. 17) e a Ma'ayan Barukh (presso Paneas/Caesarea Philippi, Phoenice: AE 1969/70, 631 = DIETZ $2000=$ ECK 2000 = AE 2000, 1503 = HD012412 = ConTI 2004, nr. 18); cfr. ARCE 1975. Queste ultime due dediche, accomunate da un testo sostanzialmente identico, sono particolarmente importanti: il dedicante è

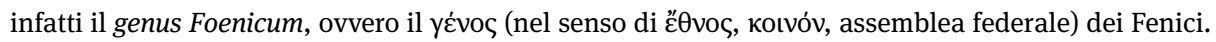
Si può trovare un termine di confronto nell'iscrizione onoraria (CIL III 167, cfr. p. 971 = ILS 1234) che, alcuni anni prima (c.a. 344-350), i decurioni di Berytos avevano dedicato al praefectus praetorio Orientis e consul ordinarius Flavius Domitius Leontius (PLRE I 502-503), dando attuazione a una delibera dell'assemblea dei Fenici (decretis provinciae Phoenices), ratificata dall'approvazione degli Augusti Costanzo II e Costante. 
tura che non solo i moderni, ma gli stessi Gregorio di Nazianzo e Sozomeno hanno inteso come una sorta di „Chiesa pagana“. ${ }^{111}$

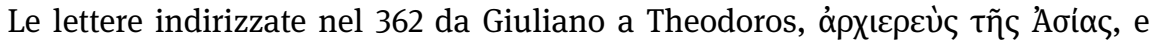

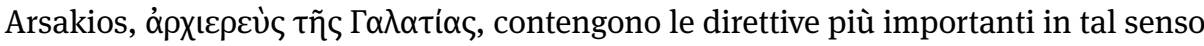
e, insieme alle fonti cristiane, rappresentano i documenti fondamentali su cui basare ogni ricostruzione storica del progetto giulianeo: ${ }^{112}$ i sommi sacerdoti federali saranno responsabili dei culti e dei riti, della cura dei templi, della selezione e del controllo di tutti i sacerdoti della provincia e dovranno eventualmente sanzionarli oppure difenderli dalle ingerenze, non rare, dei governatori. ${ }^{113}$

Joseph BIDEz, vero pioniere degli studi giulianei insieme a Franz Cumont, riconobbe non soltanto vari sacerdoti locali tra i corrispondenti dell'imperatore,

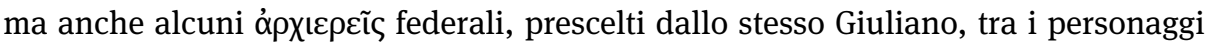
eminenti citati da Libanio nel suo immenso epistolario e schedati da OTTO SEECK: ${ }^{114}$

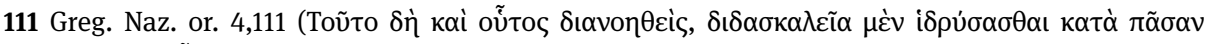

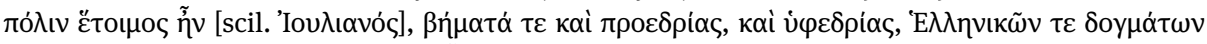

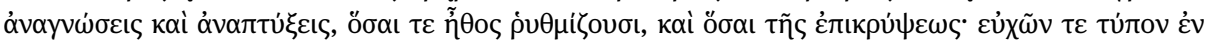

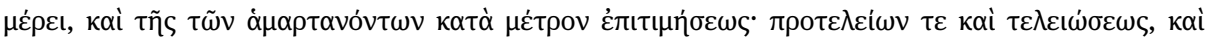

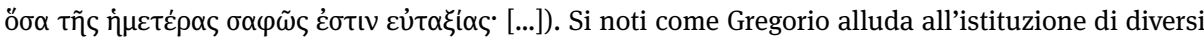

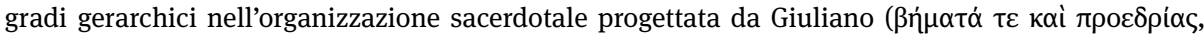

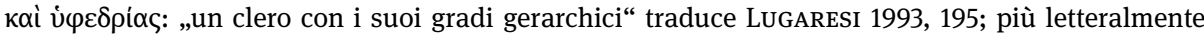
„tribune per il clero, cattedre episcopali, seggi minori“ ChIARA SANI in MoReschini 2000, 171). Soz.

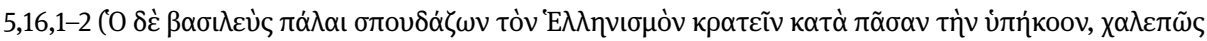

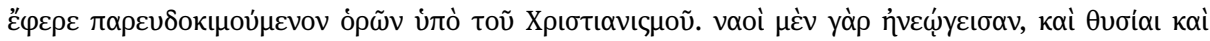

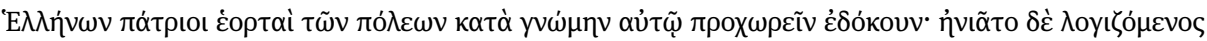

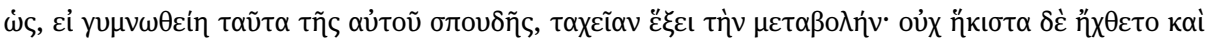

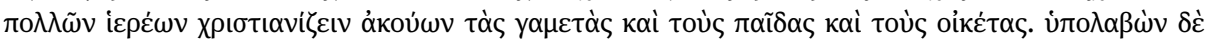

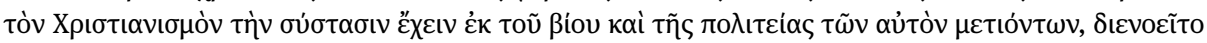

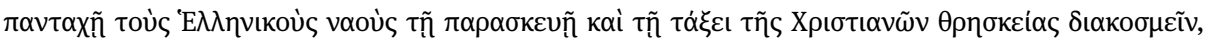

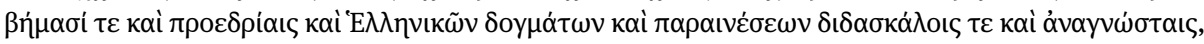

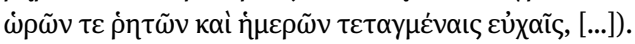

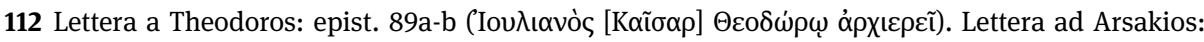

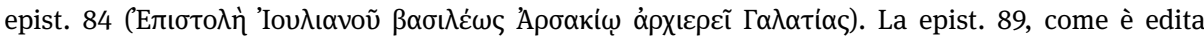
da BIDEz, è costituita dalla riunificazione di due frammenti (a-b), già proposta da Asmus 1895. Sull'unitarietà dei due frammenti della epist. 89 e sull'autenticità della epist. 84 ha espresso perplessità MAzZA 1998/2009, 234-241. L'autenticità della epist. 84, trasmessa solo da Soz. 5,16,516, è stata messa in questione da NufFelen 2002 (seguito da SCROFANI 2010, 76-88): sul problema, filologico e soprattutto storico in senso più ampio, si veda però la replica di BoufFARTIGUE 2005, che ha ribadito la paternità giulianea del documento e pare aver fugato ogni dubbio in merito; in questo senso cfr. anche ACETO 2008.

113 In particolare per gli aspetti di responsabilità giuridico-sacrale e di interrelazione gerarchica tra i sommi sacerdoti federali e i sacerdoti locali della provincia vd. infra nn. 126-127.

114 BidEZ 1930/1965, 266-268, 274-276; cfr. Olszaniec 1999b, 236-240. Le lettere di Giuliano sono citate secondo l'edizione BIDEz 1924/1960 (cfr. anche BIDEz/Cumont 1922). Le lettere di Libanio sono contrassegnate dall'indicazione dell'edizione di riferimento ( $\mathrm{F}=$ ed. $\mathrm{R}$. Foerster, X-XI, Lipsiae 1921- 
si presenteranno sommariamente tali personaggi, inquadrandoli nelle tre categorie sacerdotali in cui si articola l'ordinamento gerarchico di Massimino (vd. supra par. 6.1).

a) Sacerdoti di divinità locali, attestati sotto Giuliano e, in certi casi, prescelti dallo stesso imperatore:

- Theodora, icpcía (Cilicia?). ${ }^{115}$

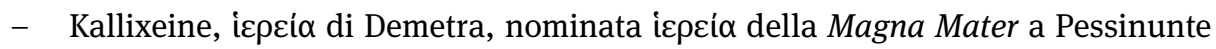
(Galatia). ${ }^{116}$

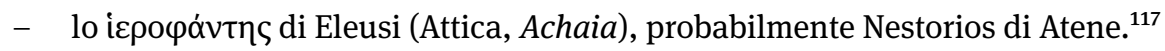

1922; W = ed. Wolf, Amstelodami 1738). Per uno studio cronologico e prosopografico dell'epistolario di Libanio vd. SEECK 1906; dell'epistolario di Giuliano vd. CALTABIANo 1991.

115 La „reverendissima“ Theodora (PLRE I 895, Theodora 3; CALTABIANo 1991, 54, nr. 30) è destinataria

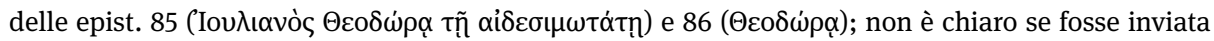
a lei anche la epist. 87 (mutila dell'intestazione); le tre lettere sono riferibili al soggiorno di Giuliano ad Antiochia (luglio 362 - marzo 363) e databili verso la fine del 362: cfr. BIDEz 1924/1960, 99-101; Caltabiano 1991, 123-124. Dalla epist. 86 si evince il ruolo di Theodora come sacerdotessa: Giuliano le scrive perché si era precedentemente rivolta al suo più stretto sodale, il filosofo Massimo di Efeso (PLRE I 583-584), lamentando di essere oggetto dell'ostilità di un altro amico del principe, Seleukos (vd. infra n. 128). Il contatto con il cilicio Seleukos ha indotto gli editori della PLRE a ipotizzare che Theodora potesse forse vivere in Cilicia. Costei, pur avendo scelto lo stile di vita sacerdotale, aveva poi mantenuto al suo servizio degli schiavi cristiani: tale fatto, ritenuto impuro e inappropriato ai corretti costumi di un sacerdote, suscita un serio ammonimento da parte di Giuliano (sul medesimo problema dei familiari e schiavi cristiani egli tornerà nella epist. 84 ad Arsakios). La sua identificazione con l'omonima vedova (PLRE I 895, Theodora 2) di Thalassius (PLRE I 886), praefectus praetorio Orientis di Costanzo II (c.a. 351-353), ipotizzata da BIDEZ 1924/1960, 99, è giustamente respinta dagli editori della PLRE.

116 Kallixeine (PLRE I 176; Caltabiano 1991, 43, nr. 7) è destinataria della epist. 81 (Iovגıavòs

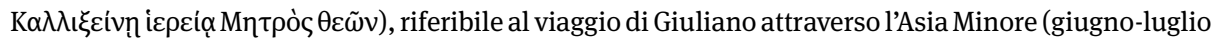
362), con una sosta devota a Pessinunte: cfr. BidEz 1924/1960, 79, 82-83; CALTABIANo 1991, 116-117. Il sacerdozio della Magna Mater Deum (Kybele) presso il grande santuario di Pessinunte (città frigia, ma

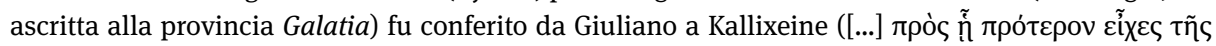

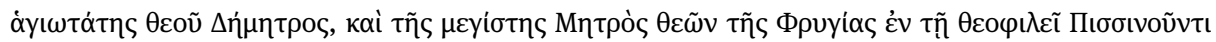

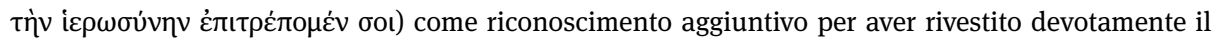
sacerdozio di Demetra, con una fedeltà degna di Penelope (e con grave rischio personale), per circa quarant'anni, ossia sotto i lunghi regni di Costantino e Costanzo II. La visita di Giuliano a Pessinunte fu però turbata da un atto sacrilego: alcuni cristiani oltraggiarono gli altari della Mater, suscitando l'ira dell'imperatore (cfr. Greg. Naz. or. 5,40); di tale evento sembra potersi cogliere un'eco nel finale della epist. 84 ad Arsakios, laddove Giuliano ammonisce severamente gli abitanti di Pessinunte a mantenere vivo il culto della Mater: cfr. BIDEZ 1924/1960, 82, 147. Si tenga presente la dimensione etnico/federale dell'antichissimo santuario di Kybele nella cosiddetta Phrygia Galatica: non a caso verso la fine del IV sec., quando la provincia Galatia sarà suddivisa in due, proprio Pessinunte sarà prescelta come capitale della nuova provincia Galatia II Salutaris.

117 Il teurgo neoplatonico Nestorios il Grande (PLRE I 626, Nestorius 2; vd. supra n. 66) sembra

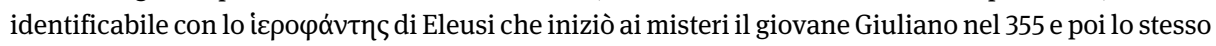


- Pegasios, già vescovo cristiano di Ilio (Troade, Hellespontus), nominato ícpeús pagano. ${ }^{118}$

Due personaggi sono insigniti di un sacerdozio la cui particolare competenza non è specificata nelle fonti, ma su cui possono formularsi delle ipotesi interpretative (vd. infra):

- Hierax di Alexandria Troas (Troade, Hellespontus). ${ }^{119}$

- Bakchios di Tarso (Cilicia). ${ }^{120}$

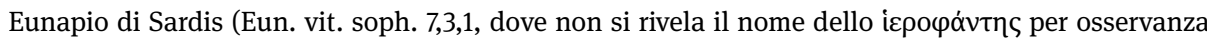

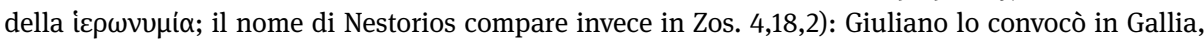
mentre preparava la guerra contro Costanzo II (probabilmente nel 361: cfr. KaLDELLIS 2005b), e, dopo la morte del cugino nella lontana Cilicia (novembre 361) e l'ingresso a Costantinopoli come unico Augusto (dicembre 361), lo rimandò in Grecia (Eun. vit. soph. 7,3,6-9), affidandogli „la tutela

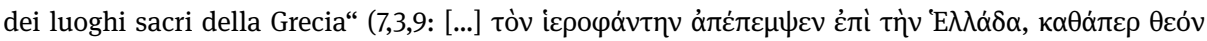

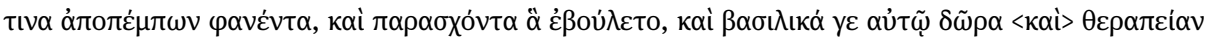

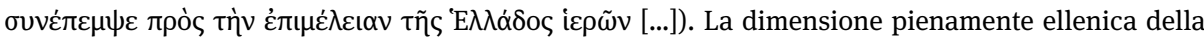
cura dei templi assegnata a Nestorios va ben oltre le normali prerogative sacrali degli ípó́pavtaı di Demetra e Kore a Eleusi (Attica): quest'incarico sembra dunque prefigurare uno dei compiti spettanti, secondo Giuliano, al sommo sacerdote federale (vd. infra n. 134).

118 Pegasios era vescovo di Ilio di confessione ariana (PCBE III, 783-785) e nel 354 aveva fatto da guida a Giuliano nel tour dell'antichissima città omerica e dei suoi templi (cfr. BIDEZ 1930/1965, 100104): l'opportunità della sua sorprendente nomina come sacerdote pagano è l'argomento dibattuto nella epist. 79 (mutila dell'intestazione: cfr. infra n. 132).

119 Il sofista Hierax di Alexandria Troas (SEECK 1906, 175, Hierax; PLRE I 430) è un corrispondente di Libanio: dalla epist. $527 \mathrm{~F}$ (= $441 \mathrm{~W}$ ), databile al 356, si apprende che avrebbe dovuto ottenere una cattedra di insegnamento a Kyzikos, capitale della provincia Hellespontus, ma infine non vi era riuscito; dalle epp. $796 \mathrm{~F}$ (= $706 \mathrm{~W}$ ) e $1352 \mathrm{~F}$ (= $1212 \mathrm{~W}$ ), databili tra 362 e 363, si evince un suo ruolo di alto rilievo come sacerdote, sebbene non si specifichi quale fosse il titolo sacerdotale preciso. In particolare la epist. $796 \mathrm{~F}$ mostra come egli ricevesse lettere dall'imperatore Giuliano e ne godesse il favore; nella epist. 1352 F Libanio gli raccomanda un suo giovane allievo originario della Troade, Rufinus (SEECK 1906, 255, Rufinus IX), perché ritiene che Hierax abbia un ruolo che lo rende capace di intercedere efficacemente presso i funzionari imperiali di maggiore autorità, il governatore dell'Hellespontus e il vicarius Asiae. Tali indizi suggeriscono l'idea che il sacerdozio di Hierax potesse

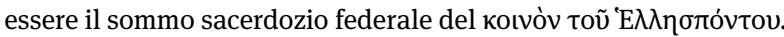

120 Bakchios (SEeck 1906, 93-94, B.; cfr. Wiemer 1995, 65), notabile di Tarso, è destinatario di varie lettere di Libanio, tra le quali le epist. $710 \mathrm{~F}(=622 \mathrm{~W}), 712 \mathrm{~F}(=624 \mathrm{~W})$ e $757 \mathrm{~F}(=669 \mathrm{~W})$, databili al

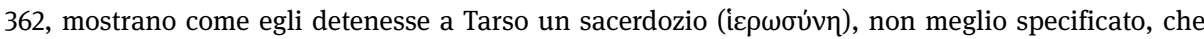

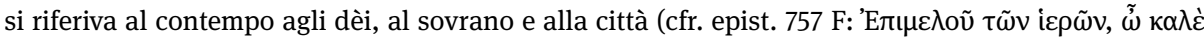

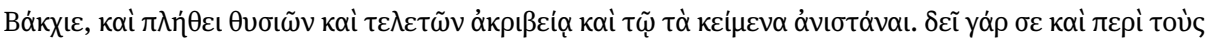

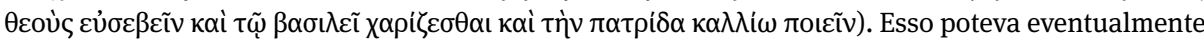
riguardare Artemide: l'epist. $710 \mathrm{~F}$ descrive infatti il restauro e l'abbellimento di una statua della dea, forse nascosta dai cristiani, poi recuperata da Bakchios e portata in solenne processione per la città, con la celebrazione finale di un grande banchetto festivo. D'altra parte l'epist. $757 \mathrm{~F}$ lascia intendere che Bakchios, nello svolgimento del suo sacerdozio, avesse ottenuto la restituzione dei beni dei templi pagani da parte di alcuni notabili cristiani, che se ne erano appropriati. Tali indizi suggeriscono 
b) Sommi sacerdoti civici del culto imperiale:

- Hesychios di Antiochia (Syria I). ${ }^{121}$

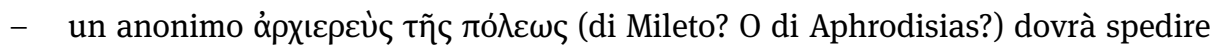
a Giuliano un rapporto sul comportamento di un anonimo governatore (praeses Cariae), cui lo stesso imperatore ha inviato una lettera di rimprovero (ep. 88), comminandogli tre mesi di penitenza, per aver maltrattato un sacerdote locale (del santuario apollineo di Didyma?); Giuliano era stato informato di tale sacri-

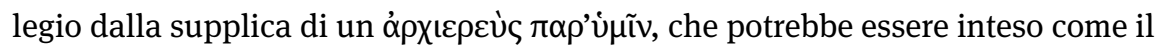

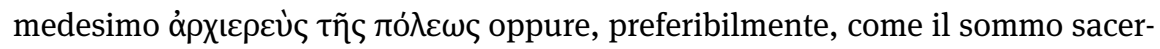
dote federale dei Carii (vd. infra, c). ${ }^{122}$

l'impressione che Bakchios non fosse semplicemente uno ípeús di Artemide, ma rivestisse un sacerdozio civico che comportava, in senso più ampio, la cura e il restauro di tutti i templi locali (cfr.

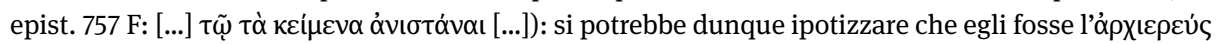

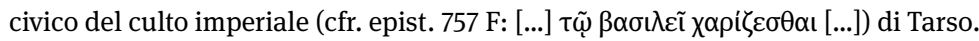

121 Hesychios (SEECK 1906, 175, Hesychius II; cfr. WIEMER 1995, 65), notabile antiocheno imparentato con Libanio, riceve la epist. $724 \mathrm{~F}$ (= $636 \mathrm{~W}$ ), databile al 362, da cui si deduce il suo ruolo di sommo sacerdote civico, responsabile della cura e del restauro dei templi ("O

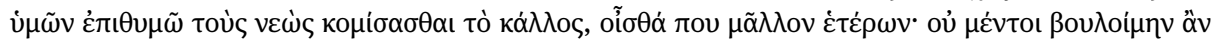

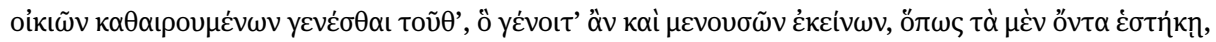

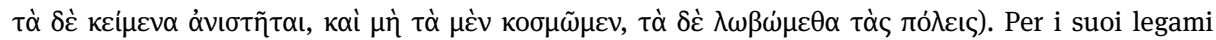
familiari vd. la epist. $372 \mathrm{~F}$ (= $375 \mathrm{~W}$ ), databile al 358.

122 L'epist. 88 (mutila dell'intestazione e del principio) appartiene al gruppo di lettere ascrivibili al soggiorno antiocheno (luglio 362 - marzo 363) e sembra databile verso la fine del 362 (forse di poco anteriore alla epist. 89): cfr. BiDEz 1924/1960, 101-102; CALTABIANo 1991, 125-126. Con essa Giuliano si rivolge a un personaggio innominato che si caratterizza per le funzioni giuridiche proprie di un governatore provinciale: la ripetuta menzione del celebre santuario oracolare di Apollo a Didyma presso Mileto permette di collocare gli eventi nella provincia Caria, e quindi di riconoscere nell'anonimo un praeses Cariae (PLRE I 1023, Anonymus 118). Tale governatore aveva commesso un

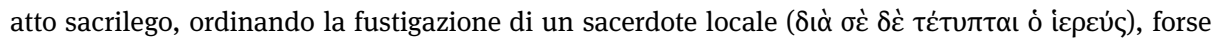
di Didyma o Mileto: Giuliano gli scrive dunque per esprimere un duro rimprovero e impartirgli una penitenza esemplare, alludendo inoltre polemicamente alla sua personale contiguità con i deprecabili

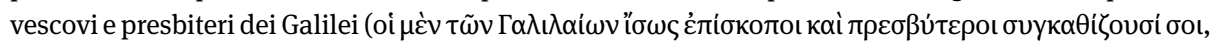

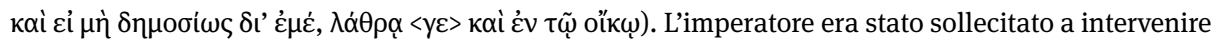

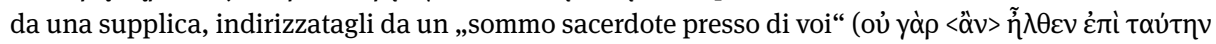

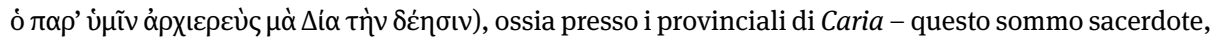
che si rivolge direttamente all'imperatore a fronte di un grave atto di malgoverno, andrà dunque

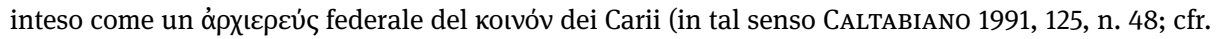
SCROFANi 2005, 199, n. 17) e non come un semplice ảpxıعрú́ civico di Mileto (così BIDEZ 1924/1960, 101). D’altra parte Giuliano dichiara che non riammetterà il governatore alla „comunione di culto“ pagana se non dopo la completa espiazione di tale peccato, ma comunque in maniera subordinata

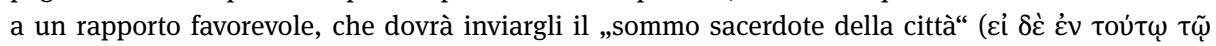

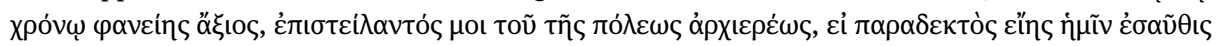

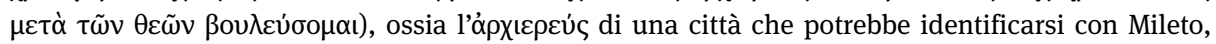
probabile patria del sacerdote oltraggiato, oppure con Aphrodisias, la capitale amministrativa di

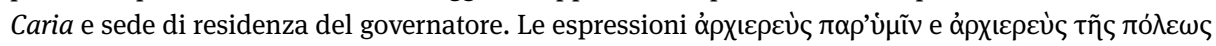


Si propone qui di aggiungere altri tre personaggi, che potrebbero eventualmente essere riconosciuti come $\alpha \rho \chi \imath \_\rho \varepsilon \tilde{\varsigma}$ civici:

- Theodoros, destinatario della ep. 30, nella cui intestazione è indicato come

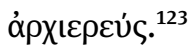

- Ploutarchos, destinatario della ep. 153, che potrebbe forse identificarsi con l'o-

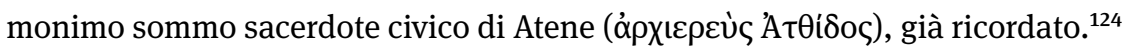

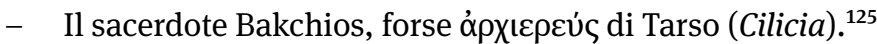

non starebbero qui a indicare il medesimo sommo sacerdote, ma due ả $\rho x ı \varepsilon \rho \varepsilon \tilde{~}$ distinti per livello di competenza territoriale. Si noti un particolare importante: lo stesso Giuliano, per esprimere la suprema autorità giuridico-sacrale che legittima il suo intervento, si dichiara significativamente

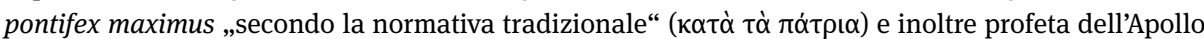

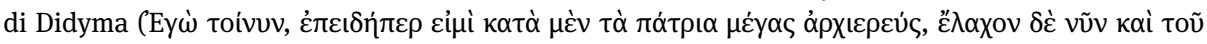

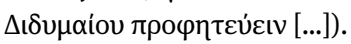

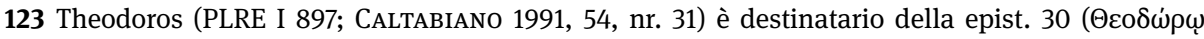

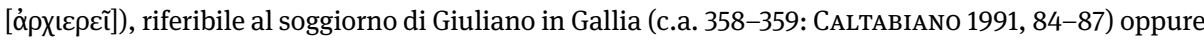

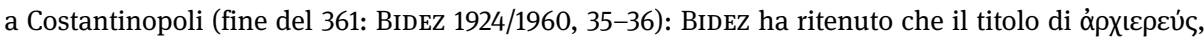
presente nell'intestazione della lettera, sia forse un'inserzione secondaria, dettata dal fatto che Theodoros ricevette nel 362 una seconda lettera da Giuliano, la epist. 89 (vd. supra n. 112), quando l'imperatore lo aveva nominato sommo sacerdote federale del kotvóv d'Asia (vd. infra n. 126); il titolo sarebbe dunque stato aggiunto all'intestazione della epist. 30 da un copista che avesse raccolto, una dopo l'altra, le due lettere indirizzate a Theodoros, e BIDEZ proponeva pertanto di espungerlo, per quanto la tradizione manoscritta sia concorde sul punto. Si potrebbe però immaginare un'altra soluzione, che eviti di presumere un errore di carattere filologico: la epist. 30 colloca Theodoros in Grecia, dove ha subito un grave affronto da parte del proconsul Achaiae (PLRE I 1014, Anonymus 49), mostrando una capacità di sopportazione tipica di un vero filosofo, per la quale Giuliano lo celebra, paragonandolo a Socrate. In tale circostanza, non meglio chiarita, Theodoros si era inoltre assunto la difesa della città presso la quale dimorava, forse in una condizione assimilabile all'esilio (comminatogli da Costanzo II?): Giuliano lo paragona infatti, per questo atto generoso verso la città, al filosofo stoico Musonio Rufo, esiliato da Nerone. In realtà si potrebbe ipotizzare che Theodoros avesse tentato di difendere la città davanti al governatore provinciale in quanto egli era allora sommo sacerdote civico

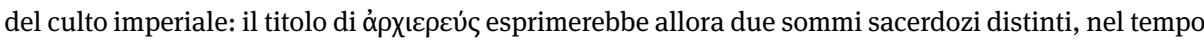

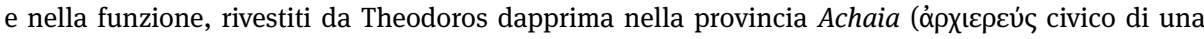

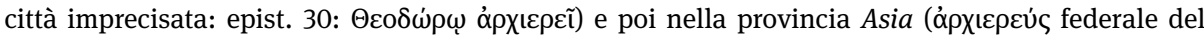

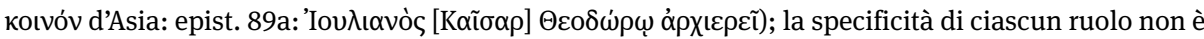
esplicitato dalle intestazioni delle lettere, ma può evincersi dai rispettivi contenuti.

124 Ploutarchos (CALtabiano 1991, 52, nr. 26) è il destinatario della epist. 153, di datazione incerta, caratterizzata da toni amicali ma da contenuti assai generici. CHANIoTIS 1987 ha ipotizzato di identificare l'ignoto personaggio con l'omonimo praeses Insularum (PLRE I 708, Plutarchus 4), che aveva visitato l'antro di Zeus sul monte Ida a Creta e fu autore di un epigramma votivo per Hera Pambasileia e pro salute dell'Imperatore (verosimilmente Giuliano), dedicato presso l'Heraion di Samo (SEG 1, 405 B = IGRRP IV 1725 = IG XII 6.2, 584 = ROBERT 1948, 55-59 = PH344358); tale praeses Insularum Ploutarchos sarebbe forse figlio dell'omonimo proconsul Achaiae (circa la metà del IV sec.: PLRE I 707-708, Plutarchus 3). In precedenza BIDEZ 1924/1960, 206, n. 1 aveva invece proposto il nome del filosofo neoplatonico e futuro scolarca Putarchos (PLRE I 708, Plutarchus 5: vd. supra n. 66),

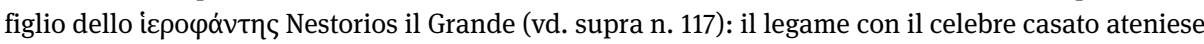


c) Sommi sacerdoti federali del culto imperiale, nominati da Giuliano:

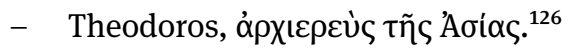

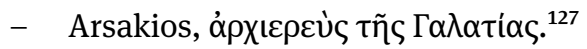

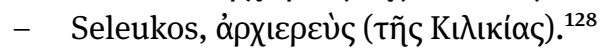

sembra assai suggestivo, ma per motivi di età dei vari personaggi (Ploutarchos lo scolarca sarebbe stato assai giovane negli anni di Giuliano), si potrebbe, forse meglio, pensare al nonno omonimo,

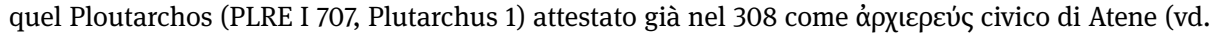
supra n. 65), che all'epoca giulianea dovremmo però immaginare ormai molto anziano.

$125 \mathrm{Su}$ Bakchios di Tarso vd. supra n. 120.

126 Lo stesso Theodoros, già destinatario della epist. 30 (vd. supra n. 123), anch'egli allievo del comune maestro Massimo di Efeso (PLRE I 583-584), nel 362 fu nominato da Giuliano sommo sacerdote federale del koเvóv d'Asia e in questo ruolo ricevette la epist. 89 (vd. supra n. 112), riferibile al soggiorno di Giuliano ad Antiochia (luglio 362 - marzo 363) e databile all'inverno 362-363 (forse di poco posteriore alle epp. 84 e 88): cfr. Bidez 1924/1960, 102-105; Caltabiano 1991, 125-126. Giuliano dichiara espressamente di voler porre Theodoros come supervisore generale di tutti i sacra

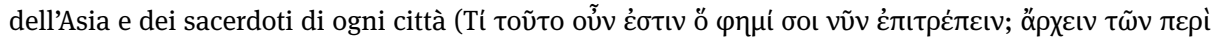

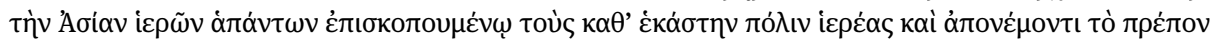

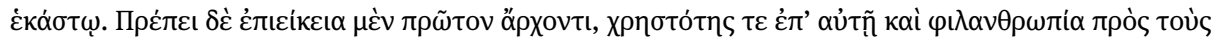

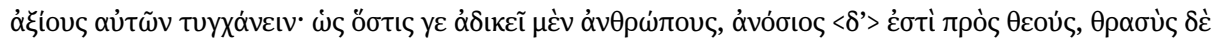

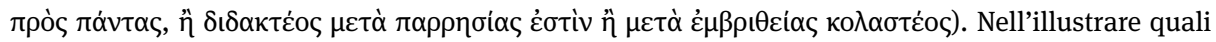
debbano poi essere le qualità di un buon sacerdote, Giuliano chiarisce che Theodoros avrà il compito di istruire tutti gli altri sacerdoti, non solo nelle città, ma anche nelle campagne, e che sarà legittimato a farlo grazie al sostegno dell'imperatore stesso, che è pontifex maximus per volere degli dei ([...] ö $\pi \omega \varsigma$

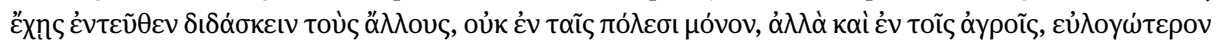

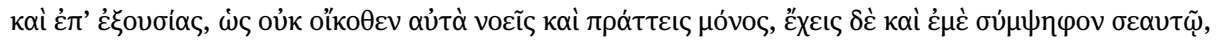

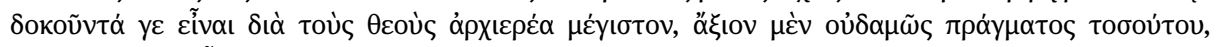

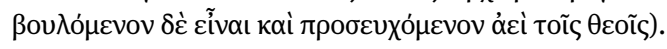

127 Arsakios (PLRE I 110, Arsacius 3; CALtabiano 1991, 42, nr. 4), sommo sacerdote federale del Koเvóv di Galazia, è destinatario della epist. 84 di Giuliano (vd. supra n. 112), riferibile al soggiorno di Giuliano ad Antiochia (luglio 362 - marzo 363) e databile all'inverno 362-363 (forse di poco anteriore alla epist. 89): cfr. Bidez 1924/1960, 95-99; CALtABiano 1991, 126. Giuliano lascia intendere come tutti i sacerdoti di Galazia debbano essere subordinati ad Arsakios e, come lui, sintonici con l'imperatore

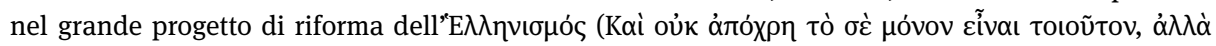

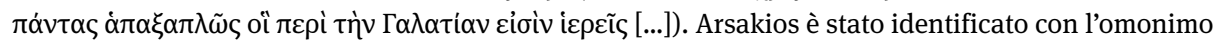
notabile galata, della cui famiglia Libanio ricorda cursoriamente un membro, non nominato, nella epist. 386 F (= 303 W), databile alla primavera-estate 361 (cfr. SEEcK 1906, 378) e indirizzata all'exallievo, allora notarius presso Costanzo II (c.a. 358-361), Honoratus figlio di Quirinus (SEECK 1906, 180, Honoratus II; PLRE I 439, Honoratus 3).

128 Seleukos (SEEcK 1906, 272-273, Seleucus; PLRE I 818-819, Seleucus 1; cfr. WIEMER 1995, 92), ricco notabile della provincia Cilicia, è destinatario, come altri membri della sua famiglia (specialmente la moglie Alexandra), di varie lettere di Libanio: in particolare dalla epist. $770 \mathrm{~F}(=680 \mathrm{~W})$, databile al

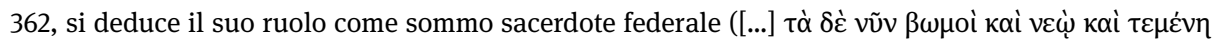

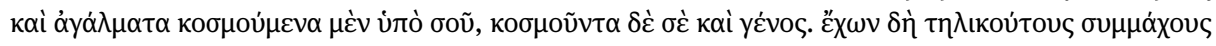

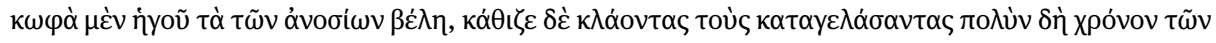

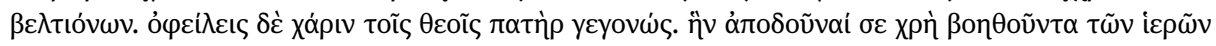

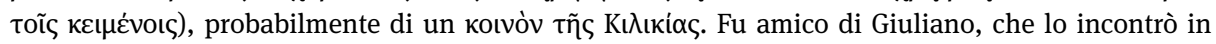




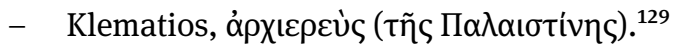

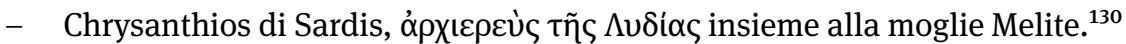

Bithynia (Lib. epist. $13 \mathrm{~F}=13 \mathrm{~W}$ ) e gli concesse il titolo di comes (cfr. Iul. epist. 86: vd. supra n. 115): nel 362 Seleukos fu nominato ỏpxıعev́s e nel 363 accompagnò personalmente il sovrano nella campagna persiana (Lib. epist. $1508 \mathrm{~F}=1078 \mathrm{~W}$ ). $\mathrm{Nel}$ 364-365 fu sottoposto a processo, condannato all'esilio nel Pontus e al bando da ogni città e i suoi beni furono confiscati: si è pensato che, nel ruolo di sommo sacerdote, avesse sostenuto con eccessivo entusiasmo la politica religiosa di Giuliano. Durante l'esilio pare avesse cominciato a comporre un resoconto storico sulla guerra persiana di dell'imperatore (epist. 1508 F): la sua attività storiografica ha suggerito l'identificazione, suggestiva ma problematica, con lo storico-grammatico e poeta Seleukos di Emesa (PLRE I 819, Seleucus 3), capitale della Phoenice Libanensis, che è attestato dalla Suida come autore, tra le altre opere, di П $\alpha \rho$ ıкó in 2 libri. Su Seleukos e altri cronisti che furono al fianco di Giuliano in Persia e ne narrarono le gesta (tra cui vari ufficiali dell'esercito e funzionari imperiali: il protector domesticus Ammiano Marcellino di Antiochia l'italico Eutropio, il protector e poeta Kallistos, il notarius Philagrios, il tribunus Magnus di Carrhae, l'archiatra e forse quaestor Oribasio di Pergamo), in particolare sul soldato e cronografo cappadoce Eutychianos, cfr. CASSIA 2014, 178-180.

129 Klematios (SEECK 1906, 111-112, Clematius III), ricco notabile della provincia Palaestina (I), era stato compagno di studi di Libanio ad Atene: molti anni più tardi tre lettere del retore, indirizzate c.a. 364-365 allo stesso Klematios (epp. $1283 \mathrm{~F}=1051 \mathrm{~W} ; 1307 \mathrm{~F}=1384 \mathrm{~W}$ ) e ad Akakios (epist. $1458 \mathrm{~F}=1071$ W), mostrano come nel 362 egli fosse stato nominato da Giuliano quale sommo sacerdote federale,

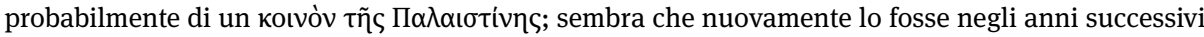

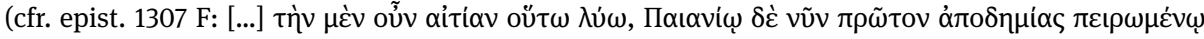

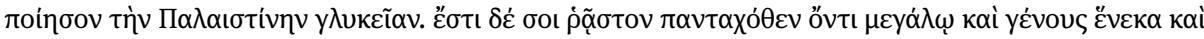

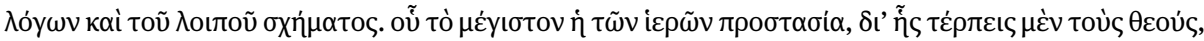

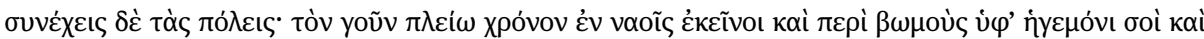

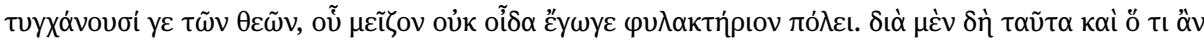

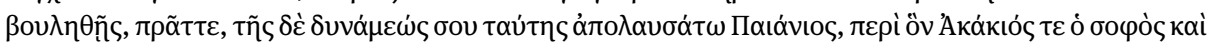

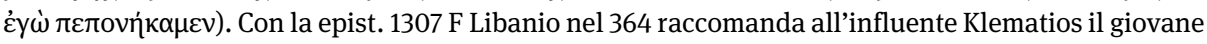
avvocato Paianios (PLRE I 657), un ex-allievo dello stesso Libanio e del collega Akakios, appena giunto in Palaestina. La successiva lettera ad Akakios (epist. $1458 \mathrm{~F}$, forse del 365), il celebre sofista originario di Cesarea Marittima (Eun. vit. soph. 17; SEECK 1906, 39-43, Acacius II; PLRE I 6, Acacius 6 - gli editori della PLRE, diversamente da SEECK, hanno tuttavia preferito riconoscere il destinatario della epist. 1458 F nell'omonimo comes domorum per Cappadociam: PLRE I 7, Acacius 8; cfr. SEECK 1906, 36-39, Acacius I; 441), suggerisce l'idea che anche Klematios fosse residente a Cesarea, capitale della Palaestina I. Dopo la breve parabola giulianea Klematios, in quanto fedele partigiano dell'imperatore e intransigente anticristiano, aveva avuto una sorte in parte analoga a quella di Seleukos (vd. supra n. 128): nel 363-364 subì infatti un processo che comportò la confisca dei beni, ma poi riuscì a rientrare in patria e recuperare una posizione importante; di tale processo riferisce Libanio nella epist. 1504 F (= 1530 W), indirizzata nel 365 al magister officiorum Decentius (SEECK 1906, 117, D. 1; PLRE I 244). 130 Chrysanthios (PLRE I 202-203) è un personaggio fondamentale nell'intera vicenda di Giuliano: ricco e nobile buleuta di Sardis, fu retore e filosofo neoplatonico, allievo di Edesio a Pergamo insieme a Massimo di Efeso, Prisco il Tesprozio ed Eusebio di Myndos, quindi maestro di Giuliano e infine dello stesso Eunapio di Sardis. Giuliano, dopo essersi insediato a Costantinopoli, al principio del 362 convocò a corte sia Massimo e Prisco, sia Chrysanthios, il quale però trasse cattivi auspici dalle consultazioni degli dèi e dunque rifiutò i ripetuti inviti dell'imperatore, spediti sia a lui che alla moglie Melite: Eunapio narra l'episodio in due passi delle Vitae, relativi alla biografia di Massimo 
Ai sommi sacerdoti federali già individuati da SEECK e BIDEZ si propone qui di aggiungere:

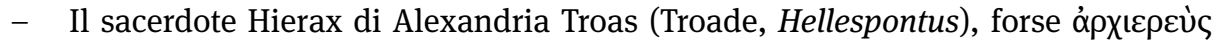

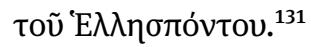

- L'anonimo destinatario della ep. 79 (sulla nomina di Pegasio di Ilio come sacer-

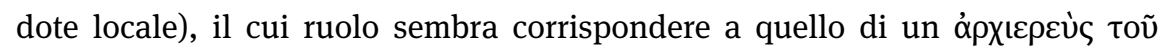

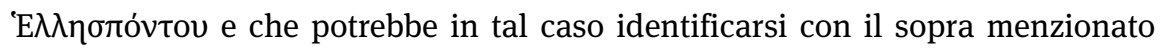
Hierax. ${ }^{132}$

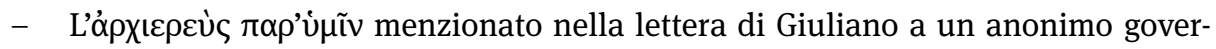

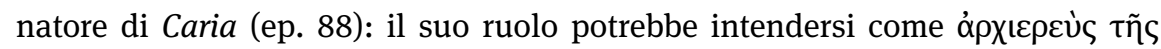

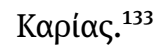

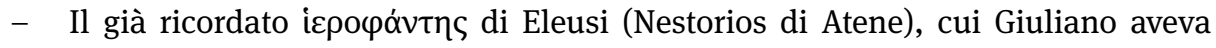
affidato la cura dei sacra della Grecia (provincia Achaia): costui avrebbe forse

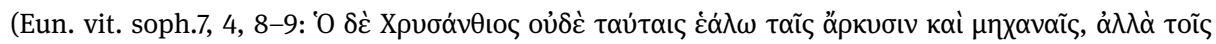

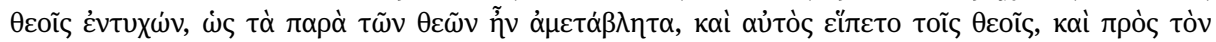

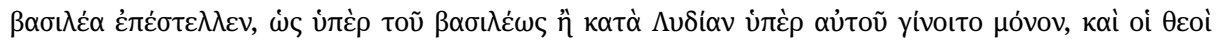

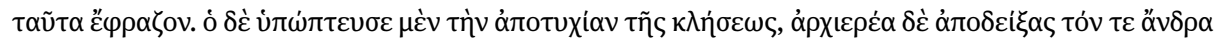

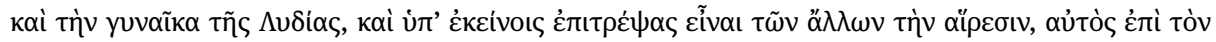

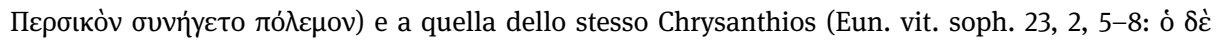

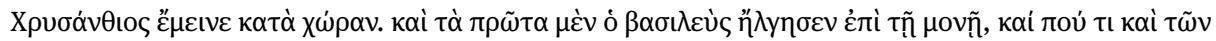

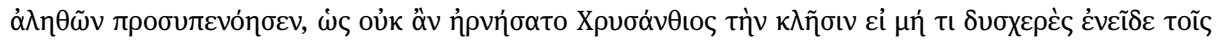

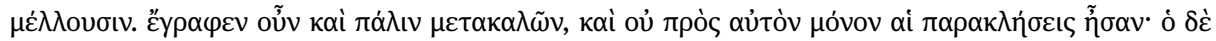

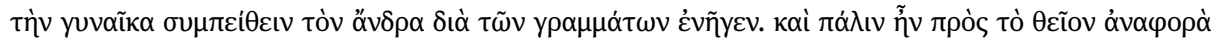

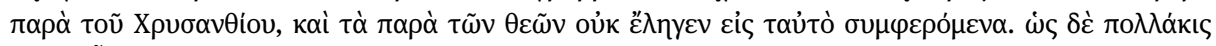

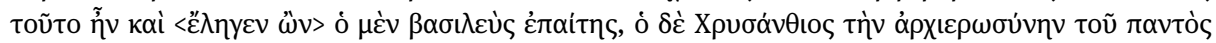

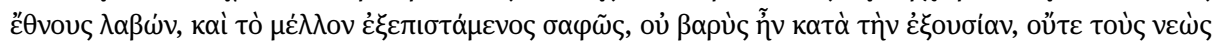

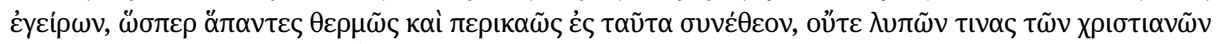

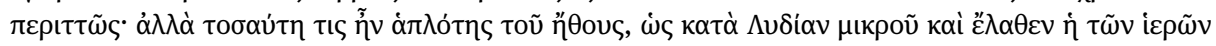

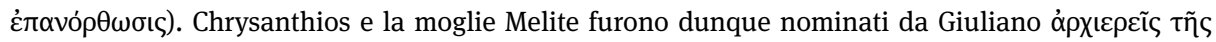
$\Lambda v \delta$ ías: nell'esercizio della sua carica sacerdotale (e specialmente nelle relazioni con i cristiani) Chrysanthios fu particolarmente prudente e moderato, riuscendo così a evitare di incorrere, pochi anni dopo, nelle vicissitudini giudiziarie che colpirono duramente alcuni colleghi più entusiasti e temerari, quali Seleukos e Klematios (vd. supra nn. 128-129).

$131 \mathrm{Su}$ Hierax di Alexandria Troas vd. supra n. 119.

132 L'epist. 79 (mutila dell'intestazione) appartiene al gruppo di lettere ascrivibili al viaggio di Giuliano attraverso l'Asia Minore (giugno-luglio 362): cfr. Bidez 1924/1960, 80-81; CALTABIANo 1991, 37-39. Con essa Giuliano si rivolge a un personaggio ignoto, che aveva espresso perplessità riguardo all'idoneità del vescovo Pegasios (vd. supra n. 118) come candidato al sacerdozio pagano: BIDEZ riteneva che tale destinatario facesse parte della gerarchia dei sommi sacerdoti pagani d'Asia; l'ipotesi

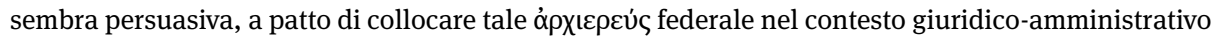
appropriato per la Troade, ovvero la provincia Hellespontus.

133 Sulla epist. 88 vd. supra n. 122. 


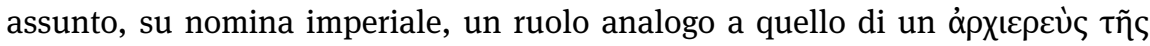

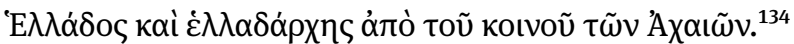

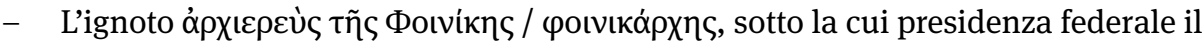
genus Foenicum decretò onorificenze per Giuliano, attestate dalle iscrizioni onorarie di Berytos e Ma'ayan Barukh. ${ }^{135}$

Questa specifica modalità di elezione diretta dei sommi sacerdoti da parte di Giuliano trova il suo più chiaro esempio nelle Vitae sophistarum di Eunapio, laddove si narrano i rapporti di amicizia tra l'imperatore e il sofista-filosofo Chrysanthios di Sardis, maestro dello stesso Eunapio e ricco buleuta della capitale di Lydia: Giuliano, non potendo convincere l'amico a recarsi alla corte di Costantinopoli, decise allora di

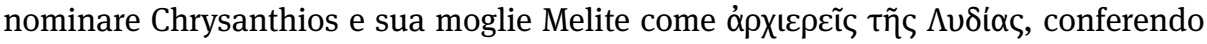
loro piena autorità sulla nomina degli altri sacerdoti della provincia e la custodia di tutti i templi. ${ }^{136}$

Nel momento in cui promuoveva l'istituzione di nuovi koเvó per le singole provinciae tardoantiche dell'Asia Minore occidentale, portando a compimento quel processo di trasformazione giuridico-amministrativa che aveva investito la provincia Asia sin dalla metà del III sec. e che ora toccava finalmente anche il suo antichissimo koıvóv, restringendolo drasticamente (come apparirà poi nell'epoca di Valente: vd.

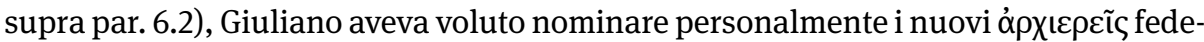
rali per ciascuna provincia, scegliendoli tra i notabili più „sintonici“ e affidabili delle grandi città, come già aveva tentato di fare, con una misura davvero innovatrice, il suo predecessore Massimino (vd. supra par. 6.1).

L'obiettivo del progetto consisteva nella rifunzionalizzazione del culto imperiale attraverso i suoi sommi sacerdoti federali: da rappresentanti dei kotvó e vettori delle loro istanze, secondo una direttrice che aveva origine „dal basso“, dalla dimensione dei sudditi provinciali (o meglio, dalle loro classi dirigenti municipali), organizzati in assemblea, e si rivolgeva all'imperatore, cercando di influenzarne la politica, si intendeva trasformarli in portavoce dell'imperatore stesso e trasmettitori dei suoi mandata, intermediari di una comunicazione che partisse „dall'alto“ per indirizzarsi autorevolmente ai provinciali, facendone i garanti dell'ottemperanza delle volontà imperiali da parte dei sudditi, obbedienti e leali. Un lucido tentativo di ridinamizzare organicamente il potenziale politico-religioso ancora contenuto, in stand by, nel fossile giuridico-sacrale del culto imperiale.

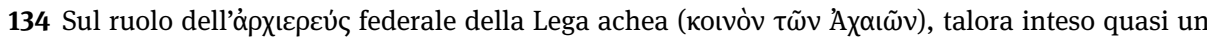
sommo sacedote „provinciale“ di tutti i Greci (provincia Achaia), vd. CAMIA 2011, 168-171, 236-242; cfr. CAMIA 2012.

135 Iscrizioni di Berytos e Ma'ayan Barukh: vd. supra n. 110. Per la phoenicarchia vd. supra n. 25. 136 Vd. i brani di Eunapio citati supra n. 130. 


\section{Database epigrafici online}

Ala2004 = C. RoueChÉ/G. BOdARD, Aphrodisias in Late Antiquity (1989), Oxford University 2004²: http://insaph.kcl.ac.uk/ala2004/

EDCS = M. CLAUSS/A. KolB (Dir.), Epigraphik-Datenbank Clauss / Slaby: http://www.manfredclauss. de/

$E D H=G \cdot A L F O ̈ L D Y^{\dagger} / C$. WITSCHEL (Dir.), Epigraphic Database Heidelberg, Heidelberger Akademie der Wissenschaften: http://edh-www.adw.uni-heidelberg.de/

EDR = S. PANCIERA/S. ORLANDI (Dir.), Epigraphic Database Roma, Sapienza Università di Roma: http://www.edr-edr.it/

IAph2007 = J. REYNOLDS/C. ROUECHÉ/G. BODARD, Inscriptions of Aphrodisias, Oxford University 2007: http://insaph.kcl.ac.uk/iaph2007/

IRT = J. REYNOLDS/J.B. WARD-PERKINS/C. ROUECHÉ/G. BodARD, Inscriptions of Roman Tripolitania (1952), Oxford University 2009²: http://inslib.kcl.ac.uk/irt2009/

LSA = R.R.R. SMIth/J.B. WARD-PERKINS/J. LenAghan/U. Gehn/C. MACHADo, Last Statues of Antiquity, Oxford University: http://laststatues.classics.ox.ac.uk/

$\mathrm{PHI}=$ Searchable Greek Inscriptions, Packard Humanities Institute, Cornell University - Ohio State University: http://epigraphy.packhum.org/

\section{Bibliografia}

АввотT/JohnSON 1926 = F.F. Аввотт/A.C. JohnSON, Municipal Administration in the Roman Empire, Princeton 1926.

ACETo 2008 = F. ACETo, Note sull'autenticità dell'Ep. 84 di Giuliano Imperatore, RCCM 50, 2008, 187-206.

AdAK/WILSON $2012=$ M. AdAK/M. WILSON, Das Vespasiansmonument von Döşeme und die Gründung der Doppelprovinz Lycia et Pamphylia, Gephyra 9, 2012, 1-40.

ALFöLDY $1973=$ G. ALFöLDY, Flamines provinciae Hispaniae citerioris, Madrid 1973.

AMOROSO 2004-2005 = C. AMOROSO, Governatori ed élites provinciali nel Tardo Impero: il ruolo dei concilia, Koinonia 28-29, 2004-2005, 67-80.

ARCE $1975=$ J.J. ARCE, Reconstrucciones de templos paganos en época del Emperador Juliano (361-363 d.C.), RSA 5, 1975, 201-215.

ARENA $2008=$ G. ARENA, Città 'premiate' e città 'punite' nell'Asia Minore tardoantica: pagani e cristiani tra promesse e minacce imperiali, MediterrAnt 11, 2008, 229-250.

Asmus 1895 = R. Asmus, Eine Encyklyka Julians des Abtrünnigen und ihre Vorläufer, ZKG 16, 1895, 45-71, 220-252.

ATHANASSIADI $1981=$ P. ATHANASSIADI, Julian and Hellenism. An Intellectual Biography, Oxford 1981.

BARNES $1982=$ T.D. BARnes, The New Empire of Diocletian and Constantine, Cambridge (MA)/ London 1982.

BARNES $1999=$ T.D. BARNES, Latin Epigraphy and the History of the Western Empire after Constantine, in: Atti dell'XI Congresso Internazionale di Epigrafia Greca e Latina, Roma 18-24 settembre 1997, Roma 1999, II, 565-576.

BARNES $2011=$ T.D. BARnes, Constantine. Dynasty, Religion and Power in the Later Roman Empire, Chichester 2011.

BASSIGNANO 1974 = M.S. BASSIGNANO, Il flaminato nelle province romane dell'Africa, Roma 1974.

BeLAYCHE $2009=$ N. BelayCHE, Ritus et cultus ou superstitio? Comment les lois du Code Théodosien (IX et XVI) de Constantin à Théodose parlent des pratiques religieuses traditionelles, in: 
S. Crogiez-PÉTRequin/P. JaIllette/O. Huck (ed.), Le Code Théodosien. Diversités des approches et nouvelles perspectives, CEFR 412, Rome 2009, 191-208.

BELAYCHE $2011=$ N. BeLAYCHE, La politique religieuse 'païenne' de Maximin Daia. De l'historiographie à l'histoire, in: G. CECCONI/C. GABRIELLI (ed.), La politica religiosa nel mondo antico e tardoantico, Munera 33, Bari 2011, 235-259.

BIDEZ 1924/1960 = J. BIDEZ (ed.), L'empereur Julien. Oeuvres complètes, I.2. Lettres et fragments, Paris $1924,1960^{2}$.

BIDEZ 1930/1965 = J. BIDEZ, La vie de l'empereur Julien, Paris 1930, rist. Paris 1965.

BIDEz/CUmont 1922 = J. BIDEz/F. CUMONt (rec.), Iuliani imperatoris epistulae leges poematia fragmenta varia, Paris/Oxford 1922.

BLECKMANN 2012 = B. BLECKMANn, Konstantin und die Kritik des blutigen Opfers, in: Bonamente/ LENSKI/LIZZI TESTA 2012, 165-180.

Bonamente $2009=\mathrm{G}$. Bonamente, Politica antipagana e sorte dei templi da Costantino a Teodosio II, in: U. CRIsCuolo/L. De GIovanNi (ed.), Trent'anni di studio sulla Tarda Antichità: bilanci e prospettive, Atti del Convegno Internazionale, Napoli 21-23 novembre 2007, Napoli 2009, 25-59.

BONAMENTE/LENSKI/LIZZI TESTA 2012 = G. BONAMENTE/N. LENSKI/R. LIZZI TESTA, Costantino prima $\mathrm{e}$ dopo Costantino. Constantine before and after Constantine, Munera 35, Bari 2012.

Bouffartigue 2005 = J. Bouffartigue, L'authenticité de la Lettre 84 de l'empereur Julien, $R P h 79$, 2005, 231-242.

BrÉLAZ 2005 = C. BRÉLAZ, La sécurité publique en Asie Mineure sous le Principat (|ler-IIlème S.

ap. J.-C.). Institutions municipales et institutions impériales dans l'Orient romain, Basel 2005.

Brown/LIzZI TESTA 2011 = P. Brown/R. LIzZI TESTA (ed.), Pagan and Christians in the Roman Empire: The Breaking of a Dialogue (IVth $-\mathrm{VI}^{\text {th }}$ Century A.D.), Proceedings of the International Conference at the Monastery of Bose, October 2008, Zürich/Berlin 2011.

CALtABIANO $1991=$ M. CALTABIANo, L'epistolario di Giuliano imperatore, Napoli 1991.

CALTABIANO $2009=$ M. CALTABIANO, La comunità degli Elleni: cultura e potere alla corte dell'imperatore Giuliano, AnTard 17, 2009, 137-149.

CAMERIERI/MANCONI $2010=$ P. CAMERIERI/D. MANCONI, Le centuriazioni della Valle Umbra da Spoleto a Perugia, Bollettino di Archeologia on line 1, 2010, 15-39.

CAMIA $2011=$ F. CAMIA, Theoi Sebastoi. Il culto degli imperatori romani in Grecia (Provincia Achaia) nel secondo secolo d.C., MEAHTEMATA 65, Atene 2011.

CAMIA 2012 = F. CAMIA, Un culto imperiale 'provinciale' in Achaia?, ASAA 90, 2012, 351-358.

CAMIA/KantirÉA $2010=$ F. CAmia/M. KantirÉA, The Imperial Cult in the Peloponnese, in: A.D. RIzAKIS/C. LePenIoti, Roman Peloponnese III. Society, Economy and Culture under the Roman Empire: Continuity and Innovation, MEAHTEMATA 63, Athens 2010, 375-406.

CAMPANILE $1994 \mathrm{a}=$ M.D. CAMPANILE, I sommi sacerdoti del koinon d'Asia (I sec. a.C. - III sec. d.C.), Studi Ellenistici VII, Pisa 1994.

CAMPANILE 1994b = M.D. CAMPANILE, I sommi sacerdoti del koinòn d'Asia: numero, rango e criteri di elezione, ZPE 100, 1994, 422-426.

CAMPANILE 2006 = M.D. CAMPANILE, Sommi sacerdoti, asiarchi e culto imperiale: un aggiornamento, in: B. VIRGILIO (ed.), Studi Ellenistici XIX, Pisa 2006, 523-584.

CAmpanile 2015 = M.D. Campanile, Licia e Panfilia, in: C. Letta/S. Segenni (ed.), Rome e le sue province. Dalla prima guerra punica a Diocleziano, Roma 2015, 199-205.

CASSIA 2014 = M. CASSIA, Fra biografia e cronografia. Storici cappadoci nell'età dei Costantinidi, Acireale/Roma 2014.

CASTELLO 2011 = M.G. CASTELLo, Il quaestor Montius e il vicarius Fl. Magnus: alcune riflessioni sul reclutamento del funzionariato sotto Costanzo II, Historiká 1, 2011, 145-185. 
CAStritius $1969=$ H. CAstritius, Studien zu Maximinus Daia, Kallmünz 1969.

CECCONI 1994 = G.A. CECCONI, Governo imperiale e élites dirigenti nell'Italia tardoantica. Problemi di storia politico-amministrativa (270-476 d.C.), Como 1994.

CECCONI 2006 = G.A. CECCONI, Honorati, possessores, curiales: competenze istituzionali e gerarchie di rango nella città tardoantica, in: R. LIzZı TESTA (Ed.), Le trasformazioni delle élites in età tardoantica, Atti del Convegno Internazionale, Perugia 15-16 marzo 2004, Roma 2006, 41-64.

CECCONI 2012 = G.A. CECCONI, II rescritto di Spello: prospettive recenti, in: BonAMENTE/LENSKI/LIZZI TESTA 2012, 273-290.

CHANIOTIS 1987 = A. ChANIOTIS, Plutarchos, praeses Insularum, ZPE 68, 1987, 227-231.

Chaniotis $2003=$ A. Chaniotis, Der Kaiserkult im Osten des Römischen Reiches im Kontext der zeitgenössischen Ritualpraxis, in: H. CANCIK/K. HITZL (Hg.), Die Praxis der Herrscherverehrung in Rom und seinen Provinzen, STAC 13, Tübingen 2003, 3-28.

ChanIOTIS $2008=$ A. CHANIOTIS, The Conversion of the Temple of Aphrodite at Aphrodisias in Context, in: J. Hahn/St. Emmel/U. GotTer (ed.), From Temple to Church. Destruction and Renewal of Local Cultic Topography in Late Antiquity, RGRW163, Leiden-Boston 2008, 243-273.

ChASTAGNOL 1960 = A. ChASTAgnol, La Préfecture urbaine à Rome sous le Bas-Empire, Paris 1960.

ChASTAGNOL 1962 = A. ChASTAGNOL, Les Fastes de la Préfecture de Rome au Bas-Empire, Paris 1962.

CHASTAGNOL 1978 = A. CHASTAGNOL, L'album municipal de Timgad, Bonn 1978.

CHASTAGNOL 1988a = A. CHASTAGNOL, Le formulaire de l'épigraphie latine officielle dans l'antiquité tardive, in: DonATI 1988, 11-65, ora in: ChASTAGNOL 2008, 133-187.

CHASTAGNOL 1988b = A. ChASTAGNOL, Sur les sacerdotales africains à la veille de l'invasion vandale, in: A. MAStino (ed.), L'Africa romana 5, Atti del V convegno di studio, Sassari 11-13 dicembre 1987, Sassari 1988, 101-110 (ora in: CHASTAGNOL 1994, 93-104.)

Chastagnol 1994 = A. Chastagnol, Aspects de l'Antiquité Tardive. [Scripta varia II], in: I. Tantillo (ed.), Saggi di Storia Antica 6, Roma 1994.

ChASTAGNOL $2008=$ A. ChAStAgnol, Le pouvoir impérial à Rome. Figures et commémorations. Scripta varia IV, textes éd. par St. Benoist - S. Demougin, Genève 2008.

Chastagnol/Duval $1974=$ A. Chastagnol/N. Duval, Les survivances du culte impérial dans l'Afrique du Nord à l'époque vandale, in: Mélanges d'histoire ancienne offerts à William Seston, Paris 1974, 87-118 (ora in: CHASTAGNOL 2008, 401-432).

ChIARAdonna $2013=$ R. ChIARAdonna, Filosofie e teologie politiche. Neoplatonisamo e politica da Plotino a Proclo, in: Costantino I. Enciclopedia costantiniana sulla figura e l'immagine dell'imperatore del cosiddetto Editto di Milano 313-2013, Roma 2013, I, 743-755.

CHRISTOL $1999=$ M. CHRIStOL, L'épigraphie latine impériale des Sévères au début du IVe siècle ap. J.-C., in: Atti dell’XI Congresso Internazionale di Epigrafia Greca e Latina, Roma 18-24 settembre 1997, Roma 1999, II, 333-357.

ChRISTOL $2013=$ M. CHRISTOL, L'oeuvre de Valerius Diogenes à Antioche de Pisidie: complèments au dossier épigraphique sur les interventions urbanistiques, ZPE 186, 2013, 279-286.

CHRISTOL $2014=$ M. Christol, Valerius Diogenes à Antioche de Pisidie: les mots du pouvoir. Compléments au dossier épigraphique, ZPE 189, 2014, 276-286.

Christol/Drew-BeAR 1999 = M. Christol/T. DreW-Bear, Antioche de Pisidie capitale provinciale et l'oeuvre de M. Valerius Diogenes, AnTard 7, 1999, 39-71.

CLAusS 1999 = M. CLAuss, Kaiser und Gott. Herrscherkult im römischen Reich, München/Leipzig 1999.

Clauss $2011=$ M. CLauss, Kein Aberglaube in Hispellum, Klio 93, 2011, 429-445.

CLINTON $1974=$ K. CLINTON, The Sacred Officials of the Eleusinian Mysteries, TAPhS 64.3, Philadelphia 1974.

CONTI 2004 = S. CONTI, Die Inschriften Kaiser Julians, Altertumswissenschaftliches Kolloquium 10, Stuttgart 2004. 
Cumont 1913 = F. Cumont, Catalogue des sculptures et inscriptions antiques des Musées royaux du Cinquantenaire, Bruxelles 1913.

CUneo 1997 = P.A. CUneo, La legislazione di Costantino II, Costanzo II e Costante (337-361), Milano 1997.

D'ANDRIA/CAGGIA/ISMAelLI 2012 = F. D'ANDRIA/M.P. CAGGIA/T. ISMAelLI (ed.), Hierapolis di Frigia. Le attività delle campagne di scavo e restauro 2004-2006, Hierapolis di Frigia V, ìstanbul 2012.

DAVENPORT $2013=$ C. DAVENPORT, The Governors of Achaia under Diocletian and Constantine, ZPE $184,2013,225-234$.

DE Dominicis 1970 = M. DE DominicIS, II „concilium provinciae“ nell'organizzazione amministrativa del Basso Impero, in: Id., Scritti romanistici, Padova 1970, 265-304.

De GIovannI 1991 = L. De GIovannI, Il libro XVI del Codice Teodosiano. Alle origini della codificazione in tema di rapporti Stato-Chiesa, Napoli $1991^{3}$.

De GIovanni 1993 = L. De GiovanNI, Costantino e il mondo pagano, Napoli $1993^{5}$.

DEININGER 1965 = J. DeININGER, Die Provinziallandtage der römischen Kaiserzeit von Augustus bis zum Ende des dritten Jahrhunderts n.Chr., München 1965.

DE Rossı 1878 = G.B. De Rossı, Una basilica di Ammaedara ed i flamines perpetui cristiani. Come si possa conciliare il titolo di flamen perpetuus con quello di christianus, BAC 1878, 25-36.

DestePhen $2013=\mathrm{S}$. Destephen, Actes conciliaires, listes de souscriptions et notices épiscopales ou du bon usage des sources ecclésiastiques, in: H. Bru/G. LabArRe (éd.), L'Anatolie des peuples, des cités et des cultures (Ile millénaire av. J.-C. - Ve siècle ap. J.-C.), Colloque International de Besançon, 26-27 novembre 2010, I, Besançon 2013, 207-228.

DESTEPHEN $2015=\mathrm{S}$. DeStePHen, Rhétorique et politique au Ve siècle: éloge de la réforme, éloge de la restauration ou éloge de la réaction?, in: L. MECELLA/U. ROBERTo (ed.), Governare e riformare l'impero al momento della sua divisione: Oriente, Occidente, Illirico, Roma 2015, (im Druck).

Dietz $2000=$ K. Dietz, Kaiser Julian in Phönizien, Chiron 30, 2000, 807-855.

DonATI 1988 = A. DonAtI (ed.), La terza età dell'epigrafia, Atti del Colloquio AIEGL - Borghesi 1986, Bologna ottobre 1986, Faenza 1988.

DowneY 1939 = G. DowneY, The Olympic Games of Antioch in the Fourth Century A.D., TAPhA 70, $1939,428-438$.

DRECOLL 1997 = C. DRECOLL, Die Liturgien im römischen Kaiserreich des 3. und 4. Jh. n. Chr., Stuttgart 1997.

DreW-Bear/TAŞLIALAn/Thomas $2002=$ T. DreW-Bear/M. TAŞLIALAN/C.M. Thomas (ed.), Actes du ler Congres International sur Antioche de Pisidie, Paris 2002.

DUCHESNE 1887 = L. DUCHESNE, Le concile d'Elvire et les flamines chrétiens, in: Mélanges L. Renier, Paris 1887, 159-174.

Eск 2000 = W. Eск, Zur Neulesung der Julian-Inschrift von Ma'ayan Barukh, Chiron 30, 2000, 857-859.

Edelmann-Singer 2015 = B. Edelmann-Singer, Koina und Concilia. Genese, Organisation und sozioökonomische Funktion der Provinziallandtage im römischen Reich, Stuttgart 2015.

ERIM/REYNOLDS $1989=$ K.T. ERIM/J.M. REYNOLDS, Sculptors of Aphrodisias in the Inscriptions of the City, in: N. BuşGELEN/M. LugAL (Hg.), Festschrift für Jale Inan Armağan, I, Istanbul 1989 [1991], 517-538.

FEISSEL 1998 = D. FEISSEL, Vicaires et proconsuls d'Asie du IVe au Vle siècle. Remarques sur l'administration du diocèse Asianique au Bas-Empire, AnTard 6, 1998, 91-104.

FEISSEL 1999a = D. FEISSEL, Les inscriptions des premiers siècles byzantins (330-641). Documents d'histoire sociale et religieuse, in: Atti dell'XI Congresso Internazionale di Epigrafia Greca e Latina, Roma 18-24 settembre 1997, Roma 1999, II, 577-590. 
FEISSEL 1999b = D. FEISSEL, Épigraphie administrative et topographie urbaine: l'emplacement des actes inscrits dans l'Éphèse protobyzantine (IVe-VIe s.), in: R. PILLINGER et al. (Hg.), Efeso paleocristiana e bizantina - Frühchristliches und byzantinisches Ephesos, Wien 1999, 121-132.

FEISSEL/WöRRLE 2015 = D. FEISSEL/M. WöRRLE, Eine Ehrung des Älteren Theodosius und ein spätantikes Edikt zur Steuererhebung aus Limyra, Chiron 45, 2015, 267-290.

FelicI/MunZI/TANTILlo 2006 = F. FeliCI/M. MunZI/I. TANTILlo, Austuriani e Laguatan in Tripolitania, in: A. AKerRaz/P. Ruggeri/A. SIRAJ/C. VISMARA (ed.), L'Africa romana 16, Atti del XVI Convegno di studio, Rabat 15-19 dicembre 2004, Roma 2006, 591-687.

Fernoux $2011=$ H. Fernoux, Le Demos et la Cité. Communautés et assemblées populaires en Asie Mineure à l'époque impériale, Rennes 2011.

FILIPPINI c.d.s. $=$ A. FILIPPINI, „Non sono atti degli apostoli ma scritti demoniaci“. Il movimento enkratita nell'Anatolia tardoantica: iscrizioni, eresiologi e testi apocrifi, in: W. AMELING (Hg.), Die Christianisierung Kleinasiens in der Spätantike, Akten der internationalen Konferenz, Köln 18.-22. März 2013, Bonn (im Druck).

FILOSI 1987 = S. FILOSI, L'ispirazione neoplatonica della persecuzione di Massimino Daia, RSCI 41, $1987,79-91$.

FISHWICK 1987-2005 = D. FISHWICK, The Imperial Cult in Latin West. Studies on the Ruler Cult in the Western Provinces of the Roman Empire, I.1-2 - III.1-4, Leiden/Boston/Köln 1987-2005.

FoWDEN $1998=$ G. FoWDEN, Polytheist religion and philosophy, in: CAH $^{2}$ XIII, 1998, 538-560.

FRASCHETTI 1999 = A. FRASCHETTI, La conversione. Da Roma pagana a Roma cristiana, Roma-Bari 1999.

FRIJA 2012 = G. FRIJA, Les Prêtres des empereurs. Le culte impérial civique dans la province romaine d'Asie, Rennes 2012.

GANGHOFFER $1963=$ R. GANGHOFFER, L'evolution des institutions municipales en Occident et en Orient au Bas-Empire, Paris 1963.

GIARDINA 2012 = A. GIARDINA, L',epoca“ di Costantino, in: BonAmENTE/LENSKI/LIzZI TESTA 2012, xxix-xlvii.

GRAF $2015=$ F. GRAF, Roman Festivals in the Greek East. From the Early Empire to the Middle Byzantine Era, Cambridge 2015.

GRANino CeCERE 2014 = M.G. GRANino CeCERE, Il flaminato femminile imperiale nell'Italia romana, Roma 2014.

Grant 1975 = R.M. Grant, The Religion of Maximin Daia, in: J. Neusner (ed.), Christianity, Judaism, and Other Graeco-Roman Cults. Studies for Morton Smith at Sixty, Leiden 1975, IV, 143-166.

GRÉGOIRE 1922 = H. GRÉGOIRE, Recueil des inscriptions grecques-chrétiennes d'Asie Mineure I, Paris 1922.

GRÉGOIRE 1933 = H. GRÉGOIRE, Notes épigraphiques, Byzantion 8, 1933, 49-88.

GREGORI 2011 = G.L. GREGORI, Ludi e munera. 25 anni di ricerche sugli spettacoli d'età romana. Scritti vari rielaborati e aggiornati, Milano 2011.

GREGORI/FILIPPINI 2013 = G.L. GREGORI/A. FILIPPINI, L'epigrafia costantiniana. La figura di Costantino e la propaganda imperiale, in: Costantino I. Enciclopedia costantiniana sulla figura e l'immagine dell'imperatore del cosiddetto Editto di Milano 313-2013, Roma 2013, I, 517-541.

GREGORI/FILIPPINI c.d.s. = G.L. GREGORI/A. FILIPPINI, Luoghi di culto pagano in Italia e nelle altre province dai Tetrarchi ai Costantinidi (e oltre): la documentazione epigrafica, in: T. CANELLA (ed.), L'impero costantiniano e i luoghi sacri, Atti del Convegno internazionale, Roma 2-4 dicembre 2013, Roma, in c.d.s.

GRELLE 1999 = F. GRELLE, I munera civilia e le finanze cittadine, in: Il capitolo delle entrate nelle finanze municipali in Occidente ed in Oriente. Actes de la Xe Rencontre franco-italienne sur l'épigraphie du monde romain, Rome 27-29 mai 1996, Rome 1999, 137-153. 
GUERBER 2010 = É. GUERBER, Les cités grecques dans l'Empire romain. Les privilèges et les titres des cités de l'Orient hellénophone d'Octave Auguste à Dioclétien, Rennes 2010.

GUIRAUD 1887 = P. GUIRAUD, Les assemblées provinciales dans l'Empire romain, Paris 1887 (rist. anast. Roma 1966).

GuIzzı 2014 = F. GuIzzı (ed.), Fra il Meandro e il Lico. Archeologia e storia in un paesaggio anatolico, Atti del Convegno internazionale, Roma 30 marzo 2012, Scienze dell'Antichità 20.2, 2014.

Guızzı c.d.s. = F. Guızzı, The Inscriptions of Temple A from Laodikeia, in: C. ŞıмşEK (ed.), The Lykos Valley and Neighbourhood in Late Antiquity, Proceedings of the $2^{\text {nd }}$ International Symposium on Archaeological Practices, Laodikeia 22-23 May 2015, İstanbul (im Druck).

HAENSCH $1997=$ R. HAENSCH, Capita provinciarum. Statthaltersitze und Provinzialverwaltung in der römischen Kaiserzeit, Mainz 1997.

HAENSCH 2006 = R. HAENSCH, Provinzialhaupstädte als „religiöse Zentren“? Die Situation in Kaiserzeit und Spätantike, in: H. CANCIK/A. SCHÄFER/W. SPICKERMANN (Hg.), Zentralität und Religion. Zum Formierung urbaner Zentren im Imperium Romanum, Tübingen 2006, 125-144.

HIRSCHMANN $2003=$ V. HIRSCHMANN, Der Schatten der Unsterblichkeit: Der Priester und Prophet Epitynchanos, EA 36, 2003, 137-152.

HORSLEY 2007 = G.H.R. HORSLEY, The Greek and Latin Inscriptions in the Burdur Archaeological Museum, Ankara 2007.

HORSTKOTTE 1988 = H.-J. HORSTKOTTE, Die 'Steuerhaftung' im spätrömischen 'Zwangsstaat', Frankfurt a.M. $1988^{2}$.

JIMÉNEZ SÁnCHEZ 2009-2010 = J.A. JIMÉnEz SÁnCHEZ, La desaparición de los espectáculos de gladiadores en Hispania, Hispania Antiqua 33-34, 2009-2010, 273-293.

JimÉnez SÁnChez c.d.s. = J.A. JIMÉnez SÁnCHEZ, Constantino y los espectáculos del anfiteatro, in: VILELLA (im Druck).

Jones $1971=$ A.H.M. Jones, The Cities of the Eastern Roman Provinces, Oxford $1971^{2}$.

JONES 2014a = C.P. JONES, Epigraphica X-XII, ZPE 188, 2014, 28-34.

JONES 2014b = C.P. JONES, Between Pagan and Christian, Cambridge (MA)/London 2014.

KALDELLIS 2005a = A. KALDELLIS, The Works and Days of Hesychios the Illoustrios of Miletos, GRBS 45, 2005, 381-403.

KALDELLIS 2005b = A. KALDELLIS, Julian, the Hierophant of Eleusis, and the Abolition of Constantius' Tyranny, CQ 55, 2005, 652-655.

KANTIRÉA $2007=$ M. KANTIRÉA, Les dieux et les dieux Augustes. Le culte impérial en Grèce sous les Julio-claudiens et les Flaviens. Études épigraphiques et archéologiques, Athènes 2007.

Kосн 1927-1928 = W. KoCH, Comment l'empereur Julien tâcha de fonder une église païenne, $R B P H$ 6, 1927, 123-146; 7, 1928, 49-82, 511-550, 1363-1385.

LANGHAMMER $1973=$ W. LANGHAMmER, Die rechtliche und soziale Stellung der Magistratus municipales und der Decuriones in der Übergangsphase der Städte von sich selbstverwaltenden Gemeinden zu Vollzugsorganen des spätantiken Zwangsstaates. 2.-4. Jahrhundert der römischen Kaiserzeit, Wiesbaden 1973.

LA RocCA 2009 = A. LA RocCA, Elio Aristide e le assemblee popolari, MediterrAnt 12, 2009, 393-408.

LARSEN $1934=$ J.A.O. LARSEN, The Position of Provincial Assemblies in the Government and Society of the Late Roman Empire, CPh 29, 1934, 209-220.

LARSEN $1955=$ J.A.O. LARSEN, Representative Government in Greek and Roman History, Berkeley/LoS Angeles 1955.

LÁZARO SÁNCHEZ 2008 = M.J. LÁZARO SÁNCHEZ, L'état actuel de la recherche sur le concile de Elvire, RSR 82, 2008, 517-546.

LEONE 2013 = A. LEONE, The End of the Pagan City. Religion, Economy, and Urbanism in Late Antique North Africa, Oxford 2013. 
LEPELLEY 1979-1981 = C. LEPELLEY, Les cités de l’Afrique romaine au Bas-Empire, I-II, Paris 1979-1981.

LEPELLEY 2011 = C. LEPELLEY, De la réaction païenne à la sécularisation: le témoignage d'inscriptions municipales romano-africaines tardives, in: BROWN/LIZZI TESTA 2011, 273-289.

LENSKI 2002 = N. LENSKI, Failure of Empire. Valens and the Roman State in the Fourth Century A.D., Berkeley/Los Angeles/London.

LEWIN 1995 = A. LEWIN, Assemblee popolari e lotta politica nelle città dell'impero romano, Firenze 1995.

Liebeschuetz 1959 = J.H.W.G. Liebeschuetz, The Syriarch in the Fourth Century, Historia 8, 1959, $113-126$.

LiebesChuetz 1972 = J.H.W.G. LIeBeschuetZ, Antioch. City and Imperial Administration in the Later Roman Empire, Oxford 1972.

LOZANO 2002 = F. LOZANO, La religiòn del Poder. El culto imperial en Atenas en época de Augusto y los emperadores Julio-Claudios, BAR 1087, Oxford 2002.

LOZANO 2010 = F. LOZANO, Un dios entre los hombres. La adoración a los emperadores romanos en Grecia, Barcelona 2010.

LUgARESI 1993 = L. LugARESI (ed.), Gregorio di Nazianzo. Contro Giuliano l’Apostata. Orazione IV, Firenze 1993.

MANGANARo 2013 = G. MANGANARo, Revisione di due iscrizioni greche, Epigraphica 75, 2013, 470-480.

MAROTTA $2013=$ V. MAROTTA, Le strutture dell'amministrazione provinciale nel quarto libro dei Discorsi Sacri, in: P. Desideri/F. FontANELla (ed.), Elio Aristide e la legittimazione greca dell'impero di Roma, Bologna 2013, 147-184.

MARTínez 1961 = G. MARTínez Diez S.I., El Epítome Hispánico. Una colleción canónica española del siglo VII. Estudio y texto crítico, Comillas 1961.

Martínez/Rodríguez 1984 = G. Martínez Diez S.I./F. Rodríguez S.I., La Colección Canónica Hispana, IV. Concilios galos, concilios hispanos (primera parte), Madrid 1984.

MAZZA 1986 = M. MAZZA, Filosofia religiosa ed Imperium in Giuliano, in: B. GENTILI (ed.), Giuliano Imperatore, Atti del Convegno SISAC, Messina 3 aprile 1984, Urbino 1986, 39-108, ora in: M. MAzzA (ed.), Le maschere del potere. Cultura e politica nella Tarda Antichità, Napoli 1986, 95-148.

MAZZA 1998/2009 = M. MAZzA, Giuliano o dell'utopia religiosa: il tentativo di fondare una chiesa pagana?, in: Giuliano Imperatore, le sue idee, i suoi amici, i suoi avversari, Atti del Convegno Internazionale, Lecce 10-12 dicembre 1998, Rudiae 10, Galatina 1998, 19-42, ora in: M. MAzzA (ed.), Tra Roma e Costantinopoli. Ellenismo Oriente Cristianesimo nella Tarda Antichità, Catania 2009, 217-244.

MAZZA $1999=$ M. MAZZA, Sileat omnibus divinandi curiositas. Sulle basi culturali della repressione religiosa nella Tarda Antichità, in: R. SORACI (ed.), Corruzione, repressione e rivolta morale nella Tarda Antichità, Atti del Convegno Internazionale, Catania 11-13 dicembre 1995, Catania 1999, 67-103.

MAZZA 2006-2009 = M. MAZZA, L'intermediazione proibita: magia e divinazione in alcune costituzioni del Teodosiano, Romanobarbarica 19, 2006-2009, 49-82.

MAZZARINO 1942/1990 = S. MAZZARINo, Stilicone. La crisi imperiale dopo Teodosio, Roma 1942, rist. con introduzione di A. GIARDINA, Milano 1990.

MAZZARINO 1951/2002 = S. MAZZARINO, Aspetti sociali del IV secolo. Ricerche di storia tardo romana, Roma 1951, rist. con introduzione di E. Lo Cascio, Milano 2002.

MAZZARINo 1966, 1-2 = S. MAZZARINo, Il pensiero storico classico, II.1-2, Roma-Bari 1966.

MAZZARINO 1970 = S. MAZZARINo, Introduzione, in: J. BURCKHARDT, L'età di Costantino il Grande, trad. it. di P. Chiarini, Roma 1970, 7-44. 
MAZZARINo 1974 = S. MAZZARINo, Antico, tardoantico ed èra costantiniana, I, Bari 1974.

MeCELLA 2015 = L. MeCELLA, L’amministrazione di Taziano e Proculo e il destino dei Lici tra Teodosio e Arcadio, in: L. MECELLA/U. Roberto (ed.), Governare e riformare l'impero al momento della sua divisione: Oriente, Occidente, Illirico, Roma 2015, http://books.openedition.org/efr/2800.

MEIGNe 1975 = M. MEIGNe, Concile ou collection d'Elvire, RHE 70, 1975, 361-387.

Merkelbach/Stauber 1998-2004 = R. Merkelbach/J. Stauber, Steinepigramme aus dem Griechischen Osten, I-V, Stuttgart/Leipzig/München 1998-2004.

Merkelbach/Stauber 1999 = R. Merkelbach/J. Stauber, „Unsterbliche Kaiserpriester“. Drei Dokumente der heidnischen Reaktion, EA 31, 1999, 157-164.

MILLAR 2006 = F. MILLAR, A Greek Roman Empire. Power and Belief under Theodosius II 408-450, Berkeley-Los Angeles 2006.

MILNER $2015=$ N.P. MILNER, A new statue-base for Constantius II and the fourth-century imperial cult at Oinoanda, AS 65, 2015, 181-203.

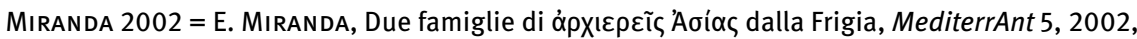
39-48.

Miranda De Martino 2014 = E. Miranda De Martino, Architrave con dedica a Diocleziano dal territorio di Hierapolis, in: GuIzzI 2014, 71-81.

Miranda De Martino/Ritti/ScardozzI 2012 = E. Miranda De Martino/T. Ritti/G. ScardozzI, L'area sacra dei Motaleis e il santuario di Apollo Karios nel territorio di Hierapolis, in: D’ANDRIA/ CAGGIA/ISMAELLI 2012, 687-737.

MitCHELL 1982 = S. MITCHELL, The Life of Saint Theodotos of Ancyra, AS 32, 1982, 93-113.

MITCHELL $1988=$ S. MITCHELL, Maximinus and the Christians in A.D. 312: A New Latin Inscription, JRS 78, 1988, 105-124.

Mitchell 1993 = S. Mitchell, Anatolia. Land, Men, and Gods in Asia Minor, 1-2, Oxford 1993.

Moltesen $1990=$ M. Moltesen, The Aphrodisian sculptures in the Ny Carlsberg Glyptothek, in: C. RoueCHÉ/K.T. ERIM (ed.), Aphrodisias Papers (1). Recent works on architecture and sculpture, JRA Suppl. Series 1, Ann Arbor 1990, 133-146.

Moltesen $2000=$ M. Moltesen, The Esquiline Group: Aphrodisian Statues in the Ny Carlsberg Glyptothek, Antike Plastik 27, 2000, 111-129.

MommSEN 1913 = T. MommSEN, Epigraphisce Analekten 8, in: Id., Gesammelte Schriften, VIII, Berlin $1913,14-24$.

MORESCHINI $2000=$ C. MoRESCHINI (ed.), Gregorio di Nazianzo. Tutte le orazioni, Milano 2000.

NeESEN 1981 = L. Neesen, Die Entwicklung der Leistungen und Ämter (munera et honores) im römischen Kaiserreich des zweiten bis vierten Jahrhunderts, Historia 30, 1981, 216-223.

NiCHOLSON $1994=$ O. NiCHOLSON, The 'Pagan Churches' of Maximinus Daia and Julian the Apostate, JEH 45, 1994, 1-10.

Nuffelen 2002 = P. van Nuffelen, Deux fausses lettres de Julien l'Apostat (La lettre aux Juifs, ep. 51 [Wright], et la lettre à Arsacius, ep. 84 [Bidez]), VChr 55, 2002, 131-150.

ОВRYк 2012 = М. ОВRYк, Unsterblichkeitsglaube in den griechischen Versinschriften, UaLG 108, Berlin-Boston 2012.

OLSZANIEC 1999a = S. OlszANIEC, Restitutor Romanae religionis - Kaiser Julian als Erneuerer der heidnischen Gebräuche, EOS 86, 1999, 77-102.

OLSZANIEC 1999b = S. OlSZANIEC, Julian Apostata und seine Reform der Heidnischen Priesterschaften, EOS 86, 1999, 217-241.

ORLANDI $2011=$ S. ORLANDI, Gli ultimi sacerdoti pagani di Roma: analisi della documentazione epigrafica, in: Brown/LIZZI TESTA 2011, 425-466.

PCBE III = S. DESTEPHEN, Prosopographie chrétienne du Bas Empire, 3. Prosopographie du diocèse d'Asie (325-641), Paris 2008.

Pergami 1993 = F. Pergamı (ed.), La legislazione di Valentiniano e Valente (364-375), Milano 1993. 
PETIT 1955 = P. PetIT, Libanius et la vie municipale à Antioche au IVe siècle après J.-C., Paris 1955. PRICE 1984 = S.R.F. PRICE, Rituals and Power. The Roman Imperial Cult in Asia Minor, Cambridge 1984.

Puech 2004 = B. Puech, Des cités-mères aux métropoles, in: S. Follet (ed.), L'hellénisme d'époque romaine: nouveaux documents, nouvelles approches (ler s. a. C. - IIIe s. p. C.), Actes du Colloque international à la mémoire de Louis Robert, Paris 7-8 juillet 2000, Paris 2004, 357-404.

RAMOS-LISSÓN 1979 = D. RAMOS-LISSón, En torno a la autenticidad de algunos cánones del Concilio de Elvira, Scripta Theologica 11, 1979, 181-186.

RAMSAY $1895=$ W.M. RAMSAY, The Cities and Bishoprics of Phrygia, I.1. The Lycos Valley and SouthWestern Phrygia, Oxford 1895.

RAMSAY $1897=$ W.M. RAMSAY, The Cities and Bishoprics of Phrygia, I.2. West and West-Central Phrygia, Oxford 1897.

REICHERT 1990 = E. REICHERT, Die Canones der Synode von Elvira: Einleitung und Kommentar, Hamburg 1990.

REITZENSTEIN 2011 = D. REITZENSTEIN, Die lykischen Bundespriester. Repräsentation des kaiserzeitlichen Elite Lykiens, Berlin 2011.

REMIJSEN 2015 = S. REMIJSEN, The End of Greek Athletics in Late Antiquity, Oxford 2015.

REYNOLDS 1959 = J. REYNOLDS, Four Inscriptions from Roman Cyrene, JRS 49, 1959, 95-101.

RITTI 2006 = T. RITTI, Guida epigrafica a Hierapolis di Frigia (Pamukkale), İstanbul, 2006.

RITTI $2008=$ T. RITTI (ed.), Museo Archeologico di Denizli-Hierapolis. Catalogo delle iscrizioni greche e latine, testi di E. Miranda e F. Guizzı, Napoli 2008.

RITTI c.d.s. = T. RITTI, Hierapolis di Frigia. Istituzioni e vicende storiche, İstanbul (im Druck).

RIZAKIS/ZOUMBAKI/LEPENIOTI 2004 = A.D. RIZAKIS/S. ZOUMBAKI/C. LEPENIOTI, Roman

Peloponnese II. Roman Names in Their Social Context, Athens 2004.

RoBert 1948 = L. RoBert, Hellenica, IV. Épigrammes du Bas-Empire, Paris 1948.

ROBERTO $2014=$ U. ROBERTo, Diocleziano, Roma 2014.

ROSCINI/ZUDDAS 2014 = E. ROSCINI/E. ZUDDAS, Il coronatus ritrovato, Epigraphica 76, 2014, 231-264.

ROUECHÉ 1981 = C. ROUECHÉ, Rome, Asia and Aphrodisias in the third century, JRS 71, 1981, 103-120.

ROUECHÉ 1996 = C. ROUECHÉ, A new governor of Caria-Phrygia: P. Aelius Septimius Mannus, in: A. Chastagnol/S. Demougin/C. Lepelley (ed.), Splendidissima civitas. Études d'histoire romaine en hommage à François Jacques, Paris 1996, 231-239.

ROUECHÉ/ERIM 1982 = C. ROUECHÉ/K.T. ERIM, Sculptors from Aphrodisias: Some New Inscriptions, PBSR 50, 1982, 102-115.

RüPKE 2011/2013 = J. RÜPKE, Von Jupiter zu Christus. Religionsgeschichte in römischer Zeit, Darmstadt 2011, trad. it. a cura di R. Alciati, Tra Giove e Cristo. Trasformazioni religiose nell'impero romano, Brescia 2013.

RÜPKE/GLOCK 2005 = J. RÜPKE/A. GLOCK, Fasti sacerdotum. Die Mitglieder der Priesterschaften und das sakrale Funktionspersonal römischer, griechischer, orientalischer und jüdisch-christlicher Kulte in der Stadt Rom von 300 v. Chr. bis 499 n. Chr., I-III, Stuttgart 2005.

SaAstamoinen $2010=$ A. SaAstamoinen, The Phraseology and Structure of Latin Building Inscriptions in Roman North Africa, Helsinki 2010.

Salway 2007 = B. Salway, Constantine Augoustos (not Sebastos), in: J. Drin kwater/B. Salway (ed.), Wolf Liebeschuetz reflected, London 2007, 37-50.

SALzMAN $1987=$ M.R. SALzman, 'Superstitio' in the Codex Theodosianus and the Persecution of Pagans, VChr 41, 1987, 172-188.

SCARDOZZI 2014 = G. SCARDOZZI, Topografia antica del territorio di Hierapolis di Frigia: ricognizioni archeologiche negli altopiani di Uzunpınar e Çal, in: Guızzı 2014, 95-122.

SCHEID $2005=$ J. SCHEID, Quand faire, c'est croire. Les rites sacrificiels des Romains, Paris 2005. 
Schenk von Stauffenberg 1931 = A. Schenk von Stauffenberg, Die römische Kaisergeschichte bei Malalas, Stuttgart 1931.

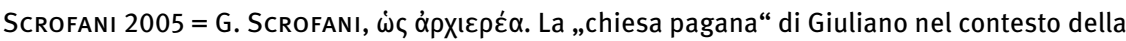
politica religiosa imperiale di III e IV secolo, SCO 51, 2005, 195-215.

SCROFANI $2010=$ G. SCROFANI, La religione impura. La riforma di Giuliano Imperatore, Brescia 2010.

SEeCK $1906=0$. SeECK, Die Briefe des Libanius zeitlich geordnet, Leipzig 1906.

SENSI 1998 = L. SENSI, Sul luogo del ritrovamento del rescritto costantiniano di Spello, in: Atti del XII Convegno Internazionale dell'Accademia Romanistica Costantiniana, Napoli 1998, 457-477.

SGO = MERKELBACH/STAUBER 1998-2004.

SOTOMAYOR 1989 = M. SOTOMAYOR MURO S.I., Las actas del concilio de Elvira. Estado de la cuestión, Revista del Centro de Estudios Históricos de Granada y su Reino 3, 1989, 35-68.

SOTOMAYOR $2000=$ M. SOTOMAYOR MURo S.I., El concilio de Elvira en el contexto de la Colección Canónica Hispana, in: Revisiones de Historia Antigua, III, Vitoria 2000, 189-199.

Sotomayor/Berdugo 2008a = M. Sotomayor MURo S.I./T. Berdugo Villena, Los cánones del Concilio de Elvira: una replica, Augustinianum 48, 2008, 369-434.

Sotomayor/Berdugo 2008b = M. Sotomayor Muro S.I./T. Berdugo Villena, Traducción de las actas del Concilio de Elvira: una respuesta a J. Vilella y P.E. Barreda, Florentia iliberritana 19, 2008, 383-418.

SOTOMAYOR/FERnÁNDEZ 2005 = M. SOTOMAYOR MURo S.I./J. Fernández UbIÑA (ed.), El concilio de Elvira y su tiempo, Granada 2005.

SQUARCIAPINO $1943=$ M. SQUARCIAPINO, La scuola di Afrodisia, Roma 1943.

SQUARCIAPINO 1983 = M. FLORIANI SQUARCIAPINO, La scuola di Afrodisia (40 anni dopo), Acl 35, 1983, 74-87.

SQUARCIAPINO 1991 = M. FLoRIANI SQUARCIAPINO, La scuola di Afrodisia (dopo 40 anni), in: R.R.R. SMITH/K.T. ERIM (ed.), Aphrodisias Papers 2. The theatre, a sculptor's workshop, philosophers, and coin-types, JRA Suppl. Series 2, Ann Arbor 1991, 123-126.

STROUMSA $2005=$ G.G. STROUMSA, La fin du sacrifice. Les mutations religieuses de l'Antiquité tardive, Paris 2005.

ŞıMŞEK 1997 = C. ŞıMŞEK, Laodikya Sütunlu Lahti, Türk Arkeoloji Dergisi 31, 1997, 269-289.

ŞIMŞEK $2007=$ C. ŞIMŞEK, Laodikeia (Laodikeia ad Lycum), İstanbul 2007.

ŞıMŞEK 2014 = C. ŞıMŞEK (Ed.), 10. Yılında Laodikeia (2003-2013 Yılları), İstanbul 2014.

ŞıMŞEK/GUıZZı $2012=$ C. ŞıMŞEK/F. GuıZzı, A Dedication of the praeses Dyscolius from Laodikeia on the Lykos, MediterrAnt 15, 2012, 511-518.

TABATA $1995=$ K. TABATA, The Date and Setting of the Constantinian Inscription of Hispellum (CIL XI, $5265=$ ILS 705), SCO 45, 1995, 369-410.

TAGLIETTI 2009-2010 = F. TAGLIETTI, I tondi Caetani con busti di divinità: una nuova testimonianza di scultura microasiatica in età tardo antica, RPARA, 82, 2009-2010, 33-71.

TANTILLo/BIGI $2010=$ I. TANTILLo/F. BIGI (ed.), Leptis Magna. Una città e le sue iscrizioni in epoca tardoromana, Cassino 2010.

TraINA 2007 = G. TrainA, 428 dopo Cristo. Storia di un anno, Roma-Bari 2007.

TROMBLEY 2011 = F.R. TROMBLEY, The Imperial Cult in Late Roman Religion (ca. A.D. 244-395). Observations on the Epigraphy, in: J. HAHN (Hg.), Spätantiker Staat und religiöser Konflikt. Imperiale und lokale Verwaltung und die Gewalt gegen Heiligtümer, Millennium Studies 34, Berlin/New York 2011, 19-54.

TROUT 2001 = D.E. TROUT, Lex and iussio: The Feriale Campanum and Christianity in the Theodosian Age, in: R.W. MAthISEN (ed.), Law, Society, and Authority in Late Antiquity, Oxford 2001, 162-178. 
VILELLA 2013 = J. VILELLA MASANA, El período preniceno del obispo Osio: estudio históricoprosopográfico, in: S. BenoIst/C. HoËT-VAN CAUWENBERGHE (ed.), La vie des autres. Histoire, prosopographie, biographie dans l'Empire Romain, Lille 2013, 193-218.

Vilella 2014 = J. Vilella MASANA, The Pseudo-lliberritan Canon Texts, ZAC 18, 2014, 210-259.

VILeLla c.d.s. = J. VILelLa MASANA (ed.), Constantinus. El primer emperador cristiano? Religión y política en el siglo IV, Actas del Congreso Internacional de Barcelona-Tarragona, 20-24 marzo 2012, Barcelona (im Druck).

VileLla/Barreda 2002 = J. Vilella MASANA/P.E. Barreda Edo, Los cánones de la Hispana atribuidos a un concilio iliberritano. Estudio filológico, Studia Ephemeridis Augustinianum 78, 2002, 545-579.

Vilella/Barreda 2006 = J. Vilella Masana/P.E. Barreda Edo, ¿Cánones del Concilio de Elvira o cánones pseudoiliberritanos?, Augustinianum 46, 2006, 285-373.

Vilella/Barreda 2013a = J. Vilella Masana/P.E. BarReda Edo, Un decenio de investigación en torno a los cánones pseudoiliberritanos. Nueva respuesta a la crítica unitaria, RHE 108, 2013, 300-336.

Vilella/Barreda 2013b = J. Vilella Masana/P.E. Barreda Edo, De nuevo sobre la traducción de los cánones pseudoiliberritanos, Veleia 30, 2013, 229-247.

VITALE $2012=$ M. VITALE, Eparchie und Koinon in Kleinasien von der ausgehenden Republik bis ins 3. Jh. n. Chr., Bonn 2012.

VITALE $2014=$ M. VITALE, Il sommo sacerdozio federale del culto imperiale nell'Oriente romano. Un riesame generale della documentazione epigrafica e numismatica, MediterrAnt 17.1, 2014, 269-290.

VORSTER $2004=$ C. VORSTER, Der Kopf einer Göttin im Vatikan als Beispiel theodosianischen Bildhauerkunst, BMMP 24, 2004, 113-153.

WIEMER $1995=$ H.-U. WIEMER, Libanios und Julian. Studien zum Verhältnis von Rhetorik und Politik im vierten Jahrhundert n.Chr., München 1995.

WISCHMEYER $1990=$ W. WISCHMEYER, M. Iulius Eugenius. Eine Fallstudie zum Thema „Christen und Gesellschaft im 3. und 4. Jahrhundert“, ZNW 81, 1990, 225-246.

ZUDDAS 2012 = E. ZUDDAS, L'Umbria nell'era costantiniana, in: A. BRAVI (ed.), Aurea Umbria. Una regione dell'impero nell'era di Costantino, Viterbo 2012, 61-70.

ZUDDAS 2013 = E. ZUDDAS, Osservazioni sui coronati Tusciae et Umbriae, Hormos n.s. 5, 2013, 103-119. 
Bereitgestellt von | De Gruyter / TCS

Angemeldet

Heruntergeladen am | 14.10.16 13:17 